\title{
FOMO-CENTRICITY: HOW SOCIAL MEDIA'S DARK DESIGNS CAUSE USERS TO RELUCTANTLY GIVE UP THEIR DATA
}

by

Fiona Westin

\author{
A thesis submitted to \\ the Faculty of Graduate and Postdoctoral Affairs \\ in partial fulfillment of \\ the requirements for the degree of \\ MASTER OF ARTS \\ Human Computer Interaction \\ at \\ CARLETON UNIVERSITY \\ Ottawa, Ontario \\ June, 2020
}

(c) Copyright by Fiona Westin, 2020 


\begin{abstract}
This thesis explores the link between the Fear of Missing Out (FoMO) and reluctant privacy-compromising behaviours on social media. We first conducted a literature review which laid the groundwork for FoMO as a possible explanation for a gap between users' privacy attitudes and behaviours. To better understand this phenomenon, we used Grounded Theory to conduct and analyze semi-structured interviews with 25 participants. We found strong evidence that participants experience ambivalence in their participation behaviours and feel pressured to participate even when they have privacy concerns to avoid missing out. We present an empirically-based high level theory describing the cyclical relationship between FoMO-centric design and privacyrelated participatory reluctance, and identify three main participatory dimensions.
\end{abstract}




\section{Acknowledgements}

First and foremost, thank you to my supervisor, Dr. Sonia Chiasson, for being my steadfast guide throughout my Master's studies. You have consistently helped to elevate my ideas and have helped me to become a better researcher and a more concise and eloquent writer. Thank you for your patience, encouragement, and for being a pillar of strength even amongst a global pandemic!

Next, I would like to thank the members of my thesis committee, Dr. Robert Biddle and Dr. Rob Teather, for your insightful discussion during my defense, which helped to strengthen the final version of this thesis. Thank you to Dr. Elizabeth Stobert, not only for chairing, but for being supportive of my academic growth over the past two years.

My appreciation of HCI would not be what it is without the expertise and passion shared with me through the classes taught by Dr. Robert Biddle, Dr. Elizabeth Stobert, Dr. Sonia Chiasson, Dr. Audrey Girouard, and Dr. Kasia Muldner. The knowledge I gained in your classes has proven invaluable during the thesis process and I look forward to continuing to apply it in future.

I want to thank my colleagues and friends in the CHORUS lab for offering their academic advice, companionship, and-perhaps most importantly in these timesmany jokes. Your collective ambition, enthusiasm, and warmth inspire me always.

Thank you to my participants for sharing their wisdom about their online experiences! You each helped to shape my theory into what it has become.

Finally, a heartfelt thanks to my family and friends for being continuously supportive of my academic endeavours and participating in many conversations about FoMO and online privacy! 


\section{Table of Contents}

Abstract ii

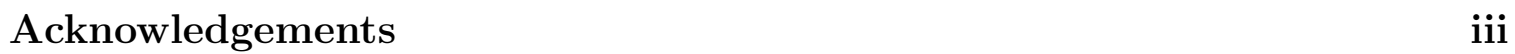

List of Tables viii

List of Figures $\quad$ ix

$\begin{array}{lll}\text { Chapter } 1 & \text { Introduction } & 1\end{array}$

1.1 Research Goal . . . . . . . . . . . . . . . . . . . . . . . 2

1.2 Contributions . . . . . . . . . . . . . . . . . . . . . . 2

1.3 Related Publications and Presentations . . . . . . . . . . . . . . . . . 3

1.4 Thesis Outline . . . . . . . . . . . . . . . . . . . . . . . . . . . . . 3

$\begin{array}{lll}\text { Chapter 2 } & \text { Background } & 5\end{array}$

2.1 Fear of Missing Out . . . . . . . . . . . . . . . . . . 5

2.2 Ambivalence in Decision-Making . . . . . . . . . . . . . . . . . . . 5

2.3 Design Patterns . . . . . . . . . . . . . . . . . . . . 6

2.4 Dark Patterns . . . . . . . . . . . . . . . . . . . . . . . . . . 7

2.5 Factors Contributing to FoMO-Centric Design . . . . . . . . . . . . . 9

2.6 Literature Survey Methodology . . . . . . . . . . . . . . . . . . . . . 9

2.7 Factor 1: User Behaviours and Motivations . . . . . . . . . . . . . . . 10

2.7 .1 Short-Term Benefits Prioritized . . . . . . . . . . . . . . . . . 10

2.7 .2 Social Isolation Avoided . . . . . . . . . . . . . . . . . . . 10

2.7 .3 Community Norms Established . . . . . . . . . . . . . . . . . 12

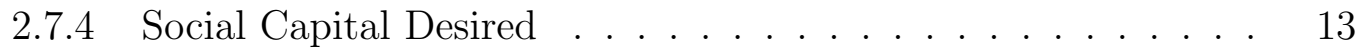

2.8 Factor 2: Design Features . . . . . . . . . . . . . . . 14

$2.8 .1 \quad$ Attention-Economic Logic . . . . . . . . . . . . . . . 15

2.8 .2 Service Denial . . . . . . . . . . . . . . . . . . . 15 
2.8 .3 Infrastructure Informs Community $\ldots \ldots \ldots \ldots$

2.8 .4 FoMO and Social Media Use . . . . . . . . . . . . . 17

2.8 .5 Other Design Considerations . . . . . . . . . . . . . . . . . 19

2.9 Research Gaps . . . . . . . . . . . . . . . . . . . . . . . 20

\begin{tabular}{lll}
\hline Chapter 3 & Methodology & 22
\end{tabular}

3.1 Grounded Theory . . . . . . . . . . . . . . . . . . . . . . . . 22

3.2 Study Overview $\ldots \ldots \ldots \ldots$

3.3 Recruitment . . . . . . . . . . . . . . . . . . . . . . . . . . . 24

3.4 Pre-Screener . . . . . . . . . . . . . . . . . . . . . . . . . . . . 24

3.5 Interview Participants $\ldots \ldots \ldots \ldots \ldots \ldots$

3.6 Pre-Interview Questionnaire . . . . . . . . . . . . . . . . . . . 26

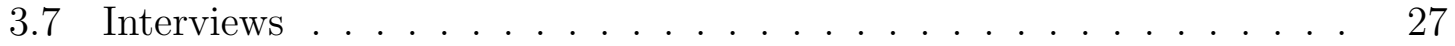

3.8 Post-Interview Questionnaire . . . . . . . . . . . . . . . . . . . . . . . 28

3.9 Analysis $\ldots \ldots \ldots \ldots \ldots$

$3.9 .1 \quad$ Researcher Background . . . . . . . . . . . . . . . . 30

3.9 .2 Coding . . . . . . . . . . . . . . . . . . . . . . 31

3.9 .3 Memos . . . . . . . . . . . . . . . . . . . . . 31

3.9 .4 Theoretical Sampling: Updating the Interview Guide . . . . . 34

3.9 .5 Theoretical Sorting, Diagramming, and Integrating . . . . . . 37

3.9 .6 Theory Construction . . . . . . . . . . . . . . . . . . 38

\begin{tabular}{lll}
\hline Chapter 4 & Results & 42
\end{tabular}

4.1 Definitions . . . . . . . . . . . . . . . . . . . . . . . . . . . . . 42

4.1 .1 Defining "Participation" . . . . . . . . . . . . . . . . . 42

4.1 .2 Defining Deliberate vs. Reactive Participation . . . . . . . . . 43

4.2 Theory Overview $\ldots \ldots \ldots \ldots \ldots$

$4.2 .1 \quad$ Fear of Missing Out . . . . . . . . . . . . . . . . 46

4.2 .2 Reactive Privacy Compromising Behaviours . . . . . . . . 47

$4.3 \quad$ Eight Symptoms of Participatory Reluctance . . . . . . . . . . . . . 48

4.3 .1 Workarounds . . . . . . . . . . . . . . . . . . . . . . . 49 
4.4 DIMENSION 1: FREQUENCY . . . . . . . . . . . . . . . . . . 50

4.4 .1 Staying in the loop . . . . . . . . . . . . . . 50

4.4 .2 Avoiding "dropping off the face of the planet" . . . . . . . 52

4.4 .3 Documenting compulsively . . . . . . . . . . . . . . . . . 53

4.4 .4 Posting to validate experiences $\ldots \ldots \ldots \ldots \ldots$

4.4 .5 PDA (Supporting friends) … . . . . . . . . . 55

$4.5 \quad$ DIMENSION 2: IMMEDIACY (Timeliness) $\ldots \ldots \ldots \ldots \ldots$

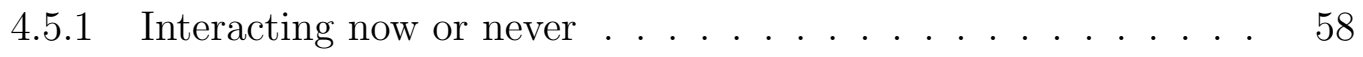

4.5 .2 Posting in the moment . . . . . . . . . . . . . . . 59

4.5 .3 Jumping on the bandwagon . . . . . . . . . . . . 60

$4.6 \quad$ DIMENSION 3: VOLUME (Depth, Variety and Reach) . . . . . . . . 61

4.6.1 All of you in one place: presenting the authoritative "true" self 62

4.6 .2 All of your friends in one place: mixing audiences . . . . . . 64

4.6 .3 Reciprocating data type . . . . . . . . . . . . . . . 65

4.6 .4 Selling yourself $\ldots \ldots \ldots \ldots$. . . . . . . . . . . 6 66

4.6 .5 MVP: Minimum Viable Presence $\ldots \ldots \ldots$. . . . . . 67

4.6 .6 Can't leave, won't leave . . . . . . . . . . . . . . . . . . 69

4.7 Non-Participatory and FoMO-Independent Participatory Behaviours. $\quad 71$

4.8 Summary of Study Findings $\ldots \ldots \ldots \ldots \ldots$

\begin{tabular}{lll}
\hline Chapter 5 & Discussion and Conclusion & 74
\end{tabular}

5.1 From Dark Patterns to Dark Infrastructure . . . . . . . . . . . . . 75

5.2 Dimensions and their Implications for Future Work . . . . . . . 76

$5.3 \quad$ How Does our "Dark Infrastructure" Differ from the Regular Pressures of Social Life? . . . . . . . . . . . . . . . . . . . . . 77

$5.4 \quad$ Are We Okay with This? . . . . . . . . . . . . . . . . . . . 78

5.5 How Might We Fight Back against FoMO-Centric Design? . . . . . . 79

5.6 Research Agenda . . . . . . . . . . . . . . . . . . . . . . . . . 83

5.7 Limitations $\ldots \ldots \ldots \ldots \ldots \ldots$

5.8 Conclusion $\ldots \ldots \ldots \ldots \ldots \ldots \ldots$ 
\begin{tabular}{lr}
\hline Bibliography & 87
\end{tabular}

\begin{tabular}{lll}
\hline Appendix A & Pre-Screener Questionnaire & 97
\end{tabular}

A.1 Consent Form . . . . . . . . . . . . . . . . . . . . . . . . . . . . . 97

A.2 Screener Questions . . . . . . . . . . . . . . . . . 98

A.3 $\quad$ Fear of Missing Out Scale (FoMOS) . . . . . . . . . . . . . . . . . . . 98

\begin{tabular}{lll}
\hline Appendix B & Pre-Interview Questionnaire & 100
\end{tabular}

B.1 Interview Informed Online Consent Form . . . . . . . . . . . . . . . . 100

B.2 Pre-Interview Demographics Questionnaire . . . . . . . . . . . . . . . 103

\begin{tabular}{lll}
\hline Appendix C & Interview Guide & 106
\end{tabular}

\begin{tabular}{lll}
\hline Appendix D & Post-Interview Questionnaire & 108
\end{tabular}

D.1 OSN Attitudes . . . . . . . . . . . . . . . . . . . . . 108

D.2 OSN Disclosure . . . . . . . . . . . . . . . . . . . . . . . . . . . . 109

D.3 Repeat of FoMOS (See Pre-screener) . . . . . . . . . . . . . . . . . . 109 


\section{List of Tables}

$2.1 \quad$ Factors Contributing to FoMO-Centric Design $\ldots . . . . . .21$

$3.1 \quad$ Interview questions $\ldots \ldots \ldots \ldots$. . . . . . . . . 28

$4.1 \quad$ Code categories . . . . . . . . . . . . . . . . 47

$4.2 \quad$ Symptoms of participatory reluctance $\ldots \ldots \ldots$

4.3 Reasons for not participating . . . . . . . . . . . . . 72 


\section{List of Figures}

$3.1 \quad$ Pre-screener FoMO scores for all respondents . . . . . . . . 25

$3.2 \quad$ Pre-screener FoMO scores for interviewees $\ldots \ldots \ldots \ldots$

$3.3 \quad$ Participants' frequency of platform use $\ldots \ldots \ldots \ldots . \ldots 27$

$3.4 \quad$ Participants' levels of privacy concern by FoMO score . . . . . 30

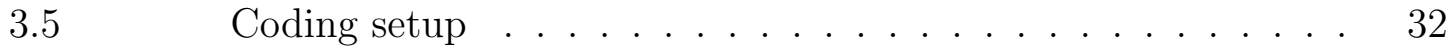

$3.6 \quad$ Example of coding process $\ldots \ldots \ldots \ldots \ldots \ldots$

$3.7 \quad$ Memo journal . . . . . . . . . . . . . . . . . . . 33

$3.8 \quad$ Affinity diagram of initial Grounded Theory categories . . . . 35

$3.9 \quad$ Late-stage affinity diagram of main design categories . . . . 36

$3.10 \quad$ Early "multiple identities" category with focused codes . . . . 39

$3.11 \quad$ Early whiteboard diagram . . . . . . . . . . . . . 40

$3.12 \quad$ Later whiteboard diagram $\ldots \ldots \ldots \ldots \ldots$

$4.1 \quad$ Diagram showing theory relationships $\ldots \ldots \ldots \ldots$

$4.2 \quad$ FoMO scores per participant $\ldots \ldots \ldots \ldots \ldots \ldots$ 


\section{Chapter 1}

\section{Introduction}

When considering how to improve security and privacy practices online, usability and informational factors may come to mind; "Is the user informed of potential risks? Are tools designed in a way that makes it easy for the user to mitigate these risks?" Say the answer to both of these questions is "yes" - this should, theoretically, mean the user is free to behave in accordance with their security and privacy attitudes. But what if that is not the case?

The Privacy Paradox [9], which acknowledges the discrepancy between users' privacy attitudes and behaviours, is a well-known phenomenon within the privacy community: users frequently report high concern for privacy, but then behave in ways that disregard privacy. Similar observations apply to users' security behaviours. There are a range of theories 9 attempting to explain this gap, but thus far none have been universally accepted, or able to explain every situation in which the discrepancy arises. In particular, there appears to be a lack of research relating to why users voluntarily proceed with risky behaviours while simultaneously feeling uncomfortable in the act.

This type of behaviour, wherein a person chooses an action against their preferences, is a phenomenon Cassidy calls "participatory reluctance" [22]. We explore the prevalence of participatory reluctance in relation to privacy behaviours. To do this, we look at privacy behaviours through the lens of Fear of Missing Out (FoMO) 81. The ubiquity of FoMO resulted in its addition to the Oxford English Dictionary in 2013 [76]; in the same year, a study showed 56\% percent of adults reported suffering from FoMO [67]. We hypothesize that this social-media-propagated phenomenon leads users to share more data than they are truly comfortable doing, in order to gain short-term social benefit and avoid negative social consequences, such as perceptions of being reclusive.

Central to our framework for examining this phenomenon is the concept of design 
patterns and, specifically, the sub-concept of dark patterns. While design patterns themselves typically have beneficial outcomes for those involved by providing clear guidance on how to solve certain problems, dark patterns tend to manipulate.

Dark patterns have recently been highlighted in the media in relation to social media [10] and are the subject of a US Government bill. Given this recent attention, we believe that a closer examination of exactly how users are manipulated towards privacy-adverse behaviors is warranted. It is through this lens that we present the propagation of the formerly mentioned FoMO-related behaviour as dark patterndriven design, calling it "FoMO-centric design." We identify FoMO-centric design as a collection of manipulative strategies within system design that benefit from users' desires to be accepted socially. By exploiting FoMO-associated behaviours and motivations, FoMO-centric design sways users to reluctantly behave in ways that compromise their own privacy-preserving standards and leave them, and whole systems, vulnerable to security threats.

We first conducted a literature review which pointed to the possible existence of FoMO-centric design. In order to explore this phenomenon in more detail, we then interviewed 25 participants about their experiences with joining, staying on, leaving, and participating in social media, which provided us with supporting empirical evidence of such design. Using the results of our interviews, we propose a theory to explain how this form of design keeps users on platforms and continuing to participate even in the face of reluctance.

\section{$1.1 \quad$ Research Goal}

We aim to uncover the relationship between the Fear of Missing Out (FoMO) and reluctant privacy-compromising behaviours. We explore if, when, and why users participate to avoid missing out while experiencing privacy-related ambivalence.

\subsection{Contributions}

In pursuit of this goal, we offer the following research contributions:

- We provide empirical evidence through a qualitative interview study with 25 
participants that participants feel pressured to participate (i.e., join platforms, post, etc.) to avoid missing out, even when they voice privacy concerns. Our data also reveals the importance of passive participatory behaviours in users joining, staying on, and actively using platforms.

- Using Grounded Theory, we present an empirically-based high level theory describing the cyclical relationship between FoMO-centric design and privacyrelated participatory reluctance, and identify three main participatory dimensions. This theory helps fill a research gap concerning the privacy paradox and voluntary yet reluctant behaviour.

- Our results support and expand Cassidy's [22] definition of participatory reluctance, by identifying 8 symptoms of participatory reluctance and showing their broad application to social media and privacy behaviours.

- We discuss practical and ethical implications of FoMO-centric design, and present preliminary recommendations and a research agenda based on our findings.

\subsection{Related Publications and Presentations}

Thus far, portions of this research have been presented as a full-paper publication 106 and a poster presentation [107]:

- Fiona Westin and Sonia Chiasson. Opt out of Privacy or "Go Home": Understanding Reluctant Privacy Behaviours through the FoMO-Centric Design Paradigm. New Security Paradigm Workshop (NSPW), 2019.

- Fiona Westin and Sonia Chiasson. Poster: Giving up Privacy for Fear of Missing Out (FOMO). SERENE-RISC Annual Cybersecurity Conference, 2019. (Best Academic Poster Award)

\subsection{Thesis Outline}

In Chapter 2, we lay a solid foundation for understanding FoMO-centric design from a psychological, sociological and design perspective by conducting a literature review 
covering key related concepts: Fear of Missing Out (FoMO), the Privacy Paradox, Participatory Reluctance, and Dark Patterns. We further cover research that displays evidence of FoMO-centric design at work. Chapter 3 describes our grounded theory interviewing and analysis process, and reports the demographics of our participants. Chapter 4 explains the results of our findings, supported by quotes from the interviews. We also explain the overall structure of our theory which emerged from our grounded theory process. Our discussion and conclusion follow in Chapter 5, where we discuss important findings and their implications for future research. 


\section{Chapter 2}

\section{Background}

In this chapter, we present existing literature relating to the Fear of Missing Out, ambivalence in decision-making, and privacy compromising behaviours relating to social pressure. The bulk of this chapter originally appeared in our NSPW 2019 paper 106].

\subsection{Fear of Missing Out}

Przybylski et al. [81] were the first researchers to operationalize the construct Fear of Missing Out (FoMO). They define FoMO as "a pervasive apprehension that others might be having rewarding experiences from which one is absent" and say it is characterized "by the desire to stay continually connected with what others are doing." According to Przybylski et al., this "self-regulatory limbo" [81] results from situational or chronic deficits in the satisfaction of three basic psychological needs - competence, autonomy, and relatedness-required for effective self-regulation and psychological health, according to the Self-Determination theory [32]. Przybylski et al. found a "robust" link between FoMO and high levels of social media engagement.

\subsection{Ambivalence in Decision-Making}

Przybylski et al. 81] found that users with high FoMO levels were more likely to feel ambivalent while using social media; that is, experience "mixed feelings" characterized by high levels of both positive and negative affect. This led users to partake in behaviours detrimental to their academic future and driving safety, despite knowing about the possible negative effects.

The presence of ambivalence amongst social media users was discussed in a privacy context by Paasonen et al. [77], who says that positive affect prompted by boredomrelieving "micro-events" drives users to continue using social media, despite feeling a 
"sense of creepiness" about the "default leakiness" of the platforms they use. Ambivalence is explained by the self-discrepancy theory [49] as a conflict between actual beliefs held by the decision-maker and idealized beliefs or beliefs the decision-maker thinks they should hold based on the behaviours of others. In other words, a person can be swayed to behave against their preferences when that person's preferences conflict with the perceived norm. The effect of norms on behaviour is already well-known in relation to the Theory of Planned Behaviour [5], which places subjective norms as one of three predictors of intention and behaviour.

Ambivalent social media use is addressed in relation to community norms by Cassidy 22 under the name participatory reluctance, which we adopt as an underlying thread for our research (See Section 2.7.2 for more on Cassidy's work).

\subsection{Design Patterns}

As we approach the problem of reluctant participation from an HCI perspective, we aim to understand how the design of systems might influence users' decisions. In doing so, we consider the role of design patterns. Design patterns were introduced by Alexander [6] as a set of flexible solutions to defined recurring architectural problems. Patterns are created through "describ[ing] the core of the solution to that problem, in such a way that you can use this solution a million times over, without ever doing it the same way twice." Since the publication of Alexander's work, the concept of patterns has gained traction in the fields of computer science and software design, including the branches of security [58] and privacy 84 .

Design patterns stand out in their ability to identify recurring real-world problems and provide a roadmap for clear, implementable solutions to those problems. These solutions may be grouped into categories of patterns; within the privacy community, categories which have received dedicated attention include user control [28] and transparency [90]. While the presentation of patterns vary in their levels of organization and implementability, effort has been made to assimilate privacy patterns into a more defined, consistent 'language' structure 29]. Security design patterns have received more widespread attention (e.g., [75,111]) and patterns exist to address many typical security problems. 
A design pattern only succeeds in being a design pattern insofar as it achieves its original, constructive purpose. When a pattern fails to achieve its goal, or results in unintended consequences, it is a pattern misapplied, and thus becomes an antipattern 35 .

\subsection{Dark Patterns}

Dark patterns [18], on the other hand, begin with malicious intent and successfully end in its planned consequences. To borrow from Fogg's definition of planned effects vs. side-effects, "Intentionality is what distinguishes between a planned effect [(intentional)] and a side effect [(unintentional)] of a technology" 42. The negative effects of dark patterns are planned. These are, at their heart, the design patterns of manipulation.

Dark patterns take advantage of humans' psychological propensity for certain thought patterns and behaviours in order to trick and manipulate users into taking an action they would have otherwise been unlikely to take. This is distinct from the purpose of persuasive design, which aims to influence positive changes in users' behaviours, in line with their interests 42$]$.

Bösch et al. [14 adopt Kahneman's [52 language of 'System 1' (automatic, unconscious) and 'System 2' (deliberate, conscious) thinking. They claim that dark patterns tend to prompt and maximize System 1 thinking, leading users to automatic, unconscious behaviours.

Dark patterns are ubiquitous in today's digital designs. Di Geronimo et al. 33 performed an analysis of 240 mobile apps downloaded from the Google Play Store, finding at least one dark pattern in $95 \%$ of them. Through an online experiment they also found that users were largely unaware of these dark patterns, highlighting the patterns' covert nature. Nouwens et al. [73] scraped the consent management platforms of 10,000 websites and found that less than $12 \%$ adhered to minimum requirements set out by the GDPR. They found certain ubiquitous dark patterns on these consent forms illicitly increased consent by up to $23 \%$. While dark patterns have primarily been discussed in terms of websites and apps, recent work has begun to explore them in a wider IoT context, such as in relation to home robots 57 . 
On top of being ubiquitous, dark patterns have been empirically found to be highly effective in manipulating user behaviour. Luguri and Strahilevitz 62 recently conducted the first large scale academic experiment to examine the effectiveness of dark patterns in altering user behaviour. Deceiving participants by informing them they had been automatically enrolled in an identity theft protection plan, they found those exposed to the corresponding "mild" opt-out dark patterns were more than twice as likely to stay enrolled than those who had not been exposed to any dark patterns, and participants exposed to 'aggressive' dark patterns were almost four times more likely to stay enrolled. The researchers concluded that "dark patterns are strikingly effective in getting consumers to do what they would not do when confronted with more neutral user interfaces." Luguri and Strahilevitz also found mild dark patterns much less likely than aggressive dark patterns to elicit backlash amongst participants, rendering subtle mild dark patterns in some ways more dangerous than those more obvious. Mild dark patterns were also less likely to be noticed by participants with less formal education.

While this psychological manipulation by dark patterns has been acknowledged, few patterns explicitly address social factors contributing to the exploitation of users, with only two notable instances. The first is Bösch et al.'s Address Book Leeching. This pattern functions on the basis of humans' "fundamental need to belong" [14], a motivation which they propose may be strong enough to counteract potential privacy concerns. The second instance is the "Social Proof" category created to encompass a number of dark patterns identified by Mathur et al. after they crawled 11,000 shopping websites 64.

With a marked research gap concerning social factors as a driving force behind certain privacy dark patterns, and an apparent link between FoMO and System 1 thinking, we set out to understand instances of socially-driven dark pattern manipulation, which we call FoMO-centric design. We note that there are likely many forces contributing to these dark patterns, but we focus our attention on FoMO for this thesis. We briefly address other possible influences in Section 2.8.5. 


\subsection{Factors Contributing to FoMO-Centric Design}

At this point in our work, we define FoMO-centric design as a collection of manipulative strategies that exploit FoMO-associated motivations and behaviours. These typically derive benefit from negative effects on the privacy and/or security of users. Some strategies result in immediate, direct behaviours by users, while other strategies are longer-term and more subtle. Users may use FoMO-centric technologies voluntarily, but this does not mean they are naive to their negative effects: they may feel exploited and continue to participate regardless.

Intuitively, we understand that FoMO likely plays a key role in users acting contrary to their privacy or security desires. But what evidence is there for such a phenomenon in existing literature? And what evidence exists to explain why it happens? We conducted a literature review to find out.

\subsection{Literature Survey Methodology}

We collected papers for our literature review by searching the ACM and IEEE digital libraries, and Google Scholar for various combinations of the key words and terms: privacy, social pressure, online sharing, privacy paradox, social media/network, problematic smartphone use, internet addiction, Fear of Missing Out/FoMO, social norm, affect, performative privacy, shame, and security and then snowballing relevant sources from the references of those papers until no new papers were found. From this collection, we selected the most relevant in informing our discussion of FoMO. Through our central searches and snowballing we collected approximately 80 papers and 20 newspaper articles, websites and blog posts that appeared relevant based on a first pass. A second pass allowed us to reduce our set of papers for careful analysis to those directly relevant to our discussion of FoMO-centric design. We then added supporting papers as necessary to expand on certain indirectly related subjects.

Collating the results of our literature survey, we find that research relating to FoMO largely falls under two broad categories: user behaviours and motivations that lead to FoMO, and design features of social media platforms that encourage feelings of FoMO. 
The elements contributing to each factor are summarized in Table 2.1. We address each factor in the following sections.

\subsection{Factor 1: User Behaviours and Motivations}

\subsubsection{Short-Term Benefits Prioritized}

The Privacy Paradox [86 is a widespread phenomenon in which the privacy behaviours of users who are self-reportedly highly privacy concerned do not reflect that concern. It was first popularized in an online context in 2000 [86 and has since been reported in a wealth of studies (e.g., [72, 80, 96, 99, 112]).

There is no consensus on what causes this phenomenon; theories range from knowledge deficiencies to the optimistic bias theory and beyond. In 2017, Barth et al. 9] published a systematic literature review organizing privacy paradox theories into main categories and sub-clusters. Our interest in this literature review lies in the "Biasedrisk assessment within the risk-benefit assessment" sub-cluster- and more specifically, the '(Immediate) gratification' sub-cluster II, as we believe it appears to relate most closely with motivations driving FoMO. It explains that the promise of immediate benefits prompts individuals to behave in ways which may be detrimental to their long term interests. Acquisti et al.'s [2] paper on privacy and rational decision-making found that even when users are sufficiently informed of benefits and risks, they often choose short-term benefits over long-term privacy benefits. Time-inconsistent discounting says that people tend to overrate the present compared to the future [2]. With respect to social media, this suggests that users value the immediate benefit of sharing more than possible future privacy benefits. Acquisti et al. speak to privacy trade-offs being "inherently intertemporal": "disclosing data often carries an immediate benefit," but that the costs are "often uncertain, and are generally incurred at a more distant point in time' [4].

\subsubsection{Social Isolation Avoided}

The term "participatory reluctance" was coined in 2016 by Cassidy [22]. This concept challenges typical binary presentations of connection and disconnection in social 
media- that is, the idea that if a user uses a site it is because they want to, and that otherwise they would discontinue use of the site. Cassidy found that users of gay social media site Gaydar continued to use the site despite voicing strong objections to both its interface, which promoted a stereotypical view of gay men, and its resulting perceived user base. Cited as a significant factor in users' decisions to stay on the site was the "lack of genuine alternatives in terms of niche SNSs [Social Network Sites] designed for the gay male community" 22 .

This lack of alternatives meant that Gaydar had gained a kind of "essential" quality for gay men. Despite the fact that users felt "othered" and "isolated" using this website, they felt the alternative (not using the website) would be worse; "akin to choosing to isolate oneself from the gay community." While users were encouraged to "go home" if they didn't like the site, Cassidy points out that leaving the "metaphorical 'club' of Gaydar [...] really does mean effectively going home." The website's only competitors consisted of much the same kinds of experiences that users hated so much in Gaydar. As a result, "users continued maintaining profiles on Gaydar, despite their relationships with the site often being defined by abhorrence- both of the site itself and its imagined audience" [22].

Users of Gaydar were technically free to not use the website, or to "go home", so to speak, but they chose to stay out of fear of isolating themselves further. This is important to keep in mind when we consider whether users are always comfortable with a "voluntary" choice. As shown, hidden factors can be at play.

Since the publication of Cassidy's paper, the concept of participatory reluctance has been discussed in relation to disconnective practices [101] of millenials [36 and politically active youths [27], posting decisions for mixed audiences [82, queer identity on social media 37, 85], and manipulation and "price" in social media [77].

Participatory reluctance might be explained in part by a commitment-based model, which says that users can get "locked in" to a website when there are no competitive alternatives, and that time spent on the site can constitute "sunk costs" which dissuade users from switching (especially if alternatives are not as good) 61]. For example, Nusair et al. [74 found that "calculatively committed Gen Y users stay in a relationship with travel related OSNs [Online Social Networks] because of the lack 
of alternatives and the switching costs associated with leaving the relationship."

\subsubsection{Community Norms Established}

Online culture has significant impact on users' behaviour and self-regulation. Tufekci 98 proposes that the cultural norms of online environments produce a certain level of "minimum [self-]disclosure" that users feel pressured to follow. She found disparities in the percentage of privacy-concerned participants who used their real names on Myspace (63\%) and Facebook (95\%). Participants reported an expectation of using their real name on Facebook. This community norm can most likely be attributed to the site's real-name policy [39], which penalizes users for using names which are deemed implausible or fake. Facebook CEO, Mark Zuckerberg, acknowledges evolving "social norm[s]" of privacy [7], but frames Facebook's privacy practices as "reflect[ing] what the current social norms are", rather than playing a role in influencing those norms.

Communities perpetuate norms once they are established. In the case of Gaydar, reluctant users continued to maintain the culture that had given them such low expectations to begin with. Cassidy describes this as the "cyclical" nature of a "culture of participatory reluctance'; "[Users] are engaging in an already existing dialogue", and feel obliged to "keep a particular narrative going" [22].

Failing to keep that narrative going may result in negative evaluation - and users are afraid of it. Wolniewicz et al. [110] discovered a strong correlation between FoMO, social smartphone use, and fears of negative evaluation. A fear of negative social effect from failing to meet the community norm of minimum disclosure may be justified; Strater et al.'s 94 participants reacted negatively when viewing partially complete Facebook profiles which hid displays of social connections such as the Friends list and the Wall. Acquisti et al. [3] found that peer pressure was a driving force behind the disparity between privacy concerns (which were generally high) and behaviours relating to joining and using Facebook.

In relation to their empirical study of peer effects in voluntary disclosure, Böhme et al. [12] discuss the "self-reinforcing" nature of peer dynamics influencing users' privacy attitudes. They suggest that interventions such as privacy-friendly UI design and user 
education may not in themselves be enough "to reverse dynamics of descriptive social norms."

Based on a literature review, Sundar et al. 95] identified six privacy heuristics for sharing in social contexts online, including the Bandwagon heuristic (mirroring the behaviour of the majority of users), the Self-presentation heuristic (sharing to improve online persona), and the Reciprocity heuristic (returning the level of personal information shared by another). They suggest these heuristics "could be prevented from being applied if their corresponding cues are absent." Sundar et al. reference Instagram's recent removal its "\# of Likes" cue, saying this "will automatically preclude the application of the bandwagon heuristic." Instagram itself has stated the decision to eliminate the likes count is intended to "remove pressure" on users [69].

Branley et al. [16] criticize models such as the Theory of Planned Behaviour, saying that these focus too much on positive, reasoned behaviour, and leave a gap in the study of negative and risky behaviours. Instead, Branley et al. apply the dual-process Prototype Willingness Model [43], used to address "non-intentional, but volitional adolescent risk behavior". They use it to study the role that "reasoned" and "reactive" pathways play in the online risk behaviours of adults and adolescents. They found that reasoned pathway antecedents including injunctive norms, descriptive norms and previous behaviour were "highly significant, positive predictors" in participants taking part in risky online behaviours such as sharing embarrassing photos and publicly sharing their current location - suggesting users may partake in risky behaviour even after reasoned thought because social norms are so important.

\subsubsection{Social Capital Desired}

Social capital is the "resources available to people through their social interactions ' 100]. Individuals who are more connected to others have increased opportunities for various supports, job-seeking, or favours. Through the use of social media, users strengthen bonds with others and can increase their social capital 38].

The desire for social capital can lead users to disregard privacy concerns. Chen et al.'s findings 25] suggest users use the Chinese social media platform WeChat despite privacy concerns in part because the "social capital yielded $[. .$.$] is too valuable to$ 
give up". Tang et al. 97] discuss social-driven location sharing, sometimes known as large-group or one-to-many sharing. This form of location sharing, usually done over social media, is presented in contrast to purpose-driven location sharing and is driven by impression management and the building of social capital.

Even when users partially blur their location for privacy purposes, they prefer to keep it minimal, so that it does not negatively interfere with any potential social benefit. "By opting to share a place name that is somewhat precise [...] participants can still appear as though they are actively involved in contributing to their social network's overall social capital. If they opt to share an overtly vague place label (e.g., 'Pennsylvania'), then it may come across as though they are intentionally being socially reclusive" 97.

Interestingly, Tang et al.'s work finds it is not uncommon for users to lie about their location to make more positive impressions on those in their network. This raises the question: if the user actually is in a place they consider to be impressive, do they feel more pressure to share that location, for the sake of social capital? This would fall in line with Bednar et al.'s finding that users feel an experience is worth less if it has not been digitally shared $[11$.

\subsection{Factor 2: Design Features}

As stated in the introduction, we define FoMO-centric design as "a collection of manipulative strategies within system design that benefit from users' desires to be accepted socially. By exploiting FoMO-associated behaviours and motivations, FoMOcentric design sways users to reluctantly behave in ways that compromise their own privacy-preserving standards." By our definition, systems qualifying as FoMO-centric display one or both of the following characteristics:

1. direct social benefit from using features that may compromise aspects of privacy or security (e.g. location sharing)

2. indirect social benefit from sharing information with company or service (e.g., being allowed to join, install, or use certain features of app or website by accepting permissions for data collection, or directly providing data such as via 
forms), which ultimately results in social approval from peers

\subsubsection{Attention-Economic Logic}

Most social media platforms are 'free' for end-users to use, but as Paasonen explains, "the price paid for using social media is that of time, attention and data, while affective ripples, releases and reattunements are that which is both generated and gained in the exchange" [77]. Sites are engineered to continuously 'grab' users in such a way that they provide the maximum engagement. This, of course, is all part of an attention-economic logic: users' attempts to continuously create and attain affective intensity "binds us to a communicative capital that desires and demands

affective responses in order to perpetuate, to reproduce, its economic logic" [51. Personal data gained from this attention grabbing are considered "business assets" for targeted advertising and trading with third companies- a central theme of privacy economics [4]. Zuboff [113] refers to the commodification of personal data like this as "surveillance capitalism".

\subsubsection{Service Denial}

Oftentimes, users' access to services is reliant on the leniency of their privacy preferences. An extreme example of this is the install-time permissions model used by Android until recently. In this "ultimatum" model (as Wijesekera et al. [109 put it), all permissions are requested before installation. If the user does not agree to required permissions (which are often privacy-sensitive), the app cannot be installed. Essentially, the user is punished and denied service for having higher-than-desired privacy standards. This happens as well, though perhaps to a lesser degree, in Android's more recent ask-on-first-use model, which takes the user's original decision out of context and applies it to all future requests [109].

Denying service to those uncomfortable with the given privacy standards will likely result in users compromising their standards. When users are facing pressure to conform to community norms and to avoid potential social fallout, giving them an ultimatum to either conform wholly and immediately to given privacy parameters or get out does not provide the user with a fair chance to consider privacy or security 
implications. This is especially true if the user is already experiencing high levels of FoMO and feeling both "out of control" of their behaviour and more likely to take risks in the name of social capital. Service Denial is recognized as a dark pattern in the form of Bösch et al.'s Forced Registration [14], but Bösch et al. do not relate it to social implications. They instead focus on the instant gratification a user gets upon registering to reach their "goal."

Some researchers, such as Guha et al. [45], have explored whether it is possible for a user to use social media websites while maintaining both privacy and full access to services. Many online providers, in lieu of re-engineering their services to protect privacy, choose to simply deny service to users who desire more stringent privacy options, since these users are, in the eyes of the providers, "unprofitable" [45]. Guha et al.'s proposed solution is 'NOYB', or "None of Your Business", which allows users more control over their information by using encryption to disallow it from being read by unauthorized parties, without interfering with functionality 45. However, it seems unlikely that most users would be willing to expend the additional effort (or even have the knowledge) required to use third-party plugins, such as NOYB [45], to preserve both their privacy and access to the service. The fact that these third-party solutions exist in the first place is symptomatic of a larger problem regarding the service's handling of users' privacy.

\subsubsection{Infrastructure Informs Community}

Cassidy [22] argues that a site's digital infrastructure has a major role to play in how people choose to interact with the site and those on it. As illustrated in his study of Gaydar, the cyclical nature of participatory reluctance culture can make it difficult or impossible for users to break out of the cycle and interact with the website in a different way that they might prefer.

By design, privacy-conscious individuals are at a disadvantage using social media from the outset. Papacharissi et al. [78] state that social media creates an "environment that equates sociality with sharing" where a reduced online presence can result in social cost. "[N]etworked social environments make it challenging for individuals to be private in spaces that were designed for sharing, not privacy" [78]. 
Taking a socio-technical "script analysis" approach, Docherty [34 investigates how, through a combination of platform design and discourse, Facebook has framed user behaviour on its platform in a dichotomy of wellness, where active participation is healthy, and not actively participating is unhealthy. This nudges users to follow certain principles "manifest in the material design of the platform itself" and places the onus of "wellbeing" on the user, guilting them into interacting as much as possible.

"While the personal choice to invest in relationships and cultivate social capital amounts to living well on Facebook, [...] this choice is simultaneously presented as the fulfillment of a natural inclination to connect with others in a shared social environment. Upon this basis, direct communications, sharing statuses, liking photos, commenting on posts-and all the other hallmarks of good, active usage, rather than being viewed as the result of a designed user-experience intended to gather data for the sake of capitalist profit, can instead be presented as the result of rational user choices fulfilling innate human social needs." 34

Users may be marketed the illusion that they have independent will to stray from the status quo if they dislike it, but the status quo can have a tremendous impact on users' behaviours. Those with high levels of FoMO, who are especially concerned with how they are viewed by others [110], may be especially susceptible to acting within the status quo. Crucially, that status quo does not arise spontaneously. It begins with how the website, app, or other technology is presented to its audience. If we create an environment where sociality and sharing are synonymous, users will share more, because they do not want to be seen as unsociable [51, 97]. Designers have a responsibility to avoid designs that take advantage of users' weaknesses for economic, or other, benefit.

\subsubsection{FoMO and Social Media Use}

Using a 10-item self-report scale developed to measure low, medium, and high latent levels of FoMO across individuals, Przybylski et al. 81] found that participants who scored low on items of competence, autonomy, and relatedness reported higher levels 
of FoMO. These participants also reported lower general mood and lower levels of life satisfaction. Correlations were found between high levels of FoMO and interaction with Facebook at "key" times of day, including during university lectures and while driving. Overall, they found FoMO 'robustly' associated with social media engagement, and presented FoMO as a "mediator" connecting psychological needs deficits to social media engagement 81 .

Through a series of semi-structured interviews, Bednar et al. 11] created a list of values fostered, values undermined, and psychological and societal resources depleted by ICTs (Information and Communication Technologies). Values fostered by ICTs included convenience, efficiency, information accessibility, belongingness, and joy. Undermined values, on the other hand, included friendship (resulting from reduced inperson contact, boredom from digital overexposure, and friends being distracted by their phones when met in person), and knowledge (through loss of competence with constant access to a search engine, fear of getting lost without a map app, and general feelings of becoming 'more stupid'). Psychological resources depleted included an impediment of control and autonomy through addiction; stress, social pressure, distractions, and feelings of wasted time. Societal resources depleted consisted of concerns of information privacy- many users were aware that social platforms 'spy' on them and sell their data to third parties, a biased view of reality, and problems associated with the powerful position of ICTs in society [11].

Users noted considerably more disadvantages than advantages to using ICTs, yet continue to use them. Bednar et al. put it succinctly: "Our interview partners are fully aware of [negative effects], but feel incapable of reacting. They expressed the wish to stop, reduce, or change their use, but they do not feel in control of their own behavior" [11]. Paasonen [77] reports a kind of "ambivalence" caused by FoMO and participatory reluctance, making users feel helpless as they continue to use social media in the face of "creepiness" invoked by awareness of data leaks: there is a sense by users that this is simply the price to pay for using the service. And the more users continue to helplessly use the service, the more helpless they are when data leaks do happen; a greater amount of information shared with the service means a greater risk to security when that information is revealed to unintended parties. 
Feeling they were "missing out" on the offline world as a result of their dependency, Bednar's participants expressed wishes for social media or smartphones to be abolished, harder sanctions for privacy violations, and even spending more time in nature [11].

Even when seemingly given free range over their behaviours, users still feel constraints on how they can act. Socially-speaking, this is clear in relation to pressure to adhere to community norms and avoiding isolation. Seeking short-term benefits over long-term privacy benefits may also be closely linked, either directly or indirectly, when the benefit is of a social nature. While these characteristics are not necessarily linked directly to FoMO, we suspect their effects would become stronger in individuals with high levels of FoMO. Users high in FoMO are likely to partake in detrimental and risky behaviours, and may put impressing others above their privacy. Finally, users may not feel that changing any of the above behaviour is within their control. Especially noteworthy is that users would like to change their behaviours, but would like external help. This suggests that built-in measures to help discourage problematic usage would be appreciated by users.

Unfortunately, evidence suggests that this type of problematic usage of social media may be by design (i.e., a dark pattern rather than an anti-pattern), and thus, design changes would need to be accompanied by an attitudinal and directional shift from those responsible for social media platforms.

\subsubsection{Other Design Considerations}

Our reasoning behind the existence of FoMO-centric design focuses on the benefits associated with privacy-compromising user behaviours as laid out above. However, these factors may not be the only reason these patterns are implemented, or why they work. Other design considerations including economic, marketing, purchasing, deceptive sales tactics, network economics, and privacy economics could reasonably be at play.

Cost-benefit models of understanding decisions by users, such as those seen in economics, posit a consumer voluntarily trading privacy for some benefit, often assuming 
a balanced relationship between user and technology. While privacy economics acknowledges the fact consumers may not be aware of future uses for their data [4], they do not necessarily focus on solutions to tackling the problem of user manipulation.

While helpful in informing our understanding of the competing priorities when it comes to motivations for using such patterns, they are out of scope of this thesis as they do not directly contribute to explaining why or how these patterns may be, directly or indirectly, privacy and security threats by ways of manipulation.

\subsection{Research Gaps}

As shown, the literature provides strong evidence that users participate despite ambivalence, that users partake in detrimental activities due to FoMO, and that social factors are a driving force in users' decisions to share. However, no literature has of yet directly addressed these three factors together (FoMO, ambivalence, and privacy behaviours). We address this research gap in the following section. 


\section{Table 2.1: Factors Contributing to FoMO-Centric Design}

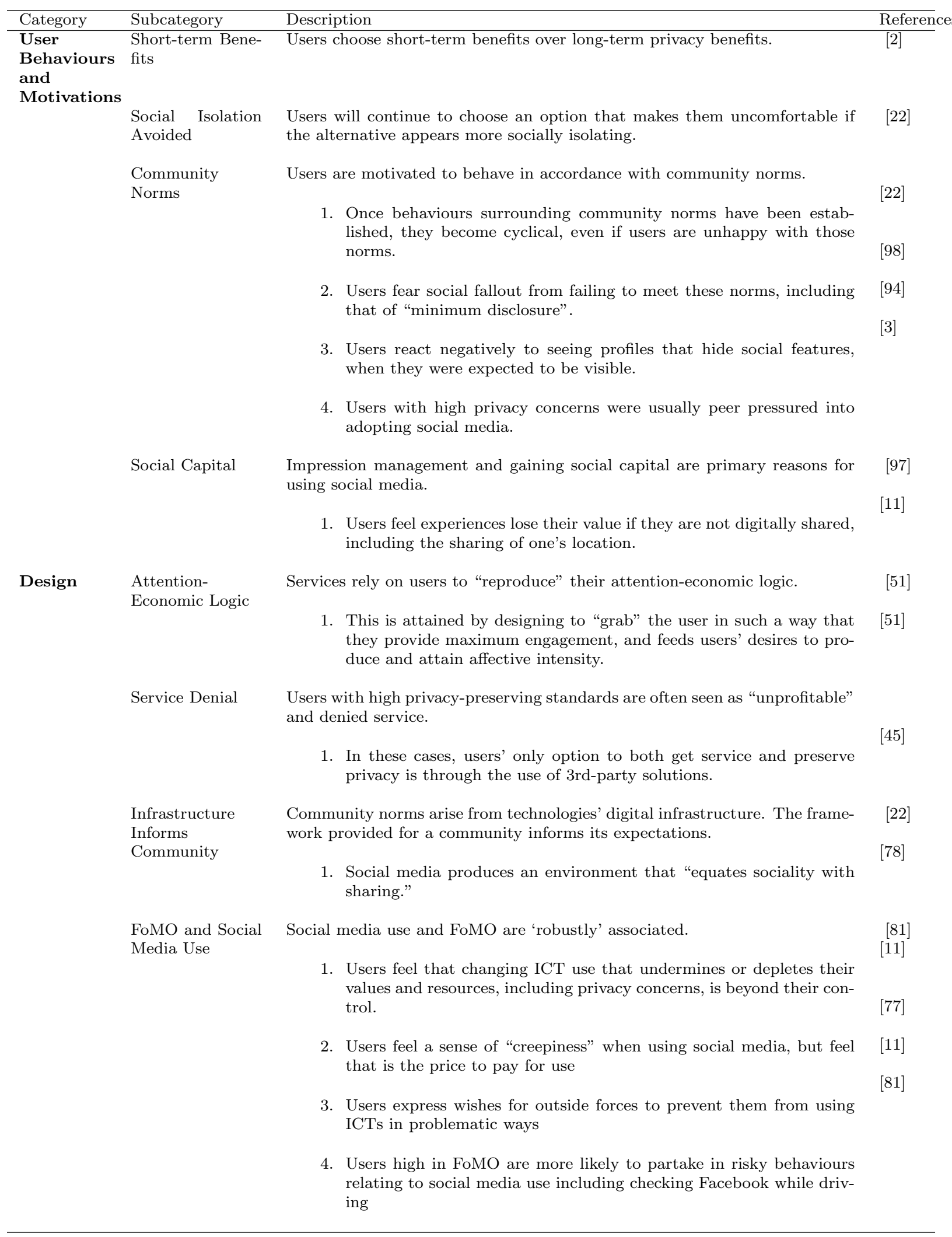




\section{Chapter 3}

\section{Methodology}

Evidence garnered from our literature review suggested users might engage in privacycompromising behaviours because of the Fear of Missing Out. We wanted to gain a better understanding of the situations in which reluctant participation happens by gathering our own qualitative data from users. Additionally, we wanted to create a theory solidly based on empirical data. For this reason, we decided to use the Grounded Theory approach in a series of user interviews. We received ethical clearance for this project from the Carleton University Research Ethics Board B, clearance number 111950.

\subsection{Grounded Theory}

We followed the methodology outlined in Charmaz' Constructing Grounded Theory [24]. Charmaz defines grounded theory methods as consisting of "systematic, yet flexible guidelines for collecting and analyzing qualitative data to construct theories from the data themselves." It is an inductive approach featuring simultaneous iterative data collection and systematic analysis, a focus on actions and processes, and the gradual raising of lower-level codes into conceptual categories. This makes it an excellent way of approaching new and unexamined areas of study, such as our proposed FoMO-centric design. Grounded theory by its nature encourages exploration over the strict validation that other methods may offer. This allows us to naturally build an understanding of factors affecting real participants before jumping to conclusions too soon and making unfounded claims or testing an irrelevant hypothesis. It also means we can slowly develop and adjust the directions of our interviews to pursue relevant areas of interest, ensuring the theory remains backed up by real data rather than purely hypothetical. Charmaz follows a constructivist approach, which sees the researcher's analyses as "located in time, place, and the situation of inquiry," 
rather than purely objective. We believe this is important to acknowledge; the researcher's theory is effectively an interpretation informed by their experiences and knowledge. This allows us to remain open to differing perspectives and enriches our inquiry, rather than let it become stagnant and inflexible. As per Charmaz's approach, our questions evolved throughout the process, meaning not all participants were asked the same questions throughout the interview (see Section 3.7 for more information).

\subsection{Study Overview}

The study included the following steps, which are described in more detail in the following sections.

1. Recruitment starts

2. Interested parties email researcher and receive a link to a pre-screener questionnaire

3. The researcher sends out a batch of invitations (5-10) to selected participants who meet desired FoMO-level and/or platform use criteria

4. Sessions are conducted with this batch of participants; sessions include:

Pre-interview questionnaire

Interview

Post-interview questionnaire

5. Transcriptions and initial coding are done on this batch of interviews

6. Interview questions are added, changed, or emphasized based on emerging themes or gaps discovered in the data

7. The cycle repeats with following batches of sessions and coding carried out, repeating Steps $3-6$.

8. The sessions end once interview topics and FoMO-levels have been sufficiently saturated 
9. The final stage of analysis begins

\subsection{Recruitment}

Between December 2019 and February 2020, we recruited participants through the following methods: (i) posts on Carleton's Research Participants Facebook group and on the researcher's social media, (ii) posters on campus, in public libraries and around the researcher's city, and (iii) emails to personal contacts. The inclusion criteria were being over the age of 18, being comfortable giving an interview in English, and being either a current or past user of social media, message boards, and/or online multiplayer video games.

\subsection{Pre-Screener}

Interested participants were asked to fill out a pre-screener questionnaire on the online survey platform Qualtric: 1 . Participants were asked if they were at least 18, were comfortable giving an interview in English, and which of the following platforms they had used: social media, instant messaging, message boards, and online multiplayer games. See Appendix A for details.

This pre-screener also included the 10-item Fear of Missing Out scale by Przyblylski et al. 81] (See Appendix A.3), which rates participants' FoMO levels on a scale from 10 to 50. We selected this scale because it is the most widely cited FoMO scale and is the foundation for much FoMO research, including some of the papers cited in our literature review. It has been scientifically validated and is also conveniently short, which allows us to quickly get an idea of our participants' FoMO levels without extensive questionnaires or interviewing. We used the information from the pre-screener, including participants' FoMO level, to decide whom to invite for an interview, primarily attempting to get a reasonable distribution of participants across the FoMO scale. Figure 3.1 shows the distribution of FoMO scores for the 62 pre-screener respondents.

\footnotetext{
1 https://qualtrics.com/
} 


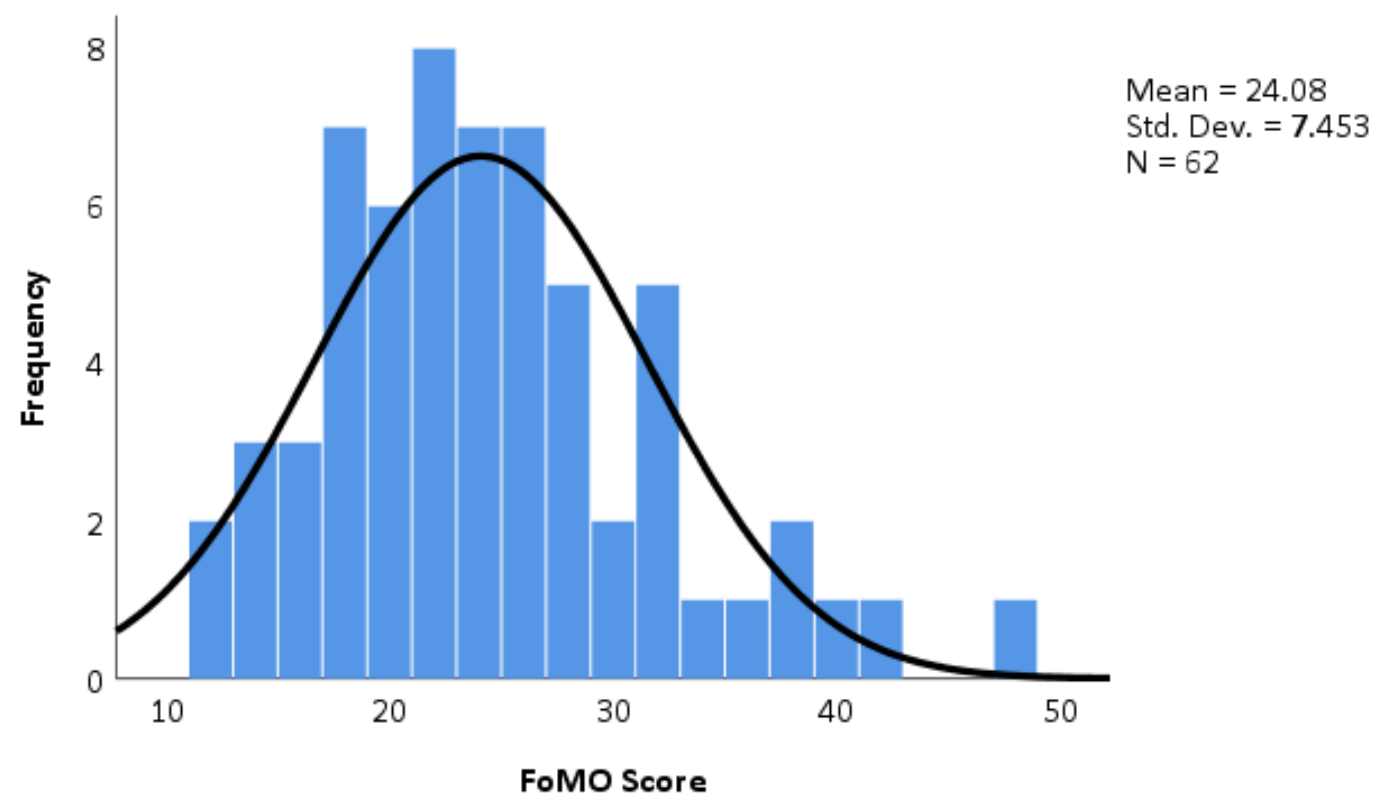

Figure 3.1: Distribution of FoMO scores for all participants recruited during the pre-screener phase.

\subsection{Interview Participants}

Participants were selected for interviews with the aim to talk to the widest possible range of participants in terms of FoMO level. Out of a total 62 pre-screener respondents, we invited 35 for an interview. The final 25 participants we interviewed had pre-screener FoMO levels ranging from 12 to 38, with an average FoMO score of 24.72 $(\mathrm{SD}=6.98)$. Figure 3.2 provides a graph of the final distribution. Note that it was not possible to score lower than 10 on the FoMO questionnaire, as out of the 10 questions the lowest available answer was strongly disagree, or 1. It was also highly unlikely to score near 50, as this would require nearly all selected answers to be in the strongly agree section.

We interviewed 18 women and 7 men between the ages of 18 and 64. Most were in their twenties, with the mean age being $25(\mathrm{SD}=9.53)$. We informally tried to balance the number of male and female participants, but our pre-screener participant pool was heavily skewed towards female participants, and the pre-screener did not ask about age or gender. Participants came from a wide variety of educational and 


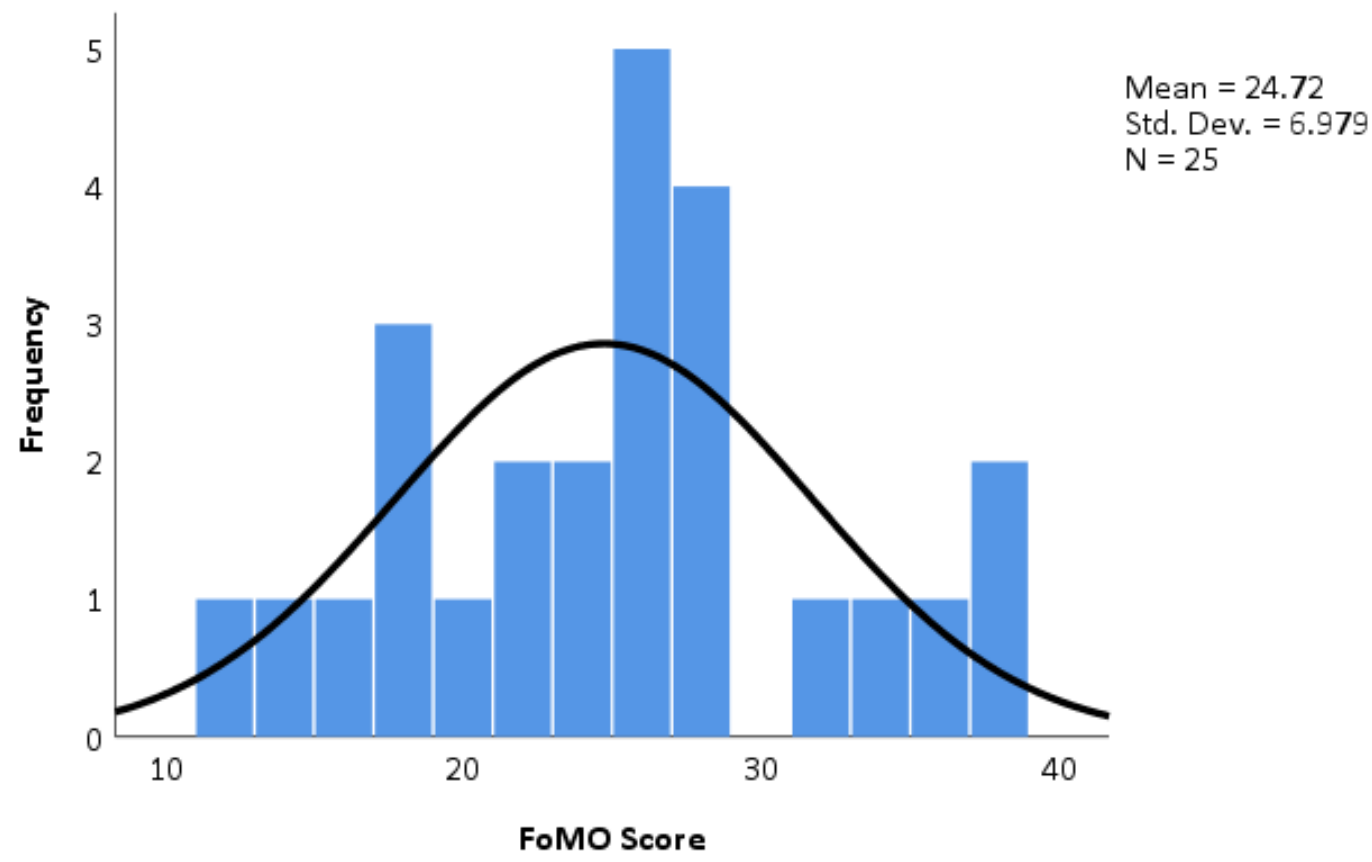

Figure 3.2: Distribution of pre-screener FoMO scores for interviewed participants.

professional backgrounds, including Computer Science and IT, Humanities, Public Relations, Healthcare, Journalism, Law, Engineering, and Psychology. 36\% were employed full-time, $32 \%$ were full-time students, $20 \%$ were either employed part-time or were part-time students, and $12 \%$ were not employed or identified their situation as "other."

\subsection{Pre-Interview Questionnaire}

Pre- and post-interview questionnaires were hosted on Qualtrics and were completed on a lab computer for in-person interviews, or on the participant's computer for remote interviews. This questionnaire contained demographic questions regarding age, occupation, gender, education level, and frequency and ways that online social platforms were used. Figure 3.3 shows how much participants used the platforms we asked them about. 


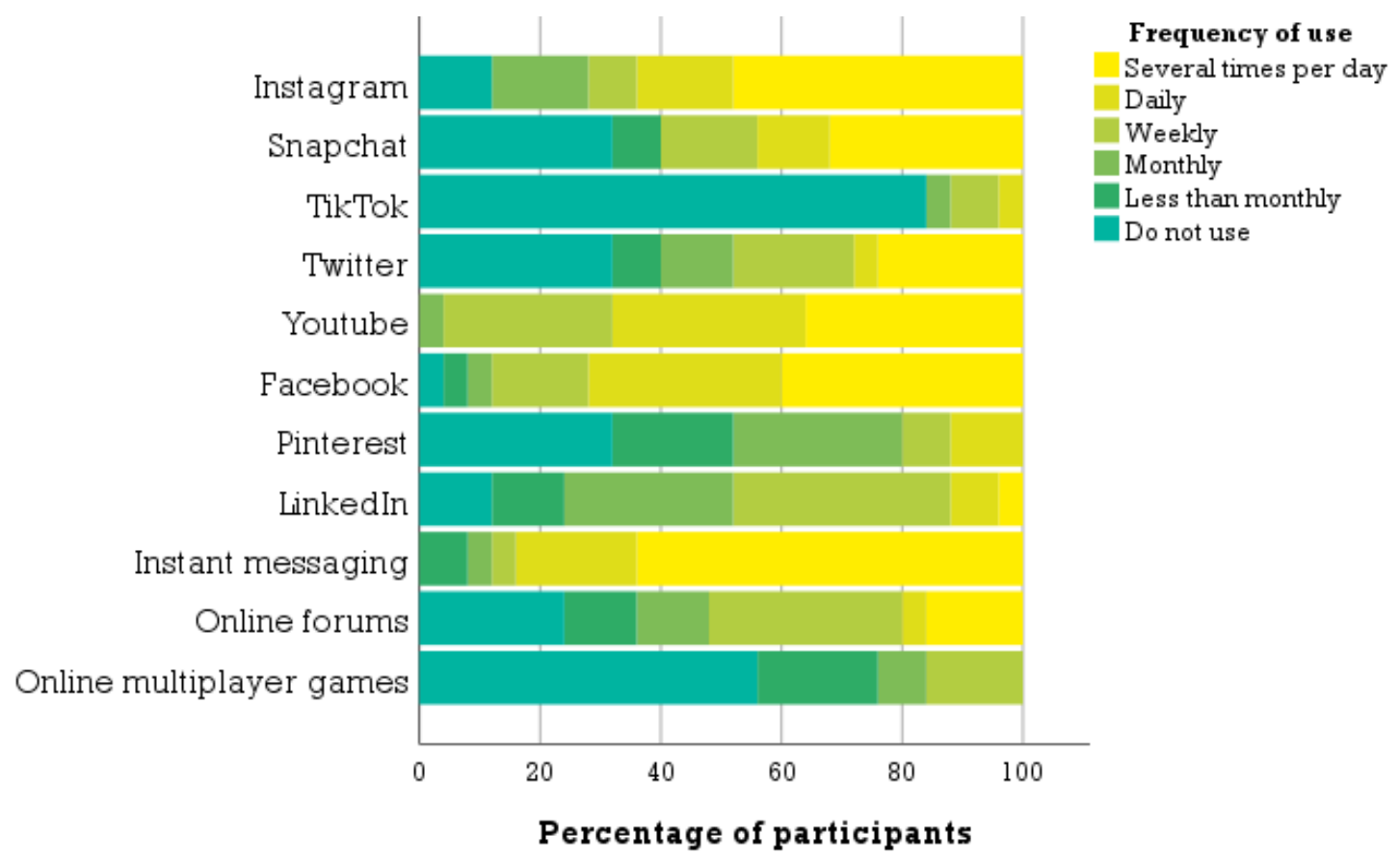

Figure 3.3: Participants' frequency of use of various platforms, from pre-interview questionnaire responses.

\subsection{Interviews}

Out of 25 selected participants, we interviewed 14 in person on the Carleton campus, and 11 using Skyp $2^{2}$ video-conferencing software. They were compensated with $\$ 20.00$ CAD either in cash or Interac e-Transfer, or equivalent amount in Amazon gift card for their time. In-person interviews were recorded on a main and a back-up audio recorder and then transferred to the researcher's computer, where they were then uploaded to the online transcription service Trint ${ }^{3}$. Remote interviews were recorded using Skype's in-app recording service, and were then converted to .mp3 format before being uploaded to Trint for transcription purposes. All transcripts were permanently removed from the Trint servers after transcription was complete. Significant observations were noted on paper by the researcher during the interviews. Interviews were semi-structured and sessions (including pre- and post-interview questionnaires) lasted up to 60 minutes.

2 https://skype.com/

3 https://trint.com/ 
Topics for the interviews were selected based on the user behaviours and motivations and on the design features we had uncovered during our background research (Table 2.1), including the concept of participatory reluctance, associations between social media and FoMO, and the impact of community norms and social capital on user behaviour. Our overarching goal for the interviews was to find examples of instances where participants experienced ambivalence (see Section 2.2) in their participation behaviours, to find out more about why they felt that way, and why they decided to participate or not.

Central topics discussed in the interviews included: (i) Posting Habits, (ii) Joining and Staying on Platforms, (iii) Leaving Platforms, and (iv) Perceptions of Others' Online Habits and Expectations. An explanation of each topic and sample questions are shown in Table 3.1. The full final interview guide (updated throughout the interview process) can be found in Appendix $\mathrm{C}$.

\begin{tabular}{l|l|l}
\hline Topic & Research intention & Sample questions \\
\hline $\begin{array}{l}\text { Posting } \\
\text { Habits }\end{array}$ & $\begin{array}{l}\text { To understand the context of the partic- } \\
\text { ipant's SNS usage. }\end{array}$ & What makes you post more? Less? \\
\hline $\begin{array}{l}\text { Joining and } \\
\text { Staying }\end{array}$ & $\begin{array}{l}\text { To learn if participants ever feel pres- } \\
\text { sured to join or stay on platforms. }\end{array}$ & $\begin{array}{l}\text { Can you think of a time you ever felt } \\
\text { reluctant to sign up for a website or } \\
\text { app? }\end{array}$ \\
\hline $\begin{array}{l}\text { Leaving } \\
\text { Platforms }\end{array}$ & $\begin{array}{l}\text { To uncover the factors that make partici- } \\
\text { pants leave platforms, or return to them. }\end{array}$ & $\begin{array}{l}\text { Have you ever deactivated or deleted } \\
\text { an account or an app? }\end{array}$ \\
\hline $\begin{array}{l}\text { Perceptions } \\
\text { of Others }\end{array}$ & $\begin{array}{l}\text { To understand how social norms might } \\
\text { affect users' attitudes or behaviours. }\end{array}$ & $\begin{array}{l}\text { Do you think your friends share sim- } \\
\text { ilar attitudes to you regarding online } \\
\text { behaviours? }\end{array}$ \\
\hline
\end{tabular}

Table 3.1: Interview topics, intentions, and examples from the interview script.

The interviews resulted in 940 minutes, or nearly 16 hours, of recordings. Once transcribed, this resulted in 293 pages of transcripts to analyze.

\subsection{Post-Interview Questionnaire}

The post-interview questionnaire consisted of two parts: (i) a survey of privacy attitudes and behaviours in regard to Online Social Network (OSN) use, and (ii) a repetition of the FoMO scale presented in the pre-screener questionnaire. Though there were slight changes up or down in most participants' FoMO scores post-interview, we found 
overall FoMO scores remained largely consistent. A Shapiro-Wilk test indicated normal distribution of participants' FoMO score data from both our pre-screener (W(25) $=.966, \mathrm{p}>.05)$ and post-interview questionnaire $(\mathrm{W}(25)=.933, \mathrm{p}>.05)$. Accordingly, we used a paired samples t-test ${ }^{4}$ to compare users' pre-screener FoMO scores $(\mathrm{M}=24.72, \mathrm{SD}=6.98)$ to their post-interview FoMO scores $(\mathrm{M}=24.16, \mathrm{SD}=7.26)$. The difference between scores was not found to be significant.

The privacy attitudes and behaviours section consists of questions from the scale featured in Krasnova et al.'s work, "Privacy concerns and identity in online social networks" [55]. We chose this scale because, unlike many privacy attitude scales, it recognizes the importance of context in discussing privacy attitudes. Specifically, it looks at certain situations that are likely relatable for participants as users of online social media, rather than asking about all-encompassing privacy attitudes, which risk being so general they are unhelpful. Furthermore, it is divided into two factors of privacy concern: concern about organizational threats (i.e., platform or third-party level), and concern about social threats (i.e., threats stemming from other users). ${ }^{5}$ The results of the privacy concern section of the questionnaire are displayed by FoMO score in Figure 3.4. As can be seen, while most participants were moderately or less concerned about social threats, concern about organizational threats was more polarized, with more participants on the high and low ends of the spectrum (though mostly high). The "information disclosure" section of the questionnaire is further divided into "amount", "honesty", and "conscious control." Krasnova et al. have said people concerned about organizational threats tend to post less, while those with high concern about social threats tend to increase their conscious control over their posting. We present these scores to get a better sense of participants' attitudes, but, considering our small sample, we do not look for statistical relationships between these scores and the qualitative data we collected. We did some exploratory analysis but no obvious relationships were found between questionnaire variables, so we chose not to pursue this further in the thesis. See Appendix $\mathrm{D}$ for the full questionnaire.

\footnotetext{
${ }^{4}$ All statistics run in IBM SPSS 26.

${ }^{5}$ It should be noted that while Krasnova et al.'s scale was otherwise replicated in this study, $S U_{-} 1$ : I am often concerned that OSN provider could share the information I provide with other parties (e.g. marketing, HR or government agencies) was omitted due to error, which may have affected results of the Organizational Threats measure.
} 

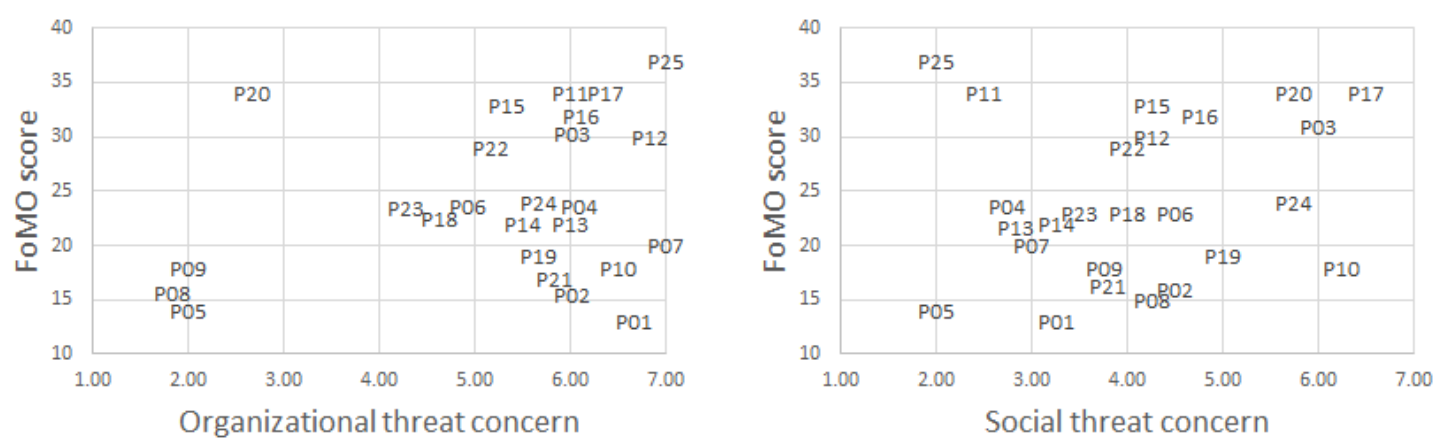

Figure 3.4: Participants' levels of privacy concern about organizational and social threats, by FoMO score. FoMO scores shown here are from post-interview responses.

\subsection{Analysis}

Our analysis is explained in the following section. Following Charmaz's Grounded Theory approach (Section 3.1), our analysis methodology involves the following: coding (open, focused, and axial), memo-writing, theoretical sampling, theoretical sorting, diagramming, and integrating, and finally, theory construction.

\subsubsection{Researcher Background}

The researcher is a Human-Computer Interaction Masters student with a background in the History of Science and Technology. As such, her approach involves a keen awareness of the impact of cultural and social factors on technological development and use, and vice-versa. This is her first time doing Grounded Theory. She acknowledges the observer not as a neutral entity, but as an active player in the research process whose perspective is influenced by their own experience and prior knowledge. While this study began with a general premise in mind supported by initial background research (that there is a connection between FoMO and privacy-compromising behaviour), the researcher has striven to maintain an open approach to the research and to perspectives differing from her own. 


\subsubsection{Coding}

Coding was conducted iteratively over the course of the alternating interviewing and analysis phases. Initial codes were noted in the researcher's memo journal postinterview and during the transcript clean-up phase. Completed transcripts were then exported, along with initial codes, to Microsoft Excel for extensive paragraph-byparagraph coding treatment (See Figure 3.5 for a photo of the in-lab setup and Figure 3.6 for an excerpt). In order to encourage a bottom-up inductive approach and avoid missing any potentially relevant themes in our research due to bias, our first pass consisted of rigorous granular level open coding. We practiced Charmaz' recommended gerund-based coding [24 to keep the focus on the actions and experiences of participants, rather than be distracted by pre-fabricated themes. As we conducted and coded more interviews and identified recurring themes within and across interviews, more abstract focused codes and categories started to emerge. This allowed us to progressively merge related low-level codes and replace them with those deemed most theoretically salient, creating our focused codes. In the final stages, we conducted axial coding by sorting focused codes into overarching higher-level categories (See Figures 3.8 and 3.9) and mapping their relationships (see Figure 4.1), forming the basis for theory construction.

\subsubsection{Memos}

A memo journal (See Figure 3.7) was kept throughout the coding process to facilitate observations, speculations and questions relating to the research and to particular codes. This aided in the development of codes and in casual theorizing about important themes accomplished through brainstorming codes, drawing connections or contrasts between codes, or developing questions to be answered through further interviewing or analysis. Overall, memos pertaining to approximately 150 codes were recorded over 190 journal pages. During the interview process, the memos aided us to ensure we were satisfactorily theoretically sampling and attaining intended depth and width in our categories (See Section 3.9.4 for more details). Once interviewing and coding was complete, these memos served as a basis for our final categories and themes as seen in Chapter 4 Results. 


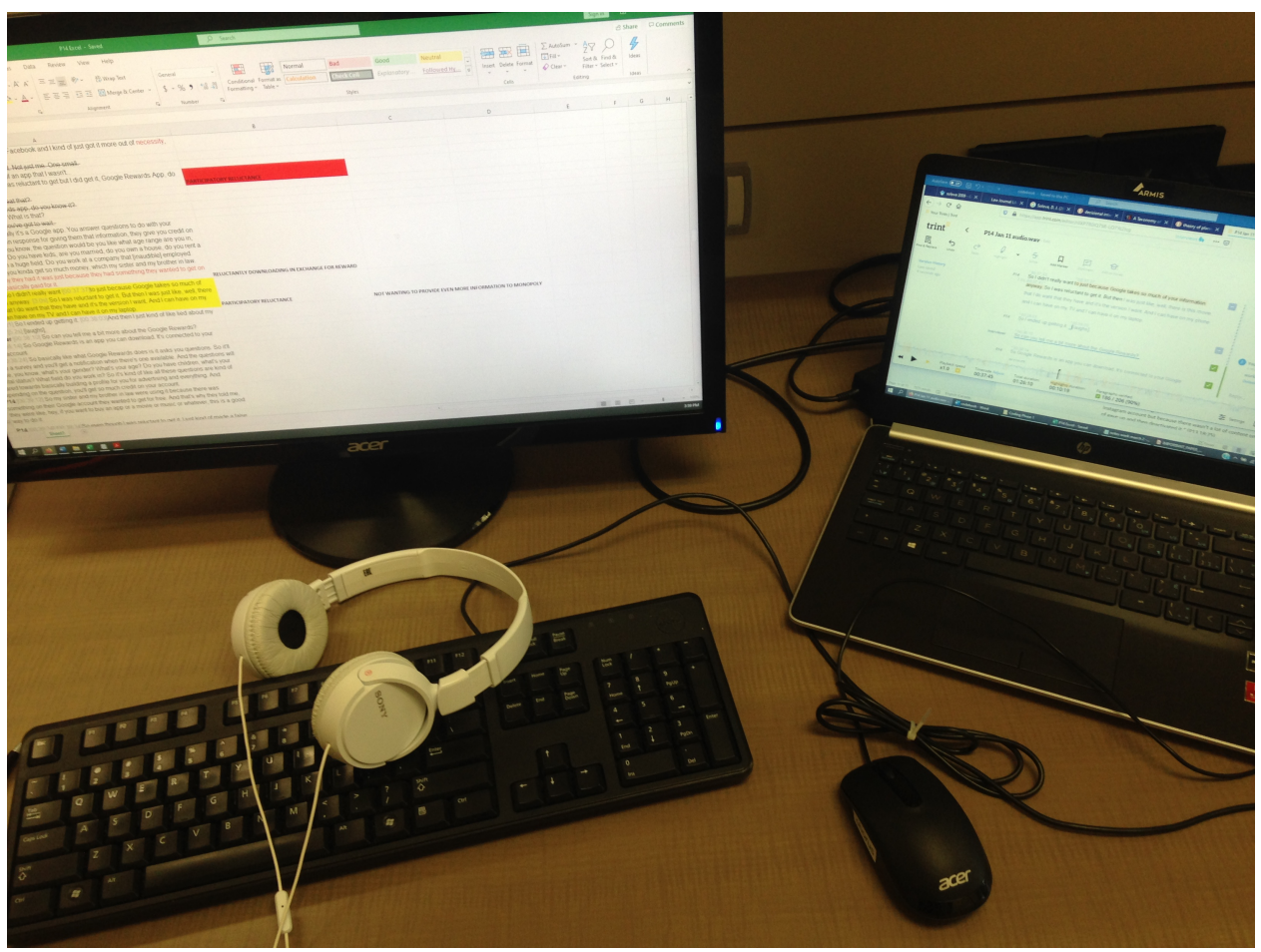

Figure 3.5: Setup for coding in CHORUS Lab, featuring Excel and Trint.

Interviewer [00:23:07] So what are some of the trends that you have participated in?

P16 [00:23:11] Um, I'd say [00:23:14]I did try the um the three hundred and sixty five day thing a few years ago where it's post a photo every day. [7.8s] I did that one by one. I did probably about a third of the way through and then I got annoyed at [00:23:28]myself so I went back and deleted them. [1.5s]

P16 [00:23:31] I think that would be the biggest trend that I did kind of like the share

something that's happening every day that you enjoy.

Interviewer [00:23:39] And when you said you were annoyed by yourself, do you mean you

felt you were posting too much or?

[00:23:45] I felt like I had to come up with a reason to post every day instead of just naturally enjoying my day, like I'd, [00:23:51] oh I have to post something I haven't posted yet. It's 5 o'clock. What can I post? What could I post? [3.9s] I'm trying to think of something and it

ended up just being more [00:23:59]time consuming [0.3s] instead of just enjoying every day

NOT POSTING/PARTIIPATING:

what do I post to show that today was great. [2.3s]

Figure 3.6: Example of coding, with interview transcript to the far left and codes bolded and capitalized to the right. 


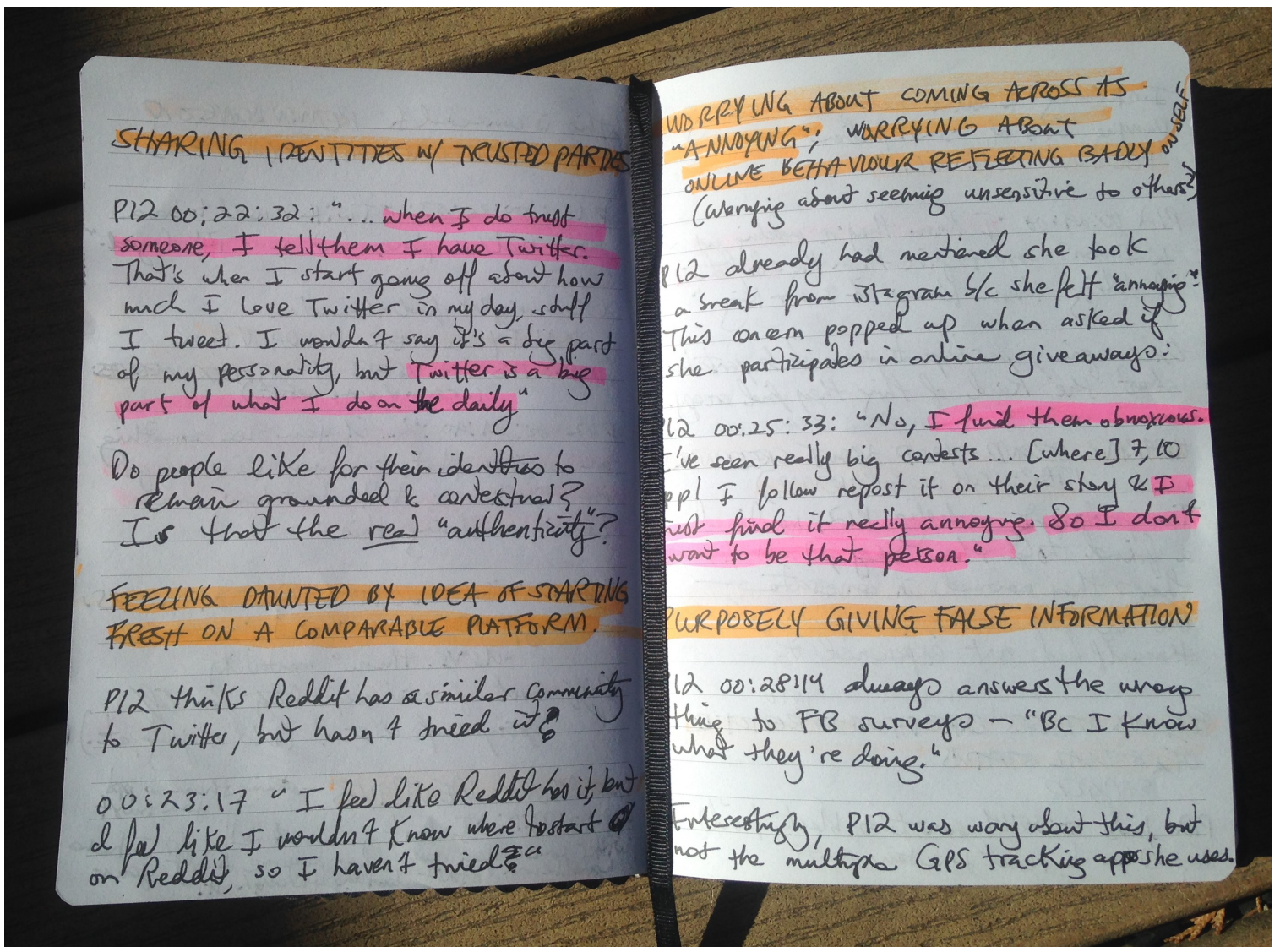

Figure 3.7: Memo journal. Tentative codes are highlighted in orange with supporting quotes from participants, observations, and questions for further investigation. 


\subsubsection{Theoretical Sampling: Updating the Interview Guide}

Through initial exploratory interviews, we established some preliminary categories by grouping related codes. These categories then required further investigation in order to flesh them out and fill in the gaps which they had unveiled in the interview guide; in other words, we attempted to saturate our categories. Grounded theory category saturation, or theoretical sampling, means "to obtain data to help you explicate your categories" [24]; that is, collecting conceptually rich data rather than a large (and often unnecessary) amount of conceptually thin data [24]. Furthermore, it "involves starting with data, constructing tentative ideas about the data, and then examining these ideas through further empirical inquiry" [24]. This is in contrast to quantitative definitions of saturation which consist of generalizing to a population in a statistically valid way.

We conducted further empirical inquiry of tentative ideas explored in our memos by updating our interview guide to reflect new questions we had about relevant aspects of participants' experiences. An affinity diagram (See Section 3.9.5 helped act as a guide in identifying the types of questions to ask, by helping us find gaps within and between categories.

Changes or additions to our interview guide originated in a variety of ways. Occasionally, specific wording used by participants inspired new questions. For example, about halfway through our interviews, a participant casually brought up "jumping on the bandwagon." We recognized this as a widely known colloquial term for following the crowd, something which we hypothesized might be central to FoMO-centric behaviour. Therefore, we added the question "Can you think of a time you ever "jumped on the bandwagon'?" to further explore this aspect of FoMO-centric behaviour in our interviews. Using this shared vocabulary with participants acted as a shortcut to learning more about this particular FoMO-driven behaviour; participants immediately understood the kinds of experiences that "jumping on the bandwagon" entailed, which made them easy to discuss.

Other times, changes to the interview guide were based on addressing topics that we had missed in the previous round, and it was not as clear cut what questions should be asked to fill these gaps. In these cases, new questions sometimes went 


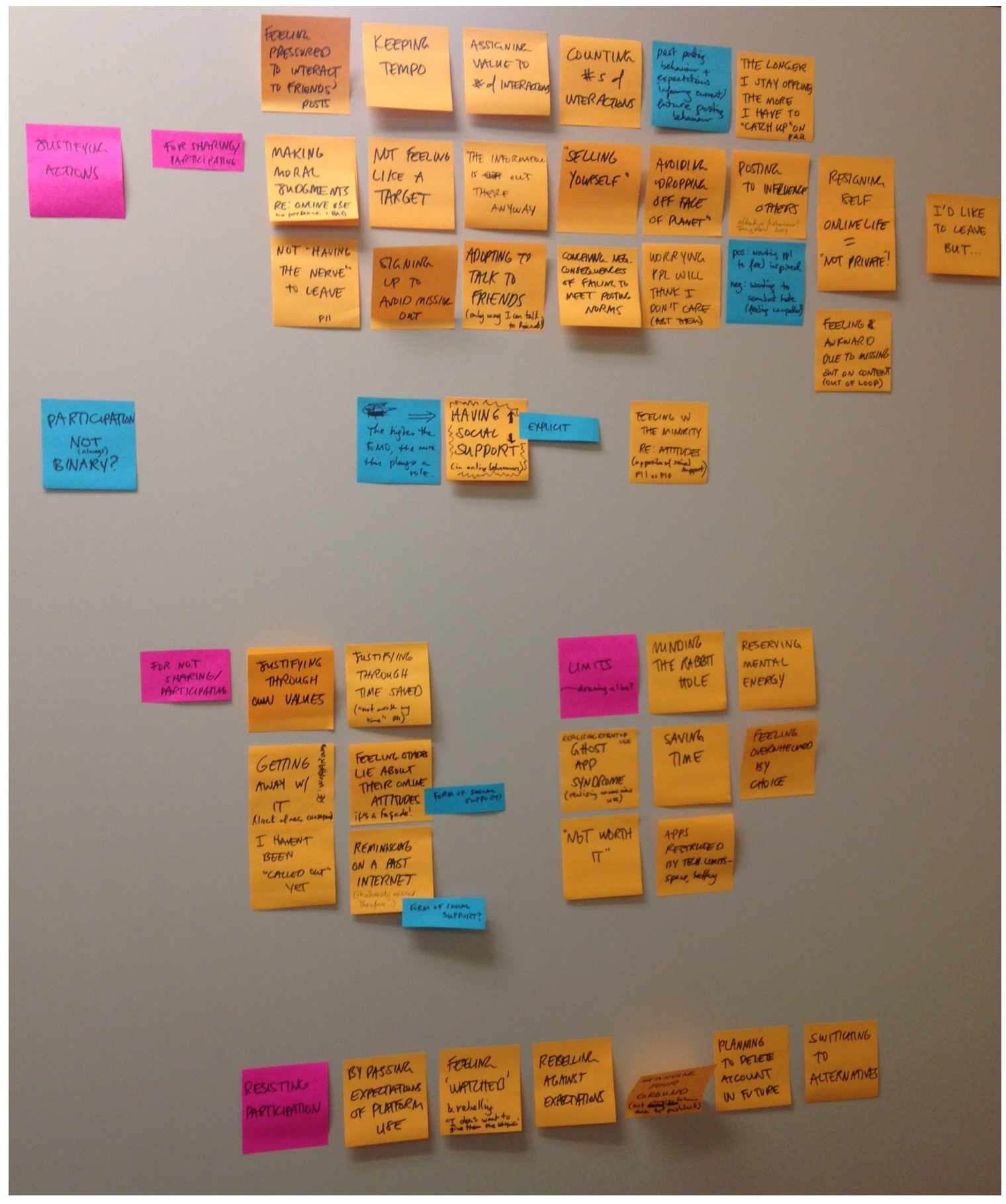

Figure 3.8: Affinity diagram of initial broad categories, featuring user justifications for and against participating. Yellow denotes codes, pink categories, and blue memos. 


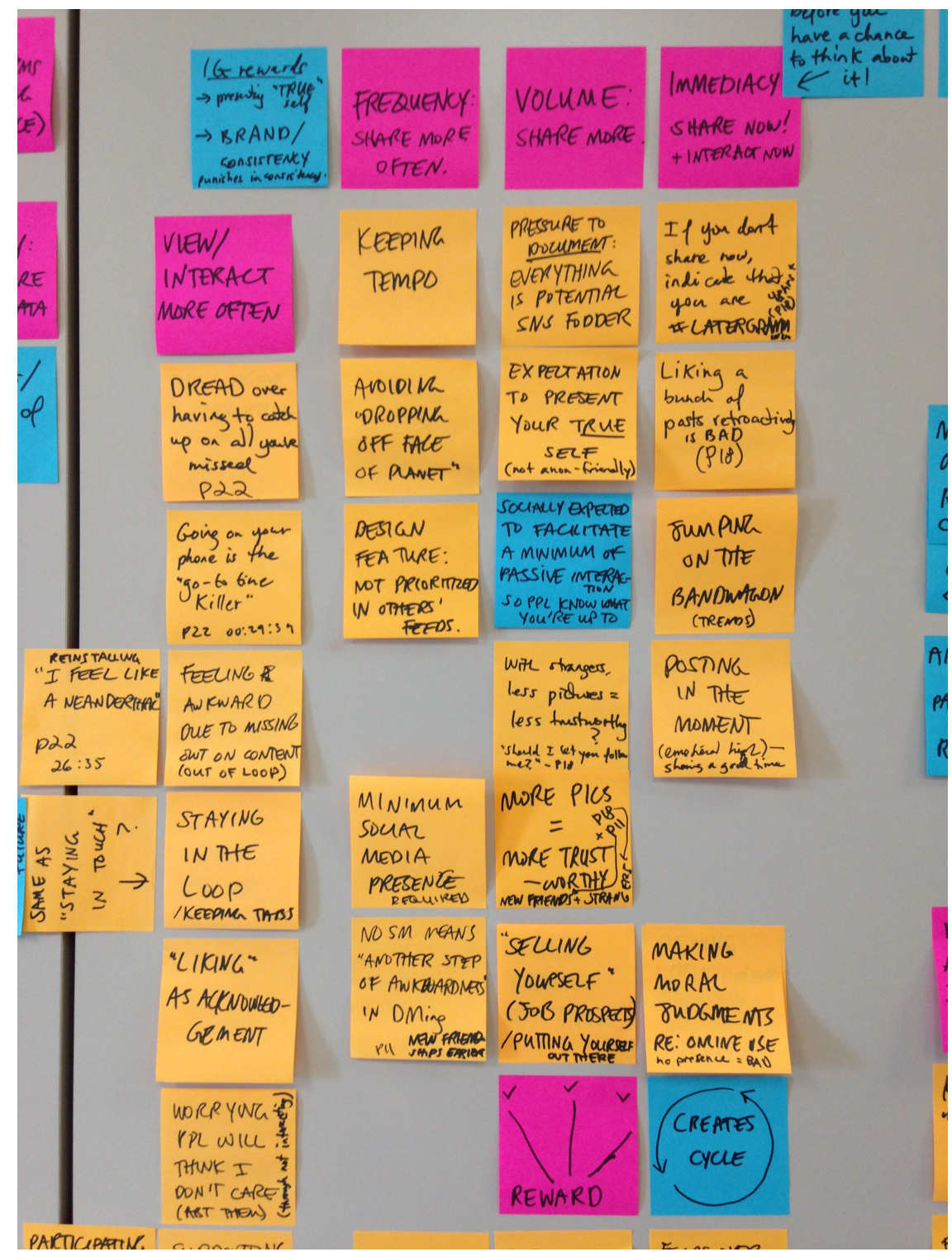

Figure 3.9: Section of late-stage affinity diagram, showing the main design categories. Yellow denotes codes, pink categories, and blue memos. 
through several iterations before we discovered the questions which elicited the richest responses from participants.

The best questions for interviews were not always universal. Certain participants responded better to some questions than others, so for the most important themes we had several questions prepared which broached the given subject in a number of different ways. For example, under our Joining and staying on websites interview theme, we included several different questions in our interview guide designed to prompt the user to tell us about times they have participated reluctantly, including: "Can you think of a time you ever felt reluctant to sign up for a website or install an app?", "Have you ever felt obliged to interact with certain kinds of media online?", and "Do you ever feel compelled to share more information online than you want to?" In some interviews, participants would respond immediately to the first of these questions they were asked and needed no further prompting. In other cases, it took this subtle rewording and mention of different kinds of events before the participant was able to recall such an experience. Where possible, it was sometimes most effective to broach the subject by relating it back to a particular situation or application which the participant had already mentioned.

\subsubsection{Theoretical Sorting, Diagramming, and Integrating}

As they were created and developed, codes were written on Post-It Notes and progressively sorted in an affinity diagram during and after the interviewing stage. The purpose was to define and develop categories, as well as to identify any gaps or areas that needed further saturation. In the early stages, many codes fell broadly into two main categories: "Justifications for participating" and "Justifications for not participating" (See Figure 3.8). This offered a basic separation of why participants participated or did not participate, which we could consider in tandem with FoMO levels. However, the more data we collected and memos we wrote and revisited, the more we found this binary model to be oversimplified and inadequate. Not all forms of participation were equal.

We recognized a need to further break down the "Justifications for participating" category to uncover more refined groups of reasons users had for participating. We 
realized there were different kinds of participation and that different participants had different motivations for each kind of participation. This led us to further break down categories into dimensions of participation, including FREQUENCY, VOLUME, and IMMEDIACY (see Figure 3.9p). We found these dimensions to be supported by information quality literature 8 . While these categories had emerged for us organically through examining data from the interviews, the literature helped to strengthen our organization of elements by pointing out aspects we had not explicitly defined, such as "width of sharing" and "distance of sharing." Awareness of these additional dimensions allowed us to further consider these aspects during interviewing and analysis, and contributed to the fleshing out of our emerging theory.

Other categories which had originally been considered major were ultimately collapsed to become a subcategory. For example, "Keeping multiple identities," a category we originally explored in some depth due to its sheer prevalence amongst participants, consisted of a number of its own focused codes (see Figure 3.10). We knew keeping multiple identities was indicative of participatory reluctance, but we struggled to situate it centrally in our theory. Through multiple iterations of whiteboard diagramming the process of FoMO-centric design, it failed to play a central role. At last we realized that considering "keeping multiple identities" as its own category was a red herring. Keeping multiple identities was not necessary to expressing reluctance to participate fully, but was rather one of several ways that participants could indicate they did feel that reluctance, by circumventing certain platform norms. As such, we collapsed the category and demoted it to a subcategory of "Workarounds." This is an example of the importance of the iterative process of sorting in developing theory. It is also indicative of the fact that simply because a behaviour is shared by many participants, it does not necessarily mean that particular behaviour is central to the theory. It may be simply a symptom of a larger issue, as was the case with "Keeping multiple identities."

\subsubsection{Theory Construction}

Our focus was on the factors that lead a participant to participate reactively and reluctantly as opposed to deliberately. Although we already suspected FoMO played 


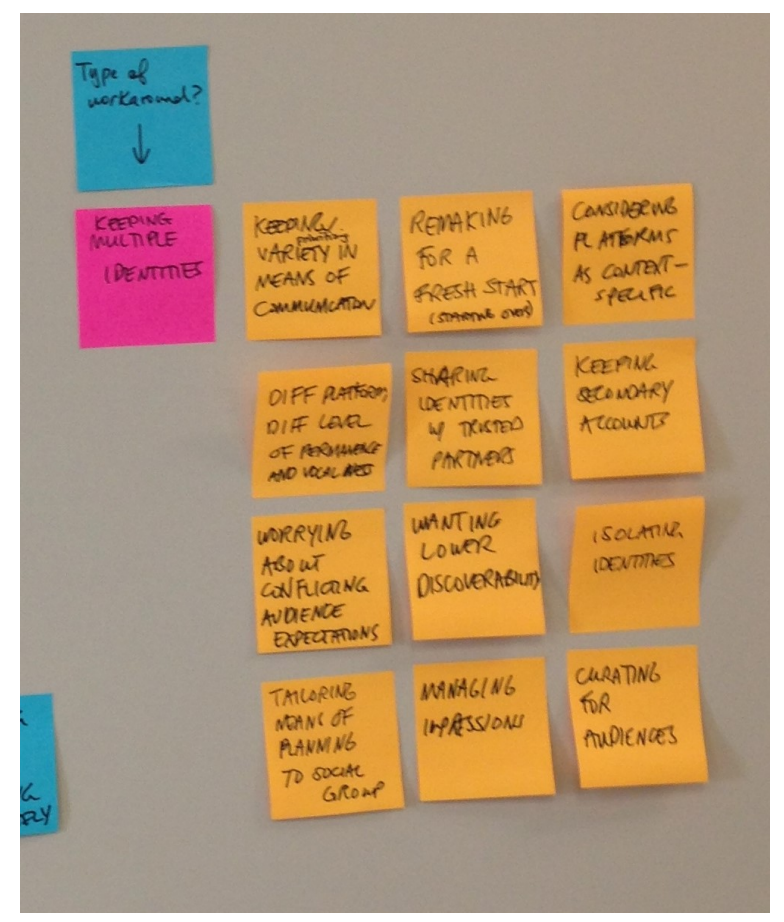

Figure 3.10: Early "multiple identities" category with focused codes

a role, we wanted to learn more about how users' FoMO might be used against them through the system design and surrounding community norms, causing them to act against their own privacy preferences. This is where most of our high-level theorizing came into play. Once we had established the bulk of our codes and categories, our main goals were (i) to discover how these categories could be theoretically linked and what relationship they had with each other, and (ii) to either reinforce or rethink our ideas about the major themes which we had developed over the course of the project.

To develop our theory, we used (i) affinity diagramming primarily for identifying and organizing categories, (ii) memo-writing for recording longer or free-flowing thoughts, and (iii) whiteboard and paper/pencil diagramming for brainstorming relationships. This form of diagramming forced us to abstract our findings enough that they could be easily summed up in a small space. This resulted in cutting out unnecessary padding and distinguishing vital parts of our theory from the more peripheral.

Figures 3.11 and 3.12 showcase how iterative diagramming aided in the development of our theory. The early attempt focused on more concrete instances of FoMO-driven reluctant behaviour and underlying motivations. However, it failed to 


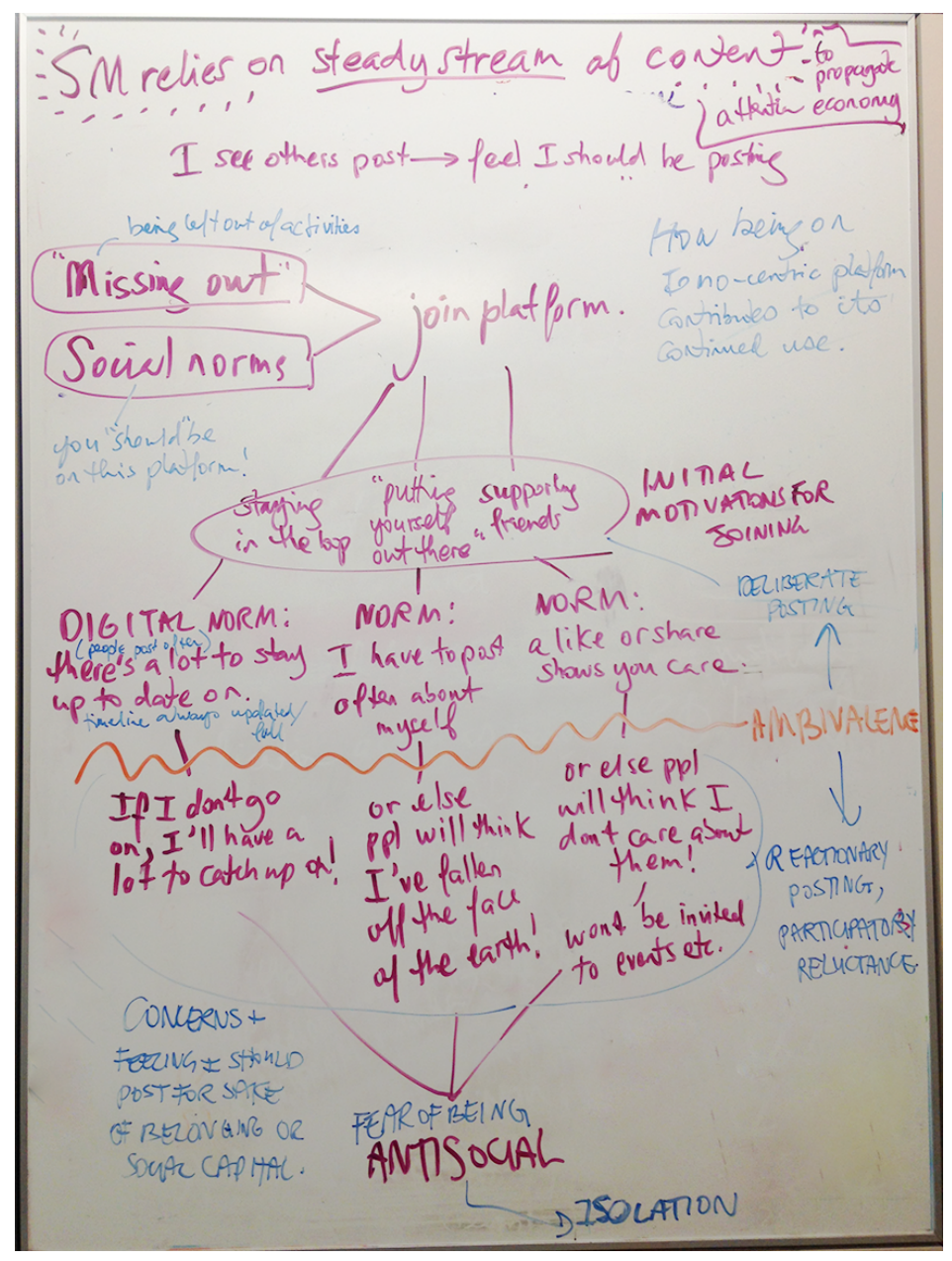

Figure 3.11: Early (from February) whiteboard diagram outlining the structure of the theory of FoMO-centric design.

account for all of our codes and categories. In tandem with our affinity diagram reorganization mentioned in Section 3.9.5, we created a later diagram, which approached participation from high-level participation dimensions, i.e., types of increased participation which could be encouraged by a combination of platform design and social factors. We posited these participation dimensions as the central drive behind reluctance or ambivalent privacy-compromising behaviours. This helped us reach a more conceptual understanding of the structure of FoMO-centric design. As a final step in theory construction and once we had our model, we returned to the literature to see how well our theory aligned with existing research. Our final theory is presented in the following chapter. 


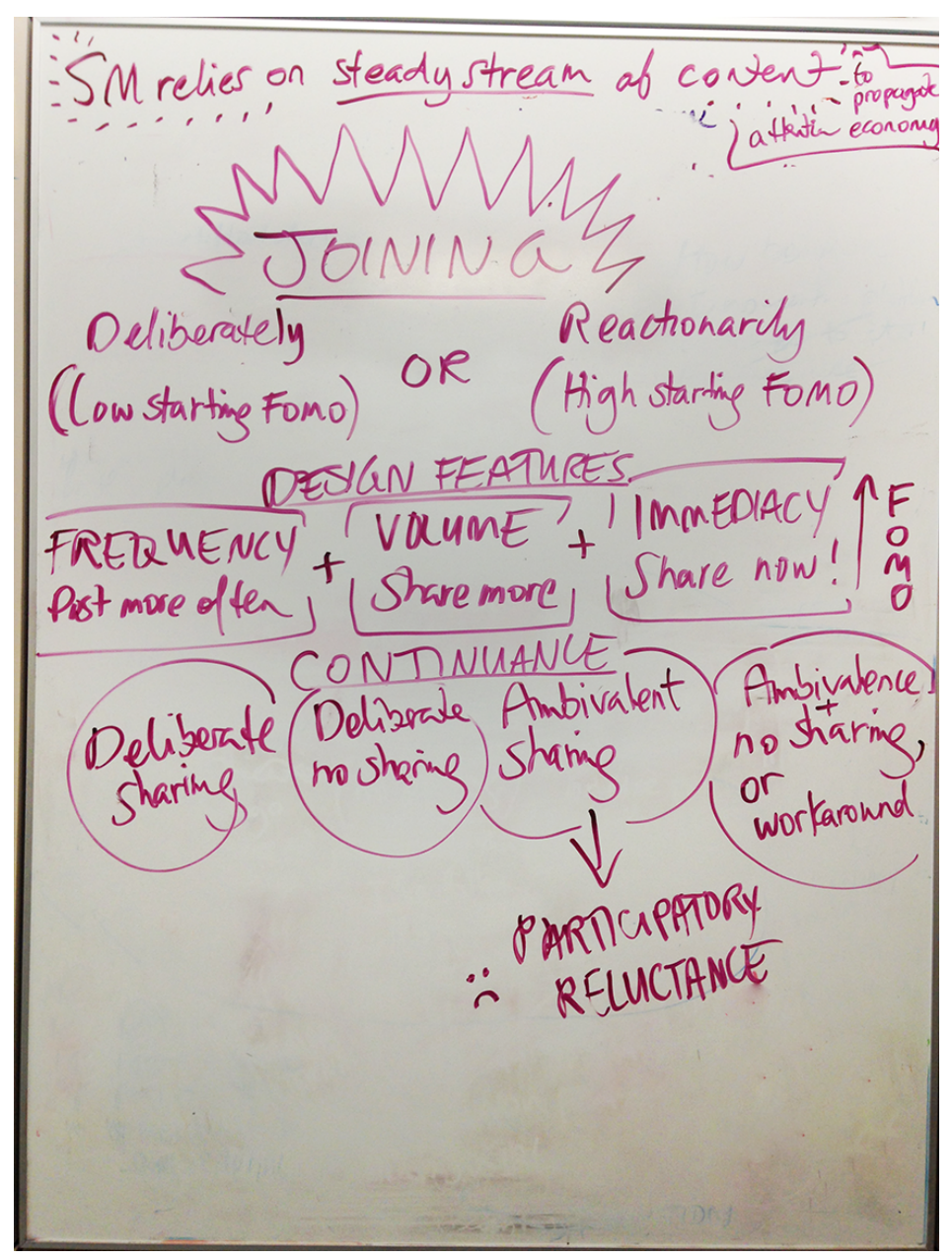

Figure 3.12: Later (from March) whiteboard diagram outlining the structure of the theory of FoMO-centric design. 


\section{Chapter 4}

\section{Results}

This chapter is structured as follows. We begin by defining recurring and central terms, including participation, deliberate and reactive behaviours, and workarounds. We then move on to the theory overview, followed by presenting the three central dimensions of our theory. For each dimension, we explain how the contained categories are likely FoMO-driven, using participants' explanations of the social expectations (i.e., community norms) present in each aspect of social media, as well as their experiences with participatory reluctance. Each time a participant is mentioned, we indicate their FoMO score and levels of privacy concern, so that this can be taken into account during interpretation. Where possible, we contrast the attitudes and behaviours of low and high FoMO participants, to see where important differences and similarities may lie.

\subsection{Definitions}

\subsubsection{Defining "Participation"}

We use the term participation rather than sharing, which is more commonly used in privacy literature. Inspired by Cassidy's Participatory Reluctance [22], participation is more flexible than the term sharing because it encompasses a larger range of behaviours we consider relevant to FoMO-centricity. In addition to sharing, participation includes passive engagement intended by the platform's design (which may then lead to sharing) such as viewing, downloading or installing new apps, using particular features, signing up for new websites or services, continuing to use a service, or taking part in a trend motivated by the platform. Furthermore, as will be explained in our results, occasionally not taking part in platform activities such as sharing or viewing can be a form of community participation, for example in the case of digital detoxing 
trends, when a user may decide to abstain from using social media for a given period of time because it has become trendy to do so. Using the term "participation" avoids the pitfalls of such behaviour being dismissed in relation to FoMO.

Conversely, the opposite of participating is not participating; this takes different forms ranging from not posting, not commenting, not participating in a trend, or abstaining from using a platform entirely. In the grey zone between participating and not participating is the use of workarounds, which will be discussed in Section 4.3.1.

\subsubsection{Defining Deliberate vs. Reactive Participation}

We identified two primary kinds of participatory behaviours: reactive behaviours, and deliberate behaviours. The existence of these two types of behaviours are supported, respectively, by the System 1- and 2-type thinking established by Kahneman [52] and discussed in relation to dark patterns in Section 2.4 .

Reactive behaviours are participatory behaviours that we propose happen as a result of higher FoMO and are indicative of the presence of FoMO-centric design, whether in a particular feature, or in the overall design of the platform. These behaviours will be discussed in the bulk of our results section.

Deliberate behaviours are behaviours where FoMO appeared to be absent or not as prominent in users' decisions - in other words, we present these as being "FoMOindependent." Although we do not focus on these behaviours in our analysis, they are discussed briefly in Section 4.7 .

While a user may deliberately choose to perform a less privacy-preserving behaviour for reasons outside of FoMO, we focus in this chapter on cases where users choose less privacy-preserving options in a FoMO-induced reactive way.

\subsection{Theory Overview}

Our theory of FoMO-centricity (diagrammed in Figure 4.1) describes how a platform's digital infrastructure exacerbates cases of FoMO and encourages particular kinds of privacy-compromising reluctant behaviours. We place the platform infrastructure centrally and we suggest that its FoMO-centric design consists of intentional dark patterns (see Section 2.4) aimed at drawing the maximum amount of engagement, 


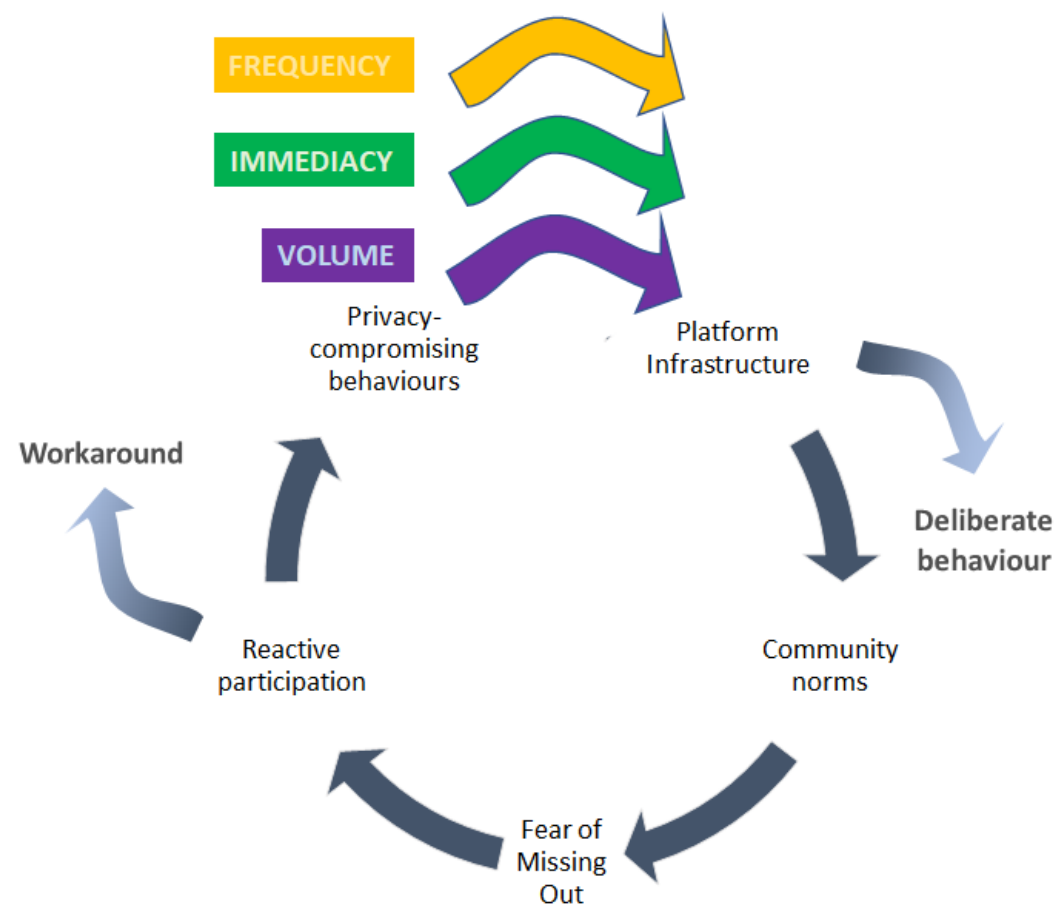

Figure 4.1: Diagram showing the proposed relationship between digital infrastructure, community norms, FoMO, and reluctant privacy-compromising behaviours.

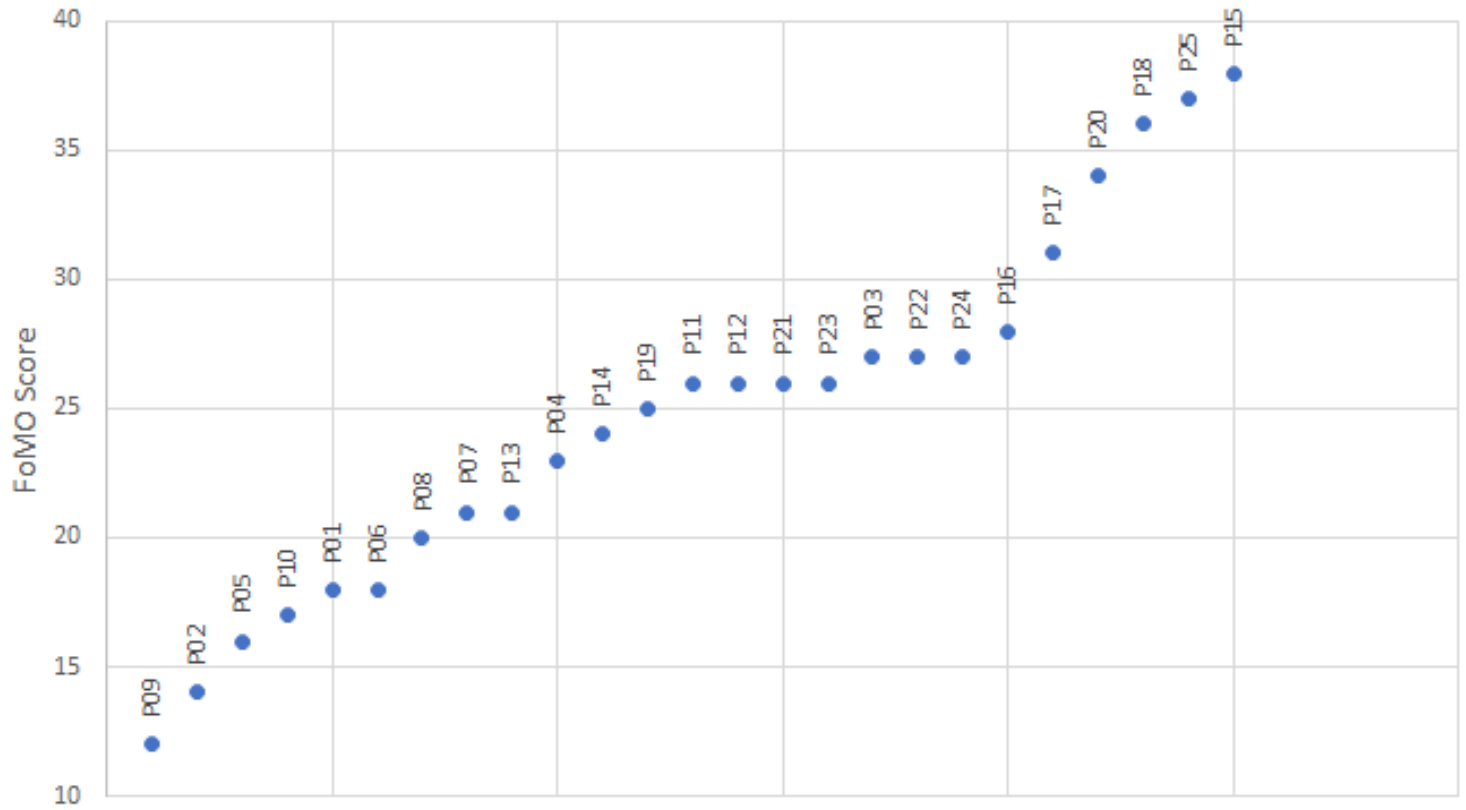

Figure 4.2: Participant FoMO scores and IDs. Scores can range from 10 to 50, with higher scores indicating higher levels of FoMO. 
sharing, and data from the user. In Chapter 2, we had defined FoMO-centric design as "a collection of manipulative strategies," based on the findings from our literature review. In this chapter, however, our empirically-based theory leads us to take a step back from individual strategies and examine how both the strategies and the relationships between them impact participants' privacy-compromising behaviours.

Firstly, the digital infrastructure informs community norms, as was discussed in background section 2.7.3. Through our interviews with users, we discovered that prominent FoMO-centric norms include: expectations of high volume, frequency, and timeliness of posting. Users are encouraged to subconsciously (and in some cases, consciously), quantify otherwise qualitative interactions: they know if they post more information, more quickly, and more often, they will be more likely to succeed by the community standards of the platform and be socially accepted, or even prosper on the platform.

To illustrate how these dimensions affect users, this chapter is organized into three central categories reflecting participatory dimensions: Frequency (expectations to post often), Immediacy (expectations of timely sharing), and Volume (expectations to post high levels of detail, variety, and to a large audience). Once established, community norms are internalized and enforced by users, resulting in negative social consequences for those who do not follow them. Users feel the pressure to participate in platform norms and experience the Fear of Missing Out when they worry they may not be sufficiently involved in the community (see Section 2.7.2). The Fear of Missing Out pushes users to participate in a reactive way that may be at odds with their privacy attitudes (i.e., reluctant). This results in the ultimate goal of the platform: privacy-compromising, sharing-maximized behaviours. These behaviours are further rewarded by the platform infrastructure and perpetuate community norms of sharing-maximized behaviours, creating a self-reinforcing cycle of reluctant privacycompromising behaviours by community members. We provide evidence of a relationship between higher FoMO scores and higher rates of participatory reluctance to help explain a gap in privacy paradox research. 


\subsubsection{Fear of Missing Out}

We gave participants a questionnaire measuring their level of FoMO (see Section 3 for details). Figure 4.2 shows pre-screener FoMO scores and corresponding IDs of interview participants, with 10 being the lowest possible score and 50 the highest. While it is unlikely that participants score on either extreme (10 or 50), we found a range consistent with the normal distribution of participants who took our prescreener, which ranged from 12 to 38. Therefore, the relativity of "high" and "low" FoMo levels should be considered in relation to this range.

When discussing results from specific participants, we identify them using the notation $\mathrm{P} \#$ (FoMO score, organizational threat concern - social threat concern). The two privacy concern measures range from 1-7 (see Section 3.8). For example, participant number 3, who has a FoMO score of 27, organizational threat concern of 6 and social threat concern of 6 would be P3(27, 6-6). We have rounded the privacy concern scores to remove decimals for readability purposes. So in the case of P3, this participant has a mid-high level of FoMO and is high on both privacy concern scales.

We present the scores here for descriptive, informational purposes; as mentioned in Section 3.8, we did not conduct explicit analysis of the relationship between questionnaire and interview data. Anecdotally, there seemed to be a trend towards participants with higher FoMO scores displaying more instances of reluctance in the interviews regarding their participatory behaviours, and especially regarding privacy when they also reported high levels of privacy concern. This would make sense given the connection between FoMO and ambivalence found by Przybylski et al. [81], as well as Paasonen et al.'s [77] finding that social media users continue their use despite a "sense of creepiness" due to design that preys on their desire for positive affect (both discussed in Sections 2.2 and 2.8.4. However, our focus in this thesis is on our qualitative findings of situations where participants appeared to behave reluctantly due to the influence of FoMO-encouraging platform norms. Assessment of the connection between FoMO score and reluctant privacy behaviours would have to be explored in a further study. 


\begin{tabular}{|c|c|c|c|}
\hline Dimension & Code category & $\begin{array}{c}\text { Reinforces } \\
\text { continuance }\end{array}$ & $\begin{array}{r}\text { Prompts } \\
\text { reactive } \\
\text { sharing }\end{array}$ \\
\hline Frequency & $\begin{array}{l}\text { Staying in the loop } \\
\text { Avoiding "dropping off the face of the planet" } \\
\text { Documenting compulsively } \\
\text { Posting to validate experiences } \\
\text { PDA (Supporting friends) }\end{array}$ & $\begin{array}{l}x \\
x \\
x \\
x \\
x\end{array}$ & $\begin{array}{l}\mathrm{x} \\
\mathrm{x} \\
\mathrm{X}\end{array}$ \\
\hline Volume & $\begin{array}{l}\text { Presenting the authoritative self } \\
\text { Mixing audiences } \\
\text { Reciprocating data type } \\
\text { Selling yourself } \\
\text { MVP: Minimum Viable Presence } \\
\text { Can't leave, won't leave }\end{array}$ & $\begin{array}{l}\mathrm{x} \\
\mathrm{x} \\
\mathrm{x} \\
\mathrm{x}\end{array}$ & $\begin{array}{l}\mathrm{x} \\
\mathrm{x} \\
\mathrm{x} \\
\mathrm{x}\end{array}$ \\
\hline Immediacy & $\begin{array}{l}\text { Interacting now or never } \\
\text { Posting in the moment } \\
\text { Jumping on the bandwagon }\end{array}$ & $\mathrm{x}$ & $\begin{array}{l}\mathrm{x} \\
\mathrm{x} \\
\mathrm{x}\end{array}$ \\
\hline
\end{tabular}

Table 4.1: Code categories and their role in the cycle of FoMO-centric design. Categories which reinforce continuance keep the user returning to the platform even in the face of reluctance: the baseline of participation. Once on the platform, categories which prompt reactive sharing trigger the user to increase sharing, whether in depth and variety, audience size, or in frequency and timeliness, otherwise face potential negative social consequences.

\subsubsection{Reactive Privacy Compromising Behaviours}

We identified three types of reactive privacy-compromising behaviours which participants exhibit in reaction to FoMO-centric platforms: Frequency, Volume, and Immediacy. These are divided according to dimensions of participation, similar to dimensions of sharing seen in information quality assessment literature [8] [60]. The Frequency and Immediacy themes both relate to the time dimension of participating (frequency and timeliness, respectively), while the Volume theme focuses on content and spatial dimensions of participating. Frequency (discussed in detail in Section 4.4 covers behaviours related to a feeling of needing to constantly "keep up" with activities on the platform through both passive checking and active posting on the platform. Immediacy (discussed in detail in Section 4.5) covers behaviours related to a feeling of needing to participate immediately and with a limited amount of reflection. Finally, Volume (discussed in detail in Section 4.6) covers behaviours which result in greater depth, variety, and reach of shared data, through sharing more of 
one's data with a larger amount of people, and keeping a "minimal viable presence."

Table 4.1 lists the main categories of codes we grouped under each participatory dimension, as well as the role we see them playing in the FoMO-centric cycle. We divide FoMO-centric categories into two central roles: reinforcing continuance (baseline participation) and prompting reactive sharing (full participation). While 'reinforcing continuance' includes passive use of the platform and thus may not involve directly privacy-compromising behaviours, they lead to 'reactive sharing', which encourages privacy-compromising behaviour, unless the user uses a workaround. A single category can play one or both roles.

\subsection{Eight Symptoms of Participatory Reluctance}

\begin{tabular}{l|l|l}
\hline & Symptom & Brief description \\
\hline 1 & Taking a break & $\begin{array}{l}\text { Participant takes a temporary leave of absence from } \\
\text { the platform, then ultimately returns. }\end{array}$ \\
\hline 2 & Romanticizing an alternative & $\begin{array}{l}\text { Participant imagines a better life without the platform, } \\
\text { or with an altered version of the platform. }\end{array}$ \\
\hline 3 & Contradicting self & $\begin{array}{l}\text { Participant makes contradictory statements when it } \\
\text { comes to their comfort level with the platform. }\end{array}$ \\
\hline 4 & $\begin{array}{l}\text { Expressing awareness of } \\
\text { problematic behaviours }\end{array}$ & $\begin{array}{l}\text { Participant recognizes negative effect of platform on } \\
\text { their behaviour, yet continues to use it. }\end{array}$ \\
\hline 5 & Making moral judgements & $\begin{array}{l}\text { Participant negatively judges those who do not exhibit } \\
\text { expected behaviours in relation to social media. }\end{array}$ \\
\hline 6 & Feeling resigned & $\begin{array}{l}\text { Participant doubts the possibility of change on the } \\
\text { platform, and/or feels tethered to its continued use. }\end{array}$ \\
\hline 7 & $\begin{array}{l}\text { Rationalizing others' } \\
\text { behaviours }\end{array}$ & $\begin{array}{l}\text { Participant attributes some people's relative indepen- } \\
\text { dence from the platform to personality or situation. }\end{array}$ \\
\hline 8 & Using a workaround & $\begin{array}{l}\text { Participant circumvents platform infrastructure or } \\
\text { norms while simultaneously reaping their benefits. }\end{array}$ \\
\hline
\end{tabular}

Table 4.2: Summary of the 8 symptoms of participatory reluctance.

The self-discrepancy theory [49] [19] (also see Section 2.2) addresses cases where people feel a conflict in their actual beliefs and either their own idealized beliefs or the beliefs they think they socially should hold (ought-discrepancy). This leads to discrepancies in beliefs (also known as cognitive dissonance 41]) which result in negative feelings. Higgins [49] found that specific kinds of emotions can be mapped onto specific kinds of discrepancies. These discrepancies are also known as "ambivalence" - a key aspect of the Fear of Missing Out [81. Thus, we use the self-discrepancy theory as 
inspiration to help us identify cases where participants might have experienced a discrepancy between their actual behaviours and their privacy attitudes, i.e., displayed behaviours symptomatic of participatory reluctance, due to FoMO.

Table 4.2 summarizes the eight main recurring symptoms of participatory reluctance suggesting that participants were uncomfortable that we identified through our interviews. While these may not be privacy-compromising in themselves, they characterize participants' mindset and can lead to either workarounds or privacycompromising behaviours. These symptoms will be explained in more detail later in relation to our three dimensions of participation.

\subsubsection{Workarounds}

When users are feeling discomfort over potential participation, they will sometimes resort to a workaround. We define a workaround as a creative solution to achieve a goal without reaching it through the traditional route. These workarounds can sit in the space between reactive and deliberate behaviours. Participants, for instance, may have a reactive reason for wanting to participate in a platform as a whole - e.g., their friends have told them they need to get it - but are deliberately avoiding full participation by abstaining from sharing certain information, such as their full name. Workarounds allow users to both participate and not participate simultaneously. Participants revealed several workarounds when they are faced with a situation where they feel obliged to provide data that they don't want to share, but still want to participate in the platform or service. These workarounds are discussed throughout this chapter in relation to particular participation dimensions and types of sharing, particularly in relation to Volume, as this was the dimension for which participants had the most workarounds.

While both higher- and lower-FoMO participants mentioned workarounds, lowerFoMO participants who had demonstrated a high concern for privacy seemed to make greater use of workarounds for more practical purposes (less associated with social capital). This makes sense as workarounds require more deliberate thought than simply succumbing to the privacy-compromising behaviours. However, privacy-concerned higher-FoMO participants also made use of them, finding it important to preserve 
their privacy where possible while also preserving their ability to participate and receive social capital.

\subsection{DIMENSION 1: FREQUENCY}

Perhaps the most relentless and hard to escape of the FoMO-centric dimensions is the community norm of high frequency of use. This keeps the user returning to the platform on a frequent and regular basis in order to increase the chance they will interact or post. Our participants feel they have to keep a certain rhythm when it comes to posting, and using the platform more generally. The suggested socially acceptable time intervals for posting ranged from once a day to at least once a month, depending on platform and participant. We show that this high frequency of posting and interacting begins at a less visible level: the frequent passive consumption of content on social media, through "staying in the loop."

\subsubsection{Staying in the loop}

For our participants, checking social media is something they do often, subconsciously, and take for granted. This activity takes a passive yet critical role in affecting users' participatory behaviours, as not only are they presented with more opportunities for interaction, they are also exposed to the high-frequency posting norms of other users. P12(26, 7-4) checks social media "when I first wake up," before going to bed, and at any time she feels "bored." This was especially common amongst higher-FoMO participants, suggesting its central role in FoMO-centric dependence on the platform. P12(26, 7-4) demonstrates just how automatic the behaviour of checking can become: "[W]hen you actually delete [the app] physically, you [still] click on it. Because you know the position it is on your phone and you click on it and nothing happens and you're like, oh, wow, what happened? You [become] actually aware of how much you go on those platforms."

The act of checking social media consists not of going on the platform to deliberately find some particular information, but rather is characterized by the desire to passively or "accidentally" absorb whatever new information happens to be presented 
to the user at the time they open the app or website. As such, it is a reactive activity. We believe that this acts as a lesson to the user, informing their literacy of platform norms and providing a roadmap of socially acceptable behaviours to follow. This moulds users' perspective in a way that makes them feel pressured to participate rather than free to opt out. Users may even be aware that platforms are warping their priorities in a way that conflicts with their values, but continue to act in accordance with the presented norms nonetheless. P23(26, 4-4) explains his decision to take a break from Instagram and Snapchat, saying "I felt like I was spending most of my time using them every day." Describing a negative twisting of life perspective on the platforms, he distinguishes between life as it is presented on Instagram, and "true reality": "It was making me feel left out most of the time. [...] It was hard to tell myself that that's not true reality. [...] So I just tried to stop it and didn't use it anymore. So I could sort of get away from that perspective."

As certain aspects of platform norms can change quickly, such as what trends or subjects are currently salient on the platform, users are highly motivated to return to the platform frequently to continue staying "in the loop." In other words, being continuously up to date on what other users of their chosen platform are doing. Consequences of falling out of the loop extend beyond interactions on the platform itself and into offline life. Participants mentioned they feel awkward when they are "out of the loop," as this can translate into missing out on cultural references in real life or online conversation, or in being unaware of important events in their friends' lives or in their community. P11(26, 6-3) notes "Usually it's a matter of it coming up in social situations. And then I feel kind of awkward because I haven't seen it." P21(26, 6-4) thinks that people who aren't actively on social media are "missing a lot because I mean, not only is news provided on social media, but there's also family updates, like, so-and-so got engaged or so-and-so passed away, you know, they're missing all that news. It's a little - really shocking [how much they miss], actually."

Users' aversion to being off social media for any significant length of time is marked by a dread of having to catch up on all the content they have missed. P22(27, 5-4) explains that it's not necessarily when she's already on social media that she feels a strong compulsion to stay in the loop, but rather when she's away from it and then 
returns: "I go back on and then that's when I feel bad because I'm just like, oh, I missed this, this, this, this, this. But it's never been like I need, or I'm on the lookout for it. But that dread or that feeling comes when I'm away from it and I come back." Once back, P22(27, 5-4) then feels she has to spend extra time on the platform to catch up. Akin to checking, "catching up" doesn't involve deliberately looking for certain information, but rather is time-based, where the user passively absorbs all available content since the last point of contact: "And that's when I spend a bit more time because I'm feeling like, I don't know, I'm making up for the time that I wasn't on it. But I'm still not on the lookout for stuff. I'm just like, what did I [miss]- [what] already happened? So that I'm up to date."

\subsubsection{Avoiding "dropping off the face of the planet"}

For the active posting side of Staying in the loop, several participants referenced worrying about not posting enough, or other people that they know not posting enough. We attribute this to their perception that their friends and acquaintances share their own motivation to stay in the loop. Our participants feel that they are expected to provide others with a minimum form of passive interaction so that others know what they're up to. Some participants made jokes about letting others know they are still in the land of the living. P7(21, 7-3) noted about Instagram: "I think maybe like after a few months, I kind of feel like, oh, you know, maybe I should just put something up there so people know that I'm still around and kicking." This also goes for replying to group chats, albeit the acceptable amount of time before interacting is shorter, moving from months to weeks: "I'll respond to a meme or something [...] because I feel like, OK, you know, it's been a few weeks since I've said anything. So I just feel like I should."

$\mathrm{P} 8(20,2-4)$ is on Facebook primarily to keep her family up to date on news of her daughter, but often forgets to post. However, she still feels pressured to post for their sake, or rather, to avoid violating any social expectations: "I almost set myself an alarm to post something once a month, sort of to keep them happy," she says. When asked if he feels pressured to contribute to the group chats he's resistantly part of, P24(27, 6-6) says no, but, "It's just if I'm there, then, you know, like once 
in a while, as long as I'm showing them that I'm still alive, then that's all that really matters." Other participants, such as P15(38, 5-4), complained about others not posting enough, and displayed a certain level of entitlement to knowing about the lives of their friends on social media: "If you don't post it's like, OK, I don't know if this person's still alive or not. I don't know if they have kids or a boyfriend or girlfriend or all that. So I think that's why I think it's kind of important $[\ldots]$ just to stay connected in some way rather than not stay connected." And we found quantifiable ramifications of dropping off the face of the planet, such as from P21(26, 6-4): "people would just unfollow me if I just go MIA for like two months."

\subsubsection{Documenting compulsively}

Participants feel a compulsion and an obligation to document as much as possible, in a reactive way. This becomes especially true during holidays, special events, or while doing an activity that is perceived as high-value; everything becomes potential social media fodder. P14(24, 6-3) retells that while together with friends on Halloween, she was preoccupied with the thought that she "really should" be getting a photo of them hanging out. She also felt this way while studying abroad: "I almost felt like I had to record everything and share everything or, you know, how is anyone supposed to know that I was actually trying things abroad and having experiences and, you know, thriving?" P16(28, 6-5) is aware of this proclivity towards documenting and sharing everything, and so makes a conscious effort to avoid taking herself out of the moment too much. She does this by documenting in the moment, but waiting until later to share:

"just so that I kind of can still be a part of that moment. So like my last post, I think it was Christmas with my family. I took the picture on Christmas but I didn't post it until the next day, just to kind of make sure I was still in the moment. Cause I do know that can happen, where you want to get something up instantly - but because of that, it kind of takes away from you enjoying the moment and being present." P16(28, 6-5)

Despite taking measures not to post in the moment, this participant is still brought 
out of the present and into the future activity of posting, simply by feeling the urge to document for the sake of later posting.

Documenting everything leads to privacy concerns by participants. P25(37, 7-2) isn't worried about content being leaked that she has already posted to social media; rather, she is worried about the images which she has not posted. She already chooses "no" when most apps ask for access to her photo library, but some apps require this access to be used at all. She explains that even if the images she has saved to her phone might not be objectively "bad," she still wouldn't want them to be connected to her out of context: "Sometimes I save memes to my phone that I wouldn't want some people to see. [...] They're not bad necessarily. But, you know, there are certain things for certain people, or inside jokes or screenshots of my bank account that I don't want anyone else to see." Along these lines, when participants' camera rolls essentially comprise a journal of their entire lives - due to the need to compulsively document in case something is worth sharing - it is easy to see how concerns arise over those images getting leaked. Easy storage of virtually an unlimited number of photos on the cloud means many users feel daunted by the prospect of deleting or curating their private collections and avoid doing so [114] - meaning that in some cases, a user's entire life may be quite literally stored in their photo library. Concern over sensitive photos being leaked has been brought to the public consciousness by events such as an alledged iCloud hacking leading to the leaking of several high-profile celebrities' nude photos in 2014 [79], and more recent events such as reports that FaceApp was abusing photo permissions and harvesting users' entire photo libraries (though this accusation was later denied by app developers [105]).

\subsubsection{Posting to validate experiences}

Following compulsive documentation, participants feel they have to post any time something interesting or fun happens to them, to validate the experience to others and gain social capital. This is in line with Bednar et al.'s 11 finding that users feel an experience is worth less if not digitally shared (see Section 2.7.4). P14(24, 6-3) says only slightly sarcastically, "You have to prove you're living your fullest life [...] And if you don't post something, obviously, you didn’t do anything worth remembering." 
P22(27, 5-4) felt this pressure on her birthday: "This weekend, I went out with my friends and they were all posting, and it was for my birthday. So I just felt like I needed to post. It's like you are the whole reason why we're here; you're in every other [person's photos]." A similar compulsion to post for validation and social capital applies to vacation photos: "I mean I'm in this really beautiful country, might as well make people jealous." The social pressure to post special occasions may also take a more palpable form, such as when P22(27, 5-4) received vocal pushback from squad members when not posting about their dance competitions. "I'd be asked, 'Why didn't you post?' [...] Everyone would be posting and they're like, 'Oh, you did so well, why don't you flaunt this, this, and this'. And I'm like, 'Aaahh!' "

Participants demonstrate their ambivalence by expressing conflicting priorities between the social benefits of posting, and privacy concerns. P15(38, 5-4) aims at a balance by partaking in obfuscation when posting, to make potential identification by third parties more difficult: "I tend to put group pictures, rather than a selfie. Maybe if I put a selfie, they can use it as a piece of identification somewhere else."

Posting experiences to validate them can go a step further into a true platformreinforced cycle: manufacturing experiences for the sake of validation. Under the pressure to always maintain an online impression of having a full, exciting life, P22(27, 5-4) says she would organize events with her friends specifically with the end goal of posting their experiences online. "[It] was like, 'Oh, oh, I need to post something.' And I'll talk with my friends, like, 'Oh, let's go downtown and do this' because [...] I need to update my Instagram like once a month or what. I think at one point [I was doing this] like once every few weeks." This example marks the remarkable extent to which platform infrastructure can affect users' participatory behaviours. The motivation to share their lives becomes so great that not only do participants feel pressured to post the events that organically occur; they will go out of their way to create life experiences for the purpose of having them validated on the platform.

\subsubsection{PDA (Supporting friends)}

Several participants mentioned they feel compelled to interact with friends' posts to show support, or attention. P3(27, 6-6): "I tend to like [posts], not as much comment 
or repost. I guess just to show people that I have acknowledged their posts." P4(23, 6-3) echoes the importance of liking as a form of support, saying she feels "connected" when people like or acknowledge her posts.

Some participants interact with friends' posts to boost that friend's self-confidence.

P14(24, 6-3): "[I]f I thought someone posted a really cute selfie, I would be like, 'Oh my god, you're an angel!' And then like an angel emoticon, hearts, etc. [...] Just because for someone like me, I feel very self-conscious to have photos of myself. So if I see a friend who's posting a picture of themselves, I like to give them support and kind of remind them how awesome they are."

We found that sometimes a like can have significant meaning, helping a participant or fellow user avoid potential social embarrassment by helping their post reach the perceived minimum acceptable amount of likes.

P16(28, 6-5): "I do know some people that really feed off that liking. And if you don't like their posts, then they get very upset. And they've told me like, 'If I post a photo, and it only gets this many likes, I'll delete it because I know I look terrible.' [...] So sometimes I do feel obligated to like those ones just to kind of add that positive reinforcement, which I know is also a negative reinforcement, so I know it's bad to do that."

Milestones, such as birthdays or wedding engagements, are also important times when "you should post something publicly" to show your support, says P14(24, 6-3). However, she feels ambivalent in doing so, saying it seems like "adding to the pile" of other people's messages and she prefers for that sort of sentiment to be more privately shared, kept between the congratulatee and the congratulater.

Our participants worry that if they do not interact, friends will think they don't care about them. P14(24, 6-3) expresses her frustration over the misconception caused by not interacting: "Just because you're not going on an app and seeing pictures of your friends and liking them and commenting, doesn't mean that you don't care about that person. It just means you're just not on that app. You're just not seeing that content." Because of the guilt and social pressure participants feel by not interacting 
or showing public support for friends, participants feel pressured to always be online and ready to interact with friends' posts, to avoid giving off the impression that they don't care.

This goes as far as adopting and using certain platforms despite privacy or security grievances. P24(27, 6-6) finds TikTok invasive, but still keeps the app and uses it occasionally to encourage his friends.

"I don't really like using [TikTok] all that much. [...] I think because of the controversy surrounding it towards the end of last year... of TikTok and the Chinese government and so forth, all that stuff. So I'd rather just stay away from it. [...] But [...] some of my friends, they use TikTok. So I just have it to support them." P24(27, 6-6)

\subsection{DIMENSION 2: IMMEDIACY (Timeliness)}

FoMO-centric platforms create an infrastructure where posting, interacting with posts, responding to messages, and participating in trends retroactively is considered socially questionable, and in some cases outright unacceptable. Immediacy plays off themes such as Supporting Friends and likely feeds off users' psychological propensity towards short-term benefits (see also Section 2.7.1). Users are strongly encouraged by platform norms to interact now: they know they face a choice: interact now, or not at all. Not interacting at all may mean coming across as an uncaring friend - or at the very least, failing to show some level of support- so users feel pressured into immediately interacting with friends' posts. This results in System 1 thinking, where users interact with content reactively, rather than in a deliberate, thoughtful way. This can lead users to post in a way they might be uncomfortable with, or later regret. "False urgency" is a related dark pattern which has already been recognized in relation to e-commerce websites [21], but to our knowledge, this is the first time it has been discussed explicitly in relation to social media. 


\subsubsection{Interacting now or never}

While social media can sometimes allow for some degree of retroactive interaction, the context of a retroactive interaction can make a difference as to its degree of social acceptability. If P18(36, 5-4) gets a notification on an old photo, but it's one she recently made her profile pic again, she finds this behaviour acceptable: "Oh, ok," she describes her reaction. However, seeing that someone has recently interacted with old photos that have no clear connection with any of her recent social media activity can be a little more unsettling: “[T]hey'll just randomly one day decide to scroll through all my photos, and then start liking, and commenting. And I'm thinking, OK, so definitely you're wondering what's going on my life today, because you know, you're going through all of these photos or old albums." While P18(36, 5-4) says this can be fine with close friends, especially female friends, she describes getting these notifications of retroactive engagement with her posts as sometimes "a little too creepy." "Especially a guy going through all your stuff and you think, 'okay, why are you going through all of my pictures like this?'"

One participant recounts an especially prominent memory of a friend liking retroactively in an unacceptable way:

"[A] couple years ago we had this one friend and he would activate and deactivate his account a lot. So then when he would activate it, we all knew because he would go through all the pictures and, say, like 30 of our pictures. [...] So our friends, we were frustrated with him and they would say, 'you know what? I am removing you. Next time you activate your account, I'm not accepting you because you deactivate your account shortly afterwards and then we're stuck with those notifications. We have to scroll through all these things, we miss out on important things.' " $(\mathrm{P} 18(36,5-4))$

This is a example of clear social pushback from interacting with social media in a way that falls outside of its established community norms.

Many online platforms make users' online statuses and read receipts visible to others to encourage an environment where users expect a response shortly after they 
know that another user is online or has seen their message. P1(18) explains how she tries to get around the expectation to respond immediately: "There are certain people that I need to respond to if I ever post or if they know I'm online... [but who I] don't necessarily want to reply to immediately. So I have a private story. They don't get to see I'm on Snapchat, but I'm actually posting all the time." Instant messaging services such as WhatsApp display the user's online status publicly. This can put pressure on the individual to reply to others in a timely manner. P1(18, 7-3) switches off her read receipts to mediate pressure to respond instantly, but points out that "unfortunately my online shows." She wishes her online status was more opaque to others.

Users know they must respond now, or risk offending others by making them think they are lower-priority, or worse, are being intentionally snubbed to send a message. Again, users are compelled to respond as fast as possible, without much thought or deliberation. This can cause users to share information which they would not have shared, had they felt they had the time to deliberate.

\subsubsection{Posting in the moment}

Generally, participants mentioned that even if they do not post material immediately after the event, they would usually do so in a timely manner, driven by a high concern over the temporal relevance of their post. People assume that a photo that has been recently posted has also be recently taken. If it's been longer than the "socially acceptable" 24-48 hours, says P18(36, 5-4), you have to make that clear to your audience by tagging it with \#latergram. Otherwise, you risk misleading or offending: "[P]eople might say, 'Oh, you didn't take me today' or 'That's a really nice photo of you today.' You say 'Oh, well that was many days ago.' So I feel as though your audience wants to be notified as to when this event happened." Waiting too long to post about an event is viewed by participants as socially unacceptable.

P18(36, 5-4): "So, a couple of weeks ago it was New Year's. If I posted something about New Year's I think that would be kind of funny because New Year's passed so many days ago, but if other holidays are coming up or recently came, then I can wish people happy holidays for that. 
[...] Imagine me wishing people Merry Christmas in February, you know, when everyone was saying Happy Valentine's Day. That would be pretty irrelevant."

Some higher-FoMO participants post even more immediately than day-of, saying they usually post in the moment, during emotional highs. P15(38, 5-4): "I always post it near [the time of] the event that happened. So it's always like, emotionally I'm here [*holds hand up high*]. I never post when I'm emotionally down or at [my] baseline. I'm posting an event that depicts an emotional high." It is important to P15(38, 5-4) to capture these emotional highs in the moment and share them immediately with others, rather than waiting until he has had the time to consider the post in a more neutral state.

Unfortunately, the lack of foresight involved in posting in the moment can lead to regrets down the road over sharing overly personal content or content the user would have preferred to keep private. P21(26, 6-4) discusses her mindset when choosing to post a photo of herself in a swimsuit, versus a year later when she decided to take down the post: "I was in Cuba and the water was just, well, the beaches are just astounding there. And I was in my swimwear and I thought, "you know, why not share a photo.' I thought it was a nice photo, too. And I shared it." However, later on she found herself feeling "a little bit regretful" and decided to delete the photo from her social media:

"I decided to just take it down because I thought, I didn't want people to, like, look at my goods if you know what I mean? I don't wanna seem like a prude, excuse me. But yeah, it's just you know, I appreciate my privacy and I wanted to take it down. And, you know, wouldn't want other individuals lurking."

\subsubsection{Jumping on the bandwagon}

Users will sometimes change their short-term behaviour in order to participate in a current trend, to avoid the feeling of missing out. This can take the form of using certain profile picture filters, making or sharing certain posts, installing an app (such as FaceApp), or joining a new platform. 
P13(21, 6-3): "Whenever there are trends - like I remember the ice bucket challenge thing - I was like, 'Oh, I'll jump on that bandwagon cause it seems cool and everyone's doing it'. So I thought I might miss out. Yeah, so if there is a challenge or whatever that all my friends are doing, sometimes I'll do it as well."

Our participants feel the need to participate in the trend within a certain time frame, to avoid "missing out." They do not know when the trend will end but know that the next trend will likely take over relatively soon, so they are motivated to participate as soon as possible and not deliberate too long.

Now that we have explored the temporal aspects of reluctant participatory behaviours, we move onto the spatial: ways participants are pressured to increase their volume of posting through more detail (depth), different kinds of data (variety), and to more people (reach).

\subsection{DIMENSION 3: VOLUME (Depth, Variety and Reach)}

We find that on top of establishing the expectation to share more often and more frequently, FoMO-centric design also creates an environment where users are encouraged to quantify otherwise qualitative experiences, sharing more in terms of the level of detail of information Depth), and the Variety (differing media or types of information). As well, they are expected to make this data available to as many people as possible (Reach). Together, these aspects create a bias towards larger audiences and

a more centralized identity where everything about an individual can be found in one place. Along with the social pressure of sharing more, FoMO-centric platforms incentivize users to increase their volume of sharing by quantifying otherwise qualitative interactions (counting likes, numbers of acquaintances, etc.).

This dimension is perhaps best introduced with the following quote:

"[I]t's getting to be the norm to share more about yourself and more, um, how you're feeling and what you're doing. Everyone wants to know more about you because everyone has social media on their phone. Or most people do. So it's with you all the time. Why not share where you are? 
Put your location settings on so Snapchat can show people where you are in the city. You definitely do get that push to share more online." $\mathrm{P} 16(28,6-5)$

\subsubsection{All of you in one place: presenting the authoritative "true" self}

Some platforms have a norm of presenting one's "true" identity, that is, a singular comprehensive, multi-purpose identity to act as an authoritative representation of oneself across contexts. This expectation is encouraged by platform policies such as requiring a full real name, as discussed in Section 2.7.3. We found that pressure to maintain a multi-purpose identity can lead FoMO-suffering participants to share certain aspects of their identities or activities which they would prefer to keep private or confined to particular contexts. Conversely, platforms which have more of a norm of anonymity allow participants to post content more freely without worrying about the consequences of it being "tied" to their permanent identity. P14(24, 6-3) thinks that Twitter and Tumblr are "still pretty anonymous website[s]." For instance, she says, it's rare for users to share a photo of themselves, so there is not the same expectation to do so as on other websites. When posting on Twitter and Tumblr, "I'm not saying something that's directly connected to me. [...] I don't really think twice about reblogging or liking something that might make someone do a double take on Instagram, because it feels less tied to you." Posting on a platform like Instagram, where "you have more of a solid identity as a person," can mean "cementing something as part of your online and real life identity." We found that these connotations of permanence can put immense pressure on participants, as they are aware of a snap judgement effect: other users, including potential employers, "only really have to go through a $3 \times 3$ grid of what you've posted to kind of feel like, OK, I got a sense of this person." But if your self presentation doesn't measure up: "all you have to be is like, no, I don't feel this. No, I'm not interested."

Furthermore, once other users have made judgements about a given user based on their public online identity, it can be hard to change those perceptions, leading to a phenomenon we refer to here as typecasting. We noted that typecasting can further push participants towards continuing to share types of content they may no 
longer want associated with them, primarily motivated by maintaining consistency to appease other users' preexisting expectations. Lack of consistency in posting led to tangible negative effects for participants: less likes and interactions, lost followers, and ultimately a decrease in social capital.

P12(26, 7-4), for instance, felt she'd been typecast as a partier, since she had entered a cycle of posting and follower engagement that led her to share more of that particular aspect of her life: going to shows and partying. She expressed her ambivalence in sharing this information through regret and questioning her own motivations regarding the penultimate post that made her decide to take a break from social media: "I just remember being like, why did you even post this? This is unnecessary." For P12(26, 7-4), her frustration-driven break from social media was the only way she felt she could escape the image and posting expectations she had created for herself. This image went counter to the nuances she feels exist within her identity: "When I go on Instagram, I kind of think of like, are people going to see your personality through what you're posting? [...] For me you'll get my real personality in person." Despite taking a break from Instagram, she still plans to return.

Some privacy-conscious participants provide false information to work around sharing their "real" information, even in cases where it is mandated by the service. P2(14, 6-5): "I did not like [Quora's real name policy] so I just got really creative and made a name that sounded real, but it's obviously not." P14(24, 6-3) practices a similar behaviour when asked for personal information on some websites. "I just kind of pick the answer opposite to what I actually am." Other participants, like P20(34, 3-6) opt to provide vague information, rather than false information. "II try to keep it generic. I'm not going to be like 'I live in such-and-such,' that's really dangerous. So I'm just like, '[city name].' Generic." Participants feel ambivalent sharing comprehensively, feeling obliged to share but worrying about the potential consequences of providing real or detailed information. Every instance of sharing becomes a question of: do I want this permanently and pervasively associated with me? 


\subsubsection{All of your friends in one place: mixing audiences}

Part and parcel of presenting the authoritative self is the mixing of audiences across contexts. Many of our participants expected others to share their membership in at least one common platform, which becomes the go-to point of contact for new acquaintances. P15(38, 5-4) adds people on Instagram first, then moves onto other platforms "depending how it goes." As this platform is often shared even before other more private forms of contact such as phone numbers, acquaintances from all contexts become mixed into the same audience. This forms a master audience of sorts. The user's authoritative identity is accompanied by an authoritative audience, representing the accumulation of all of their acquaintances.

This bias towards centrality goes counter to what many participants demonstrated: that they are interested in keeping their online identities separate, rather than unified. This was shown in many forms, from using built-in features to keep separate audiences on the same account (e.g., Instagram's Private Stories, selectively blocking, or sharing certain content with only certain groups), to more creative workarounds, such as keeping multiple accounts on the same platform (e.g., personal account, work account, and/or "spam" account), or keeping one's presence on certain platforms secret or anonymous (e.g., only telling trusted people about one's Twitter or Reddit account). Some participants demonstrated privacy concerns in regard to this category by being protective of certain accounts and worrying about the negative repercussions of allowing an inappropriate audience to see their content, whether it was related to getting in trouble at work, seeming unprofessional, or even jeopardizing their own safety.

However, platforms do not make it easy for users who keep multiple identities as a workaround. P25(37, 7-2) has a blank account-that is, an account with no friends or shared content-purely to keep track of community events. However, she points out that this is made difficult because Facebook's events algorithm is designed to recommend events based on those being attended by friends. This means that she has to pro-actively find out about events. P9(12, 2-4) found a similar issue with his own blank account which he uses as a "library" to easily access content without having to worry about negative consequences of being publicly connected to differing 
beliefs from those popular in his home country. "Facebook pushed me to accept some friends. [... With a blank account,] I noticed that they blocked me from having access to many links. When I did accept [a couple of friendship requests], I saw that the connection was open. Now I can have access." Privacy-conscious users who do not wish to have a large volume of digital friends (or any at all) are thus disadvantaged when it comes to benefiting from platform features and have to take steps to avoid missing out.

\subsubsection{Reciprocating data type}

Our participants feel uncomfortable when they feel their responses are asymmetrical in terms of medium. Text should be met with text; photos should be met with photos. This is the case even if the user does not want to reply in the specified medium - they still feel pressured into thinking they should. This encourages users to increase the variety of their participation, sharing in as many mediums as possible despite possible privacy concerns.

P16(28, 6-5): "If someone constantly sends you back a photo, like keeps sending you photos or videos when you're just answering by message, there are times where I feel like 'ok I should probably send a picture' so I'll send like the one off picture. [...] It's like, aahh, different types of media are being used to communicate."

This can lead users to share forms of data about themselves they do not want to - for instance, perhaps they would prefer to reply through a medium such as text, but instead are pressured into replying with a picture of their face, such as in the case of Snapchat conversations. P22(27, 5-4) tells us some days she doesn't feel up to replying via photo, but still feels the pressure to reply back in the same medium others are using. She works around it by posting only partial photos of her face: "Sometimes I just look like a bum; I don't want to show my face. My boyfriend will be like, 'Okay, you sent me forehead pictures all day.' And I'm like, 'Yeah, I'm tired and I didn't wear makeup."' She still participates partially by sending a photo, but does not participate fully by sharing her full face. 


\subsubsection{Selling yourself}

Many participants see the ability to "sell yourself" or "put yourself out there" as a perk of online posting, but some also see it as a requirement. P3(27, 6-6) sees social media as "very beneficial" to finding employment — as well as necessary. "You got to put yourself out there through social media before you actually go to interview and make connections." He is also aware that your social media presence can make or break a first impression with a potential employer: "The stuff you put on the internet could always reflect either good or bad on you because employers have told me that they do background checks, they do check social media."

While the presence of material an employer disapproves of can be harmful to your prospects, so can a lack of material: "It might make you look less involved in the community," says P3(27, 6-6). However, publicly posting material aimed at boosting your professional profile can create a conflict with the image of yourself you may want friends or contacts from other contexts to see: P3 $27,6-6)$ is aware his friends can view his LinkedIn profile and may think he comes across as "cocky" when posting about awards or achievements. This can lead to some ambivalence when posting.

"Selling yourself" is important when it comes to personal contacts, as well. The completeness of a stranger's profile can be a way of judging how trustworthy they may be. P18(36, 5-4) uses the appearance of a potential follower's profile to judge whether or not she should accept the invite: "Some people [...] don't post things, they might have like 10 pictures and they just see what everyone else is doing. They might have no pictures. So I just make my best judgment, you know, "should I let you follow me? Should I follow you back?' " A full and active profile also makes judgements regarding reciprocity of friendship easier, therefore perhaps making the creation of new friendships more likely. P11(26, 6-3): "[T]here is another step of awkwardness involved in sending messages out to people who I don't know as well. So it can be a bit of a barrier to stay in contact, because I don't know how they'll respond to it." Social media mediates this awkwardness: "You can see what's going on, so you can comment or reply to a story or just, you know, you'd like pictures and then you can see they're liking your pictures. Then maybe you're at a similar spot."

Combined with the social expectation of sharing more, participants noted that 
platform features also promote having a complete profile by denying the user the choice to overtly decline completion. P16(28, 6-5): "On Facebook it'll say, 'not now.' So instead of saying, 'I don't want to,' it's saying, 'Oh, I don't want to do it right now.' It kind of makes it sound a bit more like an obligation." Once again, users may feel pressured to share more about themselves than they would like due to platform infrastructure.

\subsubsection{MVP: Minimum Viable Presence}

As we have seen, participants feel pressured to post with a certain level of frequency and completeness on the platforms they have joined. But joining and staying on platforms does not feel entirely voluntary, either; participants also feel there is a minimum required level of presence in terms of platform membership to avoid violating social norms and risk isolating themselves completely. This can be an issue when users feel uncomfortable with a platform's privacy and security practices. Multiple participants mentioned concern over how platforms such as Facebook and TikTok had handled users' data in the past, despite continuing to use them. P24(27, 6-6): "I don't really like using Facebook that much. It's because of these security things, like all the issues that go on with it, that I don't really like using it." Nevertheless, he keeps his account for the sake of events and messaging, which feel necessary to him.

Highly privacy-concerned P10(17, 7-6) does not have accounts on many popular social media sites. He works around requirements of minimum presence by doing what he refers to as "piggybacking," or borrowing the login credentials of others. "At work, I didn't have a Twitter or LinkedIn account and I had to find out information by using Twitter and LinkedIn. So I just asked one of my colleagues for their login details and they kindly provided them." P10 has on occasion experienced pushback from others due to this workaround-however, it has not incited him to open his own account. Note that this participant's FoMO score is low (17), which may be related to why he has not felt the need to open his own accounts despite social pushback.

Higher-FoMO participants expressed feeling socially ostracized by not having an account on a platform. P20(34, 3-6) on what prompted her to finally join Facebook: "I just felt left out [...] I'm just like, I need to get this so I won’t be left out." She was 
aware she was not being invited to certain events because she did not have an account on the platform. "[People would say] 'Oh, we sent out a Facebook invite.' I don't have Facebook, people, you know! You kind of get left out because everybody else is using it and then you're not using it so you don't get invited to things." P25(37, 7-2) closed her Facebook account and has since experienced the same phenomenon of being left out of events. "Now that I've deactivated my account, I really am missing out on a lot of different events going on, that I just don't know about because I'm not connecting the same way that I used to be." She does not think leaving non-Facebook users out is intentional on users' parts, but more a force of habit. P25 has tried to work around this by asking coworkers to tell her about upcoming social events, but finds they often forget to do so. "I tell people, could you let me know when this is happening or when there's a certain event coming up. And they're like, Yeah! For sure. And then they just don't do it. And then I feel bad if I have to follow up, I feel kind of annoying."

Users who want out of popular platforms are also facing negative assumptions from other users; another hit to social capital. P17(31, 6-7) says if she meets someone with no social media, she finds it "suspicious" and assumes the person has something to hide. "I had one friend in high school who didn't have any social media for a long time, and it was because she got in trouble over social media. So I guess I would just look at it as they don't have it for a reason, not because they're choosing." When asked what the cut-off was between being suspicious and not suspicious, she said, "as long as they have one [social media account], I think it'd be fine or I wouldn't be suspicious. But... Having none, I think that would just... I don't know." P9(12, 2-4) thinks that if a person doesn't have social media, it's a sign they lacked the self-control to properly moderate their own use while on it. These are examples of making moral judgments and rationalizing others' behaviours (see Table 4.2).

We found that in addition to the privacy concerns that come with simply having an account on a platform, the act of joining creates a domino effect of participation. Once on a platform, participants feel obliged to use it, stay in the loop, and adhere to community norms; they know that others expect them to participate if they have the account. P17(31, 6-7) was resistant to join Instagram but eventually did so due 
to social pressure. "Before I had Instagram, I was really reluctant to sign up for it because I knew once I signed up I would have to keep up with it."

\subsubsection{Can't leave, won't leave}

Multiple participants explained that they want to leave Facebook, but feel they cannot because it would mean socially isolating themselves.

"I do find that it's difficult because I want to deactivate Facebook. [...] But it's almost the norm that people have it. [...] I've [even] gotten a wedding invitation sent to my Facebook because they don't know my email. It's just that common way to find people. And so it's almost the norm that you have to have Facebook. You don't have to check it all the time, but you have to have it." P16(28, 6-5):

She romanticizes the idea of leaving, contrasting her situation to that of her cousin, who has not logged into Facebook for years. In doing so she uses the language of liberation, betraying her view of her own use of social media as tantamount to imprisonment: "It's kind of liberating because he doesn't have that, that need. He didn't have to go on Facebook, he doesn't even care about it. [...] I think it's a bit liberating to get rid of that social media account." The following participant also feels tied to the platform despite grievances with it.

"I want to leave. I want to leave all of it so badly. I think about it all the time. But it's so difficult. It's so difficult to go against the grain and push yourself even further away from everyone else. It's so difficult to sever that connection." P25(37, 7-2)

In the case of both P16(28, 6-5) and P25(37, 7-2), they know someone who does not use social media at all, yet they do not see it as a realistic goal for themselves. They attribute the ability to successfully remove oneself from social media to personality; this is known as dispositional attribution, a form of rationalization explained by attribution theory [48], used when faced with conflicting beliefs (social media cannot be left) and behaviours (leaving social media). This rationalization was demonstrated 
by several high-FoMO participants when discussing people without much online presence. P15(38, 5-4): "They're just that type of person that's like, 'I want to be isolated in my own little world, worry about these things,' [rather] than what the rest of us are doing."

We found that even if participants manage to overcome this rationalization, popular social media platforms excel at making it very difficult for them to leave once their presence has been established. Not only do they face missing out on future events and social connections, but leaving is also costly in terms of accrued social capital and emotional investment in data, especially if the participant has been using it as a form of validation as encouraged by the platform.

P21(26, 6-4): "If I were to just delete my Instagram, then I would lose everything... photos, contents, followers or people who I'm following. I would just lose all that. So then... I'd be actually a little upset if I did that, even with Facebook, too, because I do have content on there and often they're really good memories, too. [...] I would have to start over, in other words."

As such, many participants opt for taking a break from social media when they feel overwhelmed, rather than deleting it altogether. "Starting over" is too costly.

Finally, viable alternatives are hard - or impossible - to find. P13(21, 6-3) finds control over her data important. "[W]ith the whole privacy issues with Facebook, privacy is something that I take quite seriously." Consequently, she was excited to join Vero, an alternative social media platform that she describes as "kind of like a mash between Instagram and Facebook, but you have more options as to who sees your content." However, upon realizing not many of her friends were using it, she ultimately decided it was not useful to her and deleted it, falling back on Facebook. "I mean, if not a lot of people are on the app, then it's no use if I download it anyways."

Our participants plan to keep their accounts, and the memories enclosed therein, for the long haul. Even participants such as P16(28, 6-5) who expresses wishes to leave makes this declaration: "Most of us are going to grow up and keep social media forever." Our participants feel resigned to reluctantly stay on social media for the foreseeable future because the cost of missing out is too high. 


\subsection{Non-Participatory and FoMO-Independent Participatory Behaviours}

In this chapter, we have investigated the reasons why participants reluctantly compromise their privacy. However, we also find it important to investigate cases in which interviewees do not participate (either fully or at all), to compare and contrast this with the reasons users do participate. This provides us with greater clarity in the decision-making process. We provide Table 4.3 to summarize the main categories of rationalizations for not participating which we discovered over the course of our interviews. Since our focus in this thesis is more on reasons why users do participate, we will not go into each of these categories in detail. However, a brief survey of the categories provides us with an interesting insight: most reasons users had for not participating, just as in the reasons we presented for participating, are social-based: namely, avoiding embarrassment, avoiding being a target of others, avoiding violating community norms, and looking to others for implicit or explicit support of their behaviours. This makes sense if we return to the Theory of Planned Behaviour [5], which lists social norms as one of three main factors in decision-making. Participants also provided rationalizations that appeared more independent of social factors, included justifying through one's own values, and avoiding draining activities.

On a similar note, we also discovered some reasons our interviewees had for participating in social media that seemed relatively FoMO-independent, or deliberate, including: expressing the self, connecting with others over a common cause or struggle, maintaining deep or meaningful connections with others, and posting to elicit positive change. These behaviours appear to reclaim social interaction online as an end in itself, rather than reducing it to a FoMO-centric means to an end.

\subsection{Summary of Study Findings}

Through our grounded theory study, we identified a variety of situations where participants indicated FoMO-aggravated participation in social media platforms, by either admitting to participating for reasons related to social pressure, or through alluding to community norms or platform features which supported such social pressure. Analysis of our study brought us to an understanding of an overarching system of 


\begin{tabular}{|c|c|c|}
\hline Reason & Brief description & Example \\
\hline Avoiding embarrassment & $\begin{array}{l}\text { Participant considers participating to be too embarrassing. } \\
\text { In these cases a participant may participate partially (e.g., } \\
\text { downloading an app or filter) but not fully (e.g., posting). }\end{array}$ & $\begin{array}{l}\text { P20(34, 3-6): "That's just too funny. I'm } \\
\text { not sharing that. Nope. Nobody needs to } \\
\text { see that but me." }\end{array}$ \\
\hline Avoiding being a target & $\begin{array}{l}\text { Participant wants to avoid drawing unnecessary negative } \\
\text { attention to themselves by doing something that may be } \\
\text { deemed controversial. }\end{array}$ & $\begin{array}{l}\text { P14(24, 6-3): "I've seen how nasty people } \\
\text { can get online, and it's gotten to the point } \\
\text { where I just don't want to invite that kind } \\
\text { of attention." }\end{array}$ \\
\hline $\begin{array}{l}\text { Avoiding violating commu- } \\
\text { nity norms }\end{array}$ & $\begin{array}{l}\text { Participant doesn't want to risk using platform in a socially } \\
\text { unacceptable way. They may worry about coming across } \\
\text { as "annoying" to others. }\end{array}$ & $\begin{array}{l}\text { P12(26, 7-4): "I find [giveaway posts] ob- } \\
\text { noxious [...] I don't want to be another } \\
\text { person who shares it." }\end{array}$ \\
\hline Social support & $\begin{array}{l}\text { Participant receives explicit or implicit social support } \\
\text { from others, who share in or approve of the target non- } \\
\text { participatory behaviour. }\end{array}$ & $\begin{array}{l}\text { P2(14, 6-4.5): "[My friend] made an ac- } \\
\text { count with a fake name and fake informa- } \\
\text { tion. [...] so I'm obviously not the only } \\
\text { one who's made up fake names before." }\end{array}$ \\
\hline Getting away with it & $\begin{array}{l}\text { Participant experiences lack of negative consequences from } \\
\text { others and/or the platform itself for not participating, and } \\
\text { uses this as rationale for further behaviour. }\end{array}$ & $\begin{array}{l}\text { P16(28, 6-5) on unfriending a relative } \\
\text { with whom she no longer wished to share } \\
\text { her personal details: "It's been like two } \\
\text { years. She hasn't noticed." }\end{array}$ \\
\hline Avoiding draining activities & $\begin{array}{l}\text { Participating takes up too much of the participant's time } \\
\text { and energy, and is lower priority than competing activities } \\
\text { in their life. Participating may also be "draining" in that } \\
\text { it consumes too much battery life or storage space on the } \\
\text { participant's device. }\end{array}$ & $\begin{array}{l}\text { P16(28, 6-5) stopped participating in } \\
\text { a post-everyday challenge, because she } \\
\text { found coming up with a daily idea time } \\
\text { consuming, and was taking her away from } \\
\text { things she enjoyed. }\end{array}$ \\
\hline $\begin{array}{l}\text { Justifying through own val- } \\
\text { ues }\end{array}$ & $\begin{array}{l}\text { Participating is at odds with the participant's own values, } \\
\text { whether it would involve demeaning others or presenting } \\
\text { themselves inauthentically to others. }\end{array}$ & $\begin{array}{l}\text { P3(27, 6-6) declined joining a QEBA site } \\
\text { popular amongst his peers because he } \\
\text { thought it encouraged bullying. }\end{array}$ \\
\hline
\end{tabular}

Table 4.3: Summary of reasons participants gave for not participating 
FoMO-centric design, where categories of reactive privacy-compromising behaviours were divided into two temporal dimensions and one spatial dimension: Frequency, Immediacy, and Volume, respectively.

We wanted to demonstrate how the various aspects of FoMO-centric design play off and reinforce each other, through a combination of reinforcing continual behaviour and prompting reactive sharing (see Table 4.1). Reinforcing continuance categories get the user to join and to return, and discourage them from leaving. Once entrapped on the platform, categories relating to reactive sharing prompts encourage users to participate in privacy-compromising behaviours, even when reluctant. 


\section{Chapter 5}

\section{Discussion and Conclusion}

In this thesis, we aimed to uncover the relationship between the Fear of Missing Out and reluctant privacy-compromising behaviours. We first identified a gap in the literature relating to understanding why users might be participating in privacycompromising behaviours despite discomfort. We conducted a literature review which pointed us towards FoMO-driven reluctance as one possible explanation for the privacy paradox. Through our interview study, we then collected qualitative data exploring the possible phenomenon, showing that the use of social media is rife with situations in which users feel pressured to participate to avoid negative social consequences, even when they voice privacy concerns.

Using Grounded Theory, we presented an empirically-based high level theory describing the cyclical relationship between FoMO-centric design and privacy-related participatory reluctance, and identified three main participatory dimensions: Frequency, Immediacy, and Volume. This theory helps fill a research gap concerning the privacy paradox and voluntary yet reluctant behaviour. We showed how both passive and active participation play a role in participants' reactive sharing habits, through the reinforcing of community norms encouraged by platform infrastructure. Finally, our results support and expand Cassidy's 22] definition of participatory reluctance, by identifying 8 symptoms of participatory reluctance and showing their broad application to social media and privacy behaviours. Together, our findings contribute to understanding participatory reluctance, the gap between privacy attitudes and behaviours, and how social factors affect participatory and sharing behaviours.

Now, we discuss the practical and ethical implications of FoMO-centric design, along with preliminary recommendations and a research agenda based on our findings. Parts of the following discussion appeared in our NSPW 2019 paper [106], and thus some of the talking points emerged from discussions at the conference. 


\subsection{From Dark Patterns to Dark Infrastructure}

Our work is heavily inspired by work surrounding dark patterns, which explains user behaviour through the lens of intentional manipulative designs. Indeed, at the beginning of our research, we intended to uncover more specific dark patterns to explain privacy-compromising participatory reluctant behaviours. However, as our interviews and analysis progressed, we noticed something interesting: that the core of the problem of user manipulation seemed to be not within isolated dark patterns, but rather at an overarching level, where the sum was greater than its parts. As such, in this thesis via FoMO-centricity we lay the groundwork for an understanding of high-level dark digital infrastructure.

To our knowledge, this work is the first to present high-level dark design where the focus is on the intermingling parts, rather than considering each primarily in isolation. The cycle of digital infrastructure, community norms and participatory reluctance had already been proposed by Cassidy [22], but such a cycle had not yet been explored in depth. Especially given recent efforts to classify dark patterns on websites in light of the GDPR [33, 73], we believe it is crucial to consider the overall environment that a platform creates in the way we have here, so that we can remain vigilant of the ways in which users are being manipulated. A platform may appear to be free of dark patterns on a granular level-perhaps it gives users free and equal choice over privacy settings, for instance - but if we consider the overall context (being more privacy preserving results in violating platform norms and harming social relationships), suddenly the initially innocuous pattern assumes a darker tone. Rogers et al. 83] recognize this with their proposed framing of dark patterns at the "mesolevel" (patterns which "can't really be identified as bad in themselves [...] but which the cumulative effect is to keep the user within the walls of the app") and "macrolevel" (patterns together "leverage the network effects of social media and human psychological vulnerabilities" to cause damage). Our data supports this view, where the overarching effects on social media users are stronger than could be attributed to individual dark patterns. 


\subsection{Dimensions and their Implications for Future Work}

This is also, to our knowledge, the first time privacy-compromising behaviours have been organized in a similar fashion to sharing behaviours from the information quality literature - that is, in dimensions relating to content, space, and time [8]. Previous privacy work [17, 54,55] has considered amount and frequency of sharing, but has not further broken down these sections into much detail; our categories allow for a more faceted understanding of these behaviours. We do not claim our presentation of dimensions to be comprehensive as they likely could be further refined with continued interviewing, and we cannot make generalizations as to their applicability outside of FoMO-centric design. However, our breakdown of participation dimensions offers a useful guide for future research of each (or all) of the dimensions. Our findings also allow for a richer understanding of participatory behaviours, beyond simply "opting in" or "opting out".

Evidence gleaned from our interviews suggests that a user's decision to participate in privacy-compromising ways may be predicted by passive behaviours, such as "checking" social media, because these submerge users in the high-sharing privacycompromising norms on the platform. This connection between passive and active participatory behaviours is supported by Docherty [34], who suggests a combination

of platform features and discourse contributes to users feeling they should actively contribute more to the platform because it is "healthier" than simply passively using the platform. Thus, as we interpret it, users passively scrolling through a platform may prompt feelings of guilt and lead these users into participating fully to appear more social and thus "healthier" to others.

Knowing this, future work on sharing might benefit from further dissecting passive behaviours that lead to privacy-compromising behaviours and separating them from typical scales used to measure platform use. A validated scale such as the Gerson et al.'s Passive Active Use Measure [44], which measures active social use, active non-social use, and passive use, may be of help. Gerson et al. found that reward reactivity ("associated with the exhilaration of victory or the pleasure of obtaining rewards" - which we believe would be important to high-FoMO participants) was positively associated with both active social use and passive use. This appears to 
be supported by our findings, as we posit both active and passive behaviours as potentially reactive. It could be useful to explore the relationship between passive use and reluctant privacy-compromising behaviours. Are those who use platforms primarily in a passive way more likely to feel reluctant when they do post?

\subsection{How Does our "Dark Infrastructure" Differ from the Regular Pres- sures of Social Life?}

It is worth addressing an important question in our discussion of FoMO-centric design: how does what we present here as happening on social media differ from structures of social life which existed before social media? We highlight that the reason this infrastructure appears to be so effective is precisely because it does mirror certain ingrained aspects of offline social life and preys on inherent social and psychological needs. As discussed in Section 2.1, FoMO results from situational or chronic deficits in competence, autonomy, and relatedness - key factors in self-regulation and psychological health [81].

What makes FoMO-centric design stand out from pre-existing pressures of social life, and what makes it so dark, is the insidious amplification of these pressures and psychological deficits, and the resulting limitations placed on human autonomy in relation to the platforms that FoMO-centric design embodies. Massive social media user-bases (Facebook reported over 2.5 billion users in its first quarter of 2020 [93]) offer an unprecedented stage for large-scale A/B testing of even the most minute changes, allowing for meticulous fine-tuning of user manipulation. It has already been proven such tests take place: in 2014, Facebook was exposed for conducting a secret experiment involving manipulating the mood of nearly 700,000 users based on posts shown on their timelines, without their consent [13].

Users are being continuously surrounded by such finely-tuned manipulation, leading them towards a tendency to behave in a reactive and reluctant way when using the platform - which, by design, is often (see Section 4.4). This has grave implications for privacy. First is the incentivization of maximized data sharing with other users (see especially Sections 4.6.1 and 4.6.2). The other is the use of that data (and all other data collected by the platform about the user) for commercial purposes [113. 
Both aspects are violations of what Nissenbaum refers to as contextual integrity 71], a theory which says that people feel their privacy has been violated when information is transmitted outside of an appropriate context. FoMO-centric dark infrastructure creates an environment where even if users are aware that this is happening to them, they still feel they cannot leave, as discussed in Section 4.6.6.

\subsection{Are We Okay with This?}

Twenty years ago, then-CEO of Sun Microsystems was quoted as saying, "You have zero privacy anyway. Get over it" 92. Fortunately, not all authorities on technology share this attitude. To the contrary, some are making efforts to alter how technology design is approached, to put the benefit back in favour of the consumer.

Former Google Design Ethicist Tristan Harris has founded the Center for Humane Technology [46] to combat technology's "highjacking our minds and society." He says that today's technology is designed to amplify and exploit users' vulnerabilities to make them act impulsively, against their better judgement. A motivating factor is "Loss-aversion" [70] - in other words, FoMO. To combat it, users must be given the confidence that they are able to disconnect more often without missing anything vital. This could be accomplished through the introduction of "useful friction" [70] into technology to slow down users' thinking process and give them the chance to make rational, considered decisions about their technology use- rather than those based on the kind of "fight or flight" response that current technology provokes. Harris is joined by former employees of Google and Facebook; intimately familiar with the inner workings of these companies, they are determined to "correct a wrong" by raising awareness and advocating for change to bring control back to the consumer 15 .

Even current employees are speaking out against industry malpractice: Apple CEO Tim Cook published an article in Times Magazine in January 2019 [30] calling for comprehensive federal privacy legislation to "protect and empower the consumer", and regain the "vanishing ability to control our own digital lives."

This comes at a time when "digital wellness" public awareness is at an all-time high; publications such as Cal Newport's Digital Minimalism [68] (Newport has been called the "Marie Kondo" of technology [20]) arms readers with techniques for "digital 
decluttering"; so-called "digital detox" programs have also been increasing in popularity [87]. Responding to such pressure, Apple and Google have released updates to alleviate users of some of this hijacking: iOS 12's Screen Time function 108 allows the user to set "downtime" and time limits on apps, as well as content and privacy restrictions; Android 9 Pie offers an "app timer", 'do not disturb' mode, and a "wind down" feature, which gradually eliminates blue light and colour before a user-specified bedtime [4].

As laudable as such measures might be, they have been criticized as the "Malboro Lights of the tech industry" [56, a stopgap measure shifting the blame from ingrained product design to case-by-case consumer use. While on the surface digital wellness features might help users combat FoMO, they are more of a band-aid for the problem than a real solution. If anything, the fact that such additional settings are needed for imposing limits on product use is proof that the core product itself is flawed. To truly stop disadvantaging users and manipulating them into making privacy choices they do not want, technology's design must be based on a model that benefits them in the long term, rather than takes advantage of their impulses. A product that affords impulsive use will continue to afford impulsive use, even after we put a timer on it.

Of course, it is unfair to suggest designers be held solely accountable for users experiencing FoMO while using their products, since a range of outside factors affect users' experiences. However, as evidenced by our literature survey and supported by our interviews, the design of a product can aggravate cases of FoMO by provoking FoMO-related emotions and rewarding FoMO-related behaviours, contributing positively to a cycle of FoMO and product use. It is up to designers, therefore, to lessen this effect as much as possible by being held accountable for possible FoMO-traps or dark patterns in their designs, especially where privacy-sensitive data is at stake.

\subsection{How Might We Fight Back against FoMO-Centric Design?}

Here we set out some thoughts about how to move away from FoMO-centric designs and into an environment where users have autonomy over their online privacy-related choices. A failure to act will mean that users will continue to be exploited, because designs based on dark patterns, or the existence of dark infrastructures will become 
more common and more aggressive to win out in an attention-economic system. In this sense, there needs to be a shift in the ecosystem itself at a larger scale, including getting major players on board. We recognize that these recommendations are broad and that they face many challenges to implementation. FoMO designs are prevalent because they work; they achieve direct benefits for the other actors in play (and in some sense for the user as well, although at an increasingly high price). Figuring out how to address the complicated dynamics is a challenge, but we believe that a first step is recognizing and identifying the patterns as problematic in the space of security and privacy, followed by engagement by all stakeholders to work towards more transparent solutions.

Promote privacy-centric designs. As a community, we should promote and create a culture of wanting to give people control over their privacy rather than manipulate them into privacy compromising behaviours that make them uncomfortable. This is a long-standing argument by the privacy community and the basis of the Privacyby-Design $(\mathrm{PbD})$ [23], but it is worth re-iterating. Previous critiques of $\mathrm{PbD}$ have complained of the framework being "vague" 102 and too open to interpretation. To combat this, we argue that explicitly identifying FoMO-centric designs and infrastructures then proposing concrete privacy-centric alternatives is essential to addressing this problem.

Concrete design recommendations might be achieved through extrapolating Harris' concept of "useful friction." Despite the typical Silicon Valley argument that the more frictionless the better [88, a recent study by Mejtoft et al. [66] showed that users were more satisfied and preferred design alternatives with added friction, because they preferred designs where the end result of their actions was clear. We see added friction as being especially valuable to FoMO-centric design because of its prominent temporal aspect, which revolves around frequent and immediate posting. Forcing users to "slow down" and think more about their actions may help users reflect on their own FoMO and related privacy-compromising behaviours, as some of our participants demonstrated to us during the interviews. However, adding friction to an otherwise flawed system is not the ultimate answer. Ironically, many of our participants who seemed the most self-aware of their own FoMO and/or problematic behaviours still 
experienced high levels of FoMO, showing the pervasive subconscious forces underlying this phenomenon. In fact, we urge caution, as we suggest that adding friction to a highly FoMO-centric environment may simply produce greater levels of cognitive dissonance and distress without actually changing users' behaviours, since the underlying driver - social pressure - still remains. Such cognitive dissonance was exhibited in Shklovski et al.'s 89] work, where participants who became aware of an app's leakiness continued using the system as before, albeit with increased levels of discomfort.

Masnick [63] has argued that the answer to data control issues relating to today's social media is a complete overhaul in digital infrastructure, ditching privately-owned platforms altogether in favour of decentralized social spaces built on open protocols. While such a drastic restructuring of online life may not be practical, it is important to consider what aspects of social media are inherent and unchangeable, and which can be improved. As shown in Section 4.6.6, many of our participants felt resigned to a bleak, reluctantly participatory future on social media. However, designers, academics, technologists, and advocates have the power to make a change and put a feeling of empowerment back in the hands on the user. Perhaps then we will be closer to closing the gap between users' privacy attitudes and their behaviours.

Legislate against the use of identified dark patterns. In April 2019, two US Senators tabled a bill [65,104 intended to protect users against specific dark patterns. The bill signifies a positive first step but is far from a solution to the overall problem. It addresses very specific types of dark patterns ("to design, modify, or manipulate a user interface with the purpose or substantial effect of obscuring, subverting, or impairing user autonomy, decision-making, or choice to obtain consent or user data" 104) and only prohibits designs that have a "purpose or substantial effect of cultivating compulsive usage" [104] for children under the age of 13. Furthermore, it only applies to online services with more than 100 Million users. In our interpretation, only the most overt types of FoMO-centric designs would be covered, and only for very large organizations operating within the US. Clearly, additional work is needed to more broadly address this problem, both in terms of the types of practices covered and in international reach. 
The US legislation comes in the wake of the EU General Data Protection Law (GDPR) in May 2018. The introduction of the GDPR enables combating privacy intrusive exploitation of users. However, the Norwegian Consumer Council audited major technology companies' settings and found that even after the regulation was implemented, companies continued to use dark patterns to nudge users into sharing the maximum amount of data 31.

Past critiques of $\mathrm{PbD}$ have suggested that enforcing better privacy practices ignores economic needs [91], but former Ontario Privacy Commissioner and PbD founder Ann Cavoukian counters by suggesting that protecting user privacy up front saves companies more than dealing with the aftermath of a data breach or privacy infraction [40]. The reality is likely less clear-cut than either position.

Empower users against FoMO-centric design. Recognizing that there are many reasons why FoMO-centric designs exist, we cannot rely on the benevolence of service providers in eliminating all such patterns. We should also devise ways to empower users who wish to protect themselves. This may be through the use of thirdparty tools, or through awareness and education. For example, in order to combat the Authoritative Self category (see Section 4.6.1) under our Volume dimension, a tool such as Firefox's Containers feature 103 can be useful towards helping users keep multiple identities separate, as our participants demonstrated was important to them (see also Section 4.6.2).

We strongly caution, however, that the solution to this problem is not solely one of "educating the user". Similarly to what we discussed in Section 5.4, this is merely a stopgap measure, rather than a permanent solution. In the example given above, the platform infrastructure would ideally incorporate friendliness towards multiple identities. The problem of platforms failing to do so is discussed by Chew et al. 26.

\section{Educate designers and developers on dark patterns and the design patterns} that combat them. Designers and developers must first be aware of what to look out for to design in a productive way. Education about dark patterns should be included in computer science and software development curriculum. Avoiding such designs should be discussed as a matter of professional ethics, and ideally embedded in 
companies' Code of Conduct by which all employees should abide. In fact, if we look at the ACM Code of Ethics and Professional Conduct [1], a computing professional should, among others, "contribute to human well-being", "avoid harm", "be honest and trustworthy", and "respect privacy". We argue that dark patterns, including FoMO-centric designs, violate this code, and that individuals have a responsibility to actively avoid their use.

Combat monopolies Maintaining, or increasing, diversity in users' options in terms of comparable service and quality is important to curbing the 'opt in or go home' phenomenon. This is a concern with company mergers and acquisitions, where increasingly users are at the mercy of a smaller number of companies - and whatever limited privacy options (and dark patterns) they provide. In May 2019, Facebook co-founder Chris Hughes published an op-ed [50] calling on the government to break up Facebook, saying the FTC's decision to allow Facebook to acquire Instagram and WhatsApp was its "biggest mistake," and that due to Facebook's overwhelming dominance in the industry, "would-be competitors can't raise the money to take [them on]." Lawmakers [53] and 2020 US presidential candidate Elizabeth Warren [59] have voiced similar views about Facebook being broken up; Warren has proposed tech giants Amazon and Google be broken up as well.

\subsection{Research Agenda}

Besides the above recommendations, we propose a research agenda addressing the issues for FoMO-centric design and privacy.

\section{Quantitative support for relationship between FoMO and reluctant privacy-} compromising behaviours. Now that we have established qualitative grounds for FoMO-centric design, our argument could be further strengthened with the help of quantitative evidence. This might include experiments such as that conducted by Luguri et al. [62], which compared groups of users who were exposed to dark patterns versus no dark patterns. This could help show directly how users' privacy behaviours are affected by the aggravation and amplification of FoMO. However, since we found 
FoMO-centric design relies heavily on both ongoing social factors and temporal dimensions, a design experiment relating to FoMO-centric design might best be conducted in a longitudinal fashion. Secondly, a large scale survey of users' privacy behaviours in relation to their FoMO levels and privacy concerns could be of use to validate our qualitative findings of FoMO-aggravated reluctant privacy-compromising behaviours. These studies could also explore FoMO-centric designs relating to other forms of media (e.g., IoT devices, wearables) since these likely also employ dark patterns relating to user privacy.

\section{Present FoMO-centric dark infrastructure using design pattern conven-}

tions. Now that we have identified the dimensions and underlying categories of FoMO-centric design based on empirical evidence, it could be worthwhile to present these dimensions and categories in a similar fashion to existing design pattern conventions (i.e., following the template visible on the privacypatterns org website [29]). As discussed earlier, our findings are largely higher level than the typical dark pattern, but we think presenting them in keeping with these existing conventions would be valuable for dissemination and widespread ease of understanding.

Propose corresponding privacy-preserving design patterns. Establishing appropriate privacy-preserving patterns is essential to moving forward and providing viable alternatives to those wishing to avoid FoMO-centric infrastructure. This task would initially require innovation and creativity to shift thinking beyond seeing users and their data as a commodity. The resulting patterns would need to be tested to ensure their robustness.

\subsection{Limitations}

As with other interview-based research, our data is self-reported. Participants may have been selective in what they chose to share, they may have mis-remembered, or may have interpreted their past actions and feelings in ways that differed from the original.

As can be seen from Table 3.4, the privacy concern levels of most participants 
were relatively high. As the privacy attitudes questionnaire was administered after the interviews, it is possible that participants may have been primed to feel more concerned about their privacy over the course of the interview. We made an effort not to be overt about our focus on privacy during the interview. However, when privacy did come up naturally in conversation, we asked follow-up questions in relation to it and asked participants to reflect on their experience. Additionally, in-person participants may have been aware they were being interviewed in a security and privacy research lab. A combination of these factors could have skewed our levels of privacy concern towards the high end.

The gender of our participants was also largely skewed towards female. In future studies, we might recruit based on gender to ensure equal representation. We also were not able to interview any participants in the very high (40-50) range of FoMO. This could be due to the fact this range is less common amongst adults. The bulk of previous research on the Fear of Missing Out has been conducted with teen-aged or young adult participants, suggesting the highest FoMO scores may be found in teenagers. It could be interesting to run a similar study with teen participants to see if results would change.

\subsection{Conclusion}

In this thesis, we explored the relationship between the Fear of Missing Out and reluctant privacy-compromising behaviours. In the literature we found evidence of the existence of dark design stemming from the FoMO-related susceptibilities of users, causing them to reluctantly behave in less privacy-preserving ways than they would prefer. We deemed this FoMO-centric design. Using Grounded Theory to conduct and analyze interviews with 25 participants, we found evidence that participants feel pressured to participate to avoid missing out, even when voicing privacy concerns. We presented an empirically-based high level theory describing the cyclical relationship between FoMO-centric design and privacy-related participatory reluctance, helping to fill a research gap concerning the privacy paradox and voluntary yet reluctant behaviour. We provided a list of preliminary recommendations and a research agenda based on our findings. Our takeaway: When we make users choose between social 
benefits and privacy, we are not truly providing a choice. This ultimatum should be brought to the forefront so that everyone involved recognizes the manipulation and we can work towards more positive alternatives. 


\section{Bibliography}

[1] ACM Code 2018 Task Force. ACM Code of Ethics and Professional Conduct. https://www.acm.org/code-of-ethics, 2018.

[2] A. Acquisti and J. Grossklags. Privacy and rationality in individual decision making. IEEE Security Privacy, 3(1):26-33, Jan 2005.

[3] Alessandro Acquisti and Ralph Gross. Imagined communities: Awareness, information sharing, and privacy on the facebook. In George Danezis and Philippe Golle, editors, Privacy Enhancing Technologies, pages 36-58, Berlin, Heidelberg, 2006. Springer Berlin Heidelberg.

[4] Alessandro Acquisti, Curtis Taylor, and Liad Wagman. The economics of privacy. Journal of Economic Literature, 54(2):442-92, 2016.

[5] Icek Ajzen. The theory of planned behavior. Organizational Behavior and Human Decision Processes, 50(2):179 - 211, 1991. Theories of Cognitive SelfRegulation.

[6] Christopher Alexander. A pattern language: towns, buildings, construction. Oxford university press, 1977.

[7] Anita Balakrishnan, Sara Salinas, and Matt Hunter. Mark zuckerberg has been talking about privacy for 15 years - here's almost everything he's said. CNBC, Mar 2018.

[8] Xiaowen Bao and France Bouthillier. Information sharing: As a type of information behavior. In Proceedings of the Annual Conference of CAIS/Actes du congrès annuel de l'ACSI, 2007.

[9] Susanne Barth and Menno D.T. de Jong. The privacy paradox - investigating discrepancies between expressed privacy concerns and actual online behavior a systematic literature review. Telematics and Informatics, 34(7):1038 - 1058, 2017.

[10] Diane Bartz. U.s. senators introduce social media bill to ban 'dark patterns' tricks. https://www.reuters.com/article/us-usa-tech/us-senators-introducesocial-media-bill-to-ban-dark-patterns-tricks-idUSKCN1RL25Q, 2019.

[11] K. Bednar and S. Spiekermann. Aware but not in control: A qualitative value analysis of the effects of new technologies, volume 537 of IFIP Advances in Information and Communication Technology. 2018. 
[12] Rainer Böhme and Stefanie Pötzsch. Collective exposure: Peer effects in voluntary disclosure of personal data. In George Danezis, editor, Financial Cryptography and Data Security, pages 1-15, Berlin, Heidelberg, 2012. Springer Berlin Heidelberg.

[13] Robert Booth. Facebook reveals news feed experiment to control emotions. The Guardian, June 2014.

[14] Christoph Bösch, Benjamin Erb, Frank Kargl, Henning Kopp, and Stefan Pfattheicher. Tales from the dark side: Privacy dark strategies and privacy dark patterns. Proceedings on Privacy Enhancing Technologies, 2016(4):237 $254,2016$.

[15] Nellie Bowles. Early facebook and google employees form coalition to fight what they built. The New York Times, Feb 2018.

[16] Dawn Beverley Branley and Judith Covey. Risky behavior via social media: The role of reasoned and social reactive pathways. Computers in Human Behavior, $78: 183-191,2018$.

[17] Alex Braunstein, Laura Granka, and Jessica Staddon. Indirect content privacy surveys: Measuring privacy without asking about it. In Proceedings of the Seventh Symposium on Usable Privacy and Security, SOUPS 11, New York, NY, USA, 2011. Association for Computing Machinery.

[18] Harry Brignull. Dark Patterns types of dark pattern. https://darkpatterns. org/types-of-dark-pattern. Accessed: 2019-17-01.

[19] Amara T. Brook, Julie Garcia, and Monique A. Fleming. The effects of multiple identities on psychological well-being. Personality and Social Psychology Bulletin, 34(12):1588-1600, 2008. PMID: 19050334.

[20] Darrah Brustein. Want A Healthier Relationship With Technology? Meet The Marie Kondo Of Digital Decluttering. Forbes, March 2019.

[21] Corina Cara et al. Dark patterns in the media: A systematic review. Network Intelligence Studies, 7(14):105-113, 2019.

[22] Elija Cassidy. Social networking sites and participatory reluctance: A case study of gaydar, user resistance and interface rejection. New Media 6 Society, 18(11):2613-2628, 2016.

[23] Ann Cavoukian. Privacy by design: The 7 foundational principles, 2011.

[24] Kathy Charmaz. Constructing grounded theory. Sage, 2014. 
[25] Zhen Troy Chen and Ming Cheung. Privacy perception and protection on chinese social media: a case study of wechat. Ethics and Information Technology, 20(4):279-289, 2018.

[26] Monica Chew and Sid Stamm. Contextual identity: Freedom to be all your selves. In Proceedings of the Workshop on Web, volume 2. Citeseer, 2013.

[27] Tsz Hang Chu and Tien Ee Dominic Yeo. Rethinking social media and political engagement: An examination of the disconnective practices of politically active youths in hong kong. In Proceedings of the 9th International Conference on Social Media and Society, pages 41-50. ACM, 2018.

[28] Michael Colesky, Julio C. Caiza, José M. Del Álamo, Jaap-Henk Hoepman, and Yod-Samuel Martín. A system of privacy patterns for user control. In Proceedings of the 33rd Annual ACM Symposium on Applied Computing, SAC '18, pages 1150-1156, New York, NY, USA, 2018. ACM.

[29] Michael Colesky, Jaap-Henk Hoepman, Christoph Bösch, Frank Kargl, Henning Kopp, Patrick Mosby, Daniel Le Metayer, Inria Olha Drozd, Jose M. del Alamo, Yod Samuel Martin, Julio C. Caiza, Mohit Gupta, and Nick Doty. Privacy patterns. https://privacypatterns.org/. Accessed: 2018-17-12.

[30] Tim Cook. You deserve privacy online. here's how you could actually get it. Time, Jan 2019.

[31] Norwegian Consumer Council. Deceived by design: How tech companies use dark patterns to discourage us from exercising our rights to privacy. 2018.

[32] Edward Deci and Richard M Ryan. Intrinsic motivation and self-determination in human behavior. Springer Science \& Business Media, 1985.

[33] Linda Di Geronimo, Larissa Braz, Enrico Fregnan, Fabio Palomba, and Alberto Bacchelli. Ui dark patterns and where to find them: A study on mobile applications and user perception. In Proceedings of the 2020 CHI Conference on Human Factors in Computing Systems, CHI 20, page 114, New York, NY, USA, 2020. Association for Computing Machinery.

[34] Niall Docherty. Facebooks ideal user: Healthy habits, social capital, and the politics of well-being online. Social Media+ Society, 6(2):2056305120915606, 2020 .

[35] Nick Doty and Mohit Gupta. Privacy design patterns and anti-patterns patterns misapplied and unintended consequences. 2013.

[36] Ramona-Riin Dremljuga. The process and affordances of platform-specific social media disconnection. Studies of Transition States and Societies, 10(2), 2018. 
[37] Stefanie Duguay. Identity modulation in networked publics: Queer women's participation and representation on Tinder, Instagram, and Vine. PhD thesis, Queensland University of Technology, 2017.

[38] Nicole B Ellison, Charles Steinfield, and Cliff Lampe. The benefits of facebook "friends" social capital and college students' use of online social network sites. Journal of Computer-Mediated Communication, 12(4):1143-1168, 2007.

[39] Facebook. What names are allowed on facebook? https://www.facebook. com/help/112146705538576. Accessed: 2019-26-01.

[40] Liz Farmer. Canada's global player in the privacy debate. GOVERNING, May 2014.

[41] Leon Festinger. A theory of cognitive dissonance, volume 2. Stanford university press, 1962.

[42] BJ Fogg. Persuasive technology: Using computers to change what we think and do (interactive technologies). Ubiquity, 5, 2002.

[43] Meg Gerrard, Frederick X. Gibbons, Amy E. Houlihan, Michelle L. Stock, and Elizabeth A. Pomery. A dual-process approach to health risk decision making: The prototype willingness model. Developmental Review, 28(1):29 - 61, 2008. Current Directions in Risk and Decision Making.

[44] Jennifer Gerson, Anke C. Plagnol, and Philip J. Corr. Passive and active facebook use measure (paum): Validation and relationship to the reinforcement sensitivity theory. Personality and Individual Differences, 117:81 - 90, 2017.

[45] Saikat Guha, Kevin Tang, and Paul Francis. Noyb: Privacy in online social networks. In Proceedings of the First Workshop on Online Social Networks, WOSN '08, pages 49-54, New York, NY, USA, 2008. ACM.

[46] Tristan Harris. Center for humane technology. http://humanetech.com/. Accessed: 2019-19-01.

[47] Todd Haselton. How google is fighting smartphone addiction with its next android update. $C N B C$, May 2018.

[48] Fritz Heider. The psychology of interpersonal relations. New York: John Wiley and Sons, 1958.

[49] E Tory Higgins. Self-discrepancy: a theory relating self and affect. Psychological review, 94(3):319, 1987.

[50] Chris Hughes. It's time to break up facebook. The New York Times, May 2019. 
[51] Kylie Jarrett. "let's express our friendship by sending each other funny links instead of actually talking": Gifts, commodities, and social reproduction in facebook. Networked affect, pages 203-219, 2015.

[52] Daniel Kahneman. Thinking, fast and slow. Macmillan, 2011.

[53] Makena Kelly. Congress isnt buying mark zuckerbergs pitch for libra. The Verge, October 2019.

[54] Spyros Kokolakis. Privacy attitudes and privacy behaviour: A review of current research on the privacy paradox phenomenon. Computers \& Security, 64:122 $134,2017$.

[55] Hanna Krasnova, Oliver Günther, Sarah Spiekermann, and Ksenia Koroleva. Privacy concerns and identity in online social networks. Identity in the Information Society, 2(1):39-63, 2009.

[56] Rachel Kraus. 'time well spent' features are the marlboro lights of the tech industry. Mashable, August 2018. Accessed: 2019-04-07.

[57] C. Lacey and C. Caudwell. Cuteness as a dark pattern in home robots. In 2019 14th ACM/IEEE International Conference on Human-Robot Interaction (HRI), pages 374-381, 2019.

[58] M. Laverdiere, A. Mourad, A. Hanna, and M. Debbabi. Security design patterns: Survey and evaluation. In 2006 Canadian Conference on Electrical and Computer Engineering, pages 1605-1608, May 2006.

[59] Colin Lecher. Elizabeth Warren says she wants to break up Amazon, Google, and Facebook. The Verge, March 2019.

[60] Yang W Lee, Diane M Strong, Beverly K Kahn, and Richard Y Wang. Aimq: a methodology for information quality assessment. Information \& management, 40(2):133-146, 2002.

[61] Dahui Li, Glenn J. Browne, and Patrick Y. K. Chau. An empirical investigation of web site use using a commitment-based model. Decision Sciences, 37(3):427444, 2006.

[62] Jamie Luguri and Lior Strahilevitz. Shining a light on dark patterns. $U$ of Chicago, Public Law Working Paper, (719), 2019.

[63] Mike Masnick. Protocols, not platforms: A technological approach to free speech. Knight First Amendment Institute, August 2019.

[64] Arunesh Mathur, Gunes Acar, Michael Friedman, Elena Lucherini, Jonathan Mayer, Marshini Chetty, and Arvind Narayanan. Dark patterns at scale: Findings from a crawl of 11kshopping websites. 2019. 
[65] Natasha Mathur. U.s. senators introduce a bipartisan bill that bans social media platforms from using 'dark patterns' to trick its users. https://hub.packtpub.com/u-s-senators-introduce-a-bipartisan-bill-thatbans-social-media-from-using-dark-patterns-to-trick-its-users/, 2019.

[66] Thomas Mejtoft, Sarah Hale, and Ulrik Söderström. Design Friction, page 4144. Association for Computing Machinery, New York, NY, USA, 2019.

[67] Samantha Murphy. Report: $56 \%$ of social media users suffer from fomo. Mashable, Jul 2013.

[68] Cal Newport. Digital Minimalism: Choosing a Focused Life in a Noisy World. Penguin, 2019.

[69] BBC News. Instagram hides likes count in international test 'to remove pressure'. BBC News, July 2019.

[70] Casey Newton. Google's new focus on well-being started five years ago with this presentation. The Verge, May 2018.

[71] Helen Nissenbaum. Privacy in context: Technology, policy, and the integrity of social life. Stanford University Press, 2009.

[72] Patricia A Norberg, Daniel R Horne, and David A Horne. The privacy paradox: Personal information disclosure intentions versus behaviors. Journal of Consumer Affairs, 41(1):100-126, 2007.

[73] Midas Nouwens, Ilaria Liccardi, Michael Veale, David Karger, and Lalana Kagal. Dark patterns after the gdpr: Scraping consent pop-ups and demonstrating their influence. In Proceedings of the 2020 CHI Conference on Human Factors in Computing Systems, CHI 20, page 113, New York, NY, USA, 2020. Association for Computing Machinery.

[74] Khaldoon 'Khal' Nusair, Anil Bilgihan, Fevzi Okumus, and Cihan Cobanoglu. Generation y travelers' commitment to online social network websites. Tourism Management, 35:13 - 22, 2013.

[75] Open Security Architecture (OSA). https://www.opensecurityarchitecture.org/cms/, 2019.

[76] Oxford Dictionary. FOMO. https://en.oxforddictionaries.com/definition/fomo. Accessed: 2018-11-12.

[77] Susanna Paasonen. Affect, data, manipulation and price in social media. Distinktion: Journal of Social Theory, 19(2):214-229, 2018. 
[78] Zizi Papacharissi and Paige L. Gibson. Fifteen Minutes of Privacy: Privacy, Sociality, and Publicity on Social Network Sites, pages 75-89. Springer Berlin Heidelberg, Berlin, Heidelberg, 2011.

[79] Andrea Peterson and Joby Warrick. Leaks of nude celebrity photos raise concerns about security of the cloud. The Washington Post, September 2014.

[80] Chanda Phelan, Cliff Lampe, and Paul Resnick. It's creepy, but it doesn't bother me. In Proceedings of the 2016 CHI Conference on Human Factors in Computing Systems, CHI '16, pages 5240-5251, New York, NY, USA, 2016. ACM.

[81] Andrew K. Przybylski, Kou Murayama, Cody R. DeHaan, and Valerie Gladwell. Motivational, emotional, and behavioral correlates of fear of missing out. Computers in Human Behavior, 29(4):1841 - 1848, 2013.

[82] Katelyn Ritchie. To Post, or Not to Post? Exploring Adjunct Faculty and Staff Social Media Use Among a Converged Mixed Audience. PhD thesis, University of Cincinnati, 2018.

[83] Yvonne Rogers, Paul Dourish, Patrick Olivier, Margot Brereton, and Jodi Forlizzi. The dark side of interaction design. In Extended Abstracts of the 2020 CHI Conference on Human Factors in Computing Systems, CHI EA 20, page 14, New York, NY, USA, 2020. Association for Computing Machinery.

[84] Sasha Romanosky, Alessandro Acquisti, Jason Hong, Lorrie Faith Cranor, and Batya Friedman. Privacy patterns for online interactions. In Proceedings of the 2006 Conference on Pattern Languages of Programs, PLoP '06, pages 12:1-12:9, New York, NY, USA, 2006. ACM.

[85] Yoel Roth. Gay data. 2016.

[86] John Schwartz. 'opting-in': A privacy paradox. Washington Post, 2000.

[87] Oscar Schwartz. Why beating your phone addiction may come at a cost. The Guardian, March 2019.

[88] Victoria Sgarro. The tyranny of frictionless design, January 2019.

[89] Irina Shklovski, Scott D. Mainwaring, Halla Hrund Skúladóttir, and Höskuldur Borgthorsson. Leakiness and creepiness in app space: Perceptions of privacy and mobile app use. In Proceedings of the SIGCHI Conference on Human Factors in Computing Systems, CHI 14, page 23472356, New York, NY, USA, 2014. Association for Computing Machinery.

[90] Johanneke Siljee. Privacy transparency patterns. In Proceedings of the 20th European Conference on Pattern Languages of Programs, EuroPLoP '15, pages 52:1-52:11, New York, NY, USA, 2015. ACM. 
[91] Sarah Spiekermann. The challenges of privacy by design. Commun. ACM, 55(7):38-40, July 2012.

[92] Polly Sprenger. Sun on privacy: 'get over it'. Wired, Jan 1999.

[93] Statista. Number of monthly active facebook users worldwide as of 1st quarter 2020. https://www.statista.com/statistics/264810/ number-of-monthly-active-facebook-users-worldwide/. Accessed: 202009-06.

[94] Katherine Strater and Heather Richter Lipford. Strategies and struggles with privacy in an online social networking community. In Proceedings of the 22Nd British HCI Group Annual Conference on People and Computers: Culture, Creativity, Interaction - Volume 1, BCS-HCI '08, pages 111-119, Swinton, UK, UK, 2008. British Computer Society.

[95] S. Shyam Sundar, Jinyoung Kim, Mary Beth Rosson, and Maria D. Molina. Online privacy heuristics that predict information disclosure. In Proceedings of the 2020 CHI Conference on Human Factors in Computing Systems, CHI 20, page 112, New York, NY, USA, 2020. Association for Computing Machinery.

[96] Monika Taddicken. The 'privacy paradox'in the social web: The impact of privacy concerns, individual characteristics, and the perceived social relevance on different forms of self-disclosure. Journal of Computer-Mediated Communication, 19(2):248-273, 2014.

[97] Karen P. Tang, Jialiu Lin, Jason I. Hong, Daniel P. Siewiorek, and Norman Sadeh. Rethinking location sharing: Exploring the implications of social-driven vs. purpose-driven location sharing. In Proceedings of the 12th ACM International Conference on Ubiquitous Computing, UbiComp '10, pages 85-94, New York, NY, USA, 2010. ACM.

[98] Zeynep Tufekci. Can you see me now? audience and disclosure regulation in online social network sites. Bulletin of Science, Technology $\&$ Society, 28(1):20$36,2008$.

[99] Sonja Utz and Nicole C Krämer. The privacy paradox on social network sites revisited: The role of individual characteristics and group norms. Cyberpsychology: Journal of Psychosocial Research on Cyberspace, 3(2), 2009.

[100] Sebastián Valenzuela, Namsu Park, and Kerk F Kee. Is there social capital in a social network site?: Facebook use and college students' life satisfaction, trust, and participation. Journal of computer-mediated communication, 14(4):875901, 2009.

[101] Emily van der Nagel. 'networks that work too well': intervening in algorithmic connections. Media International Australia, 168(1):81-92, 2018. 
[102] Jeroen van Rest, Daniel Boonstra, Maarten Everts, Martin van Rijn, and Ron van Paassen. Designing privacy-by-design. In Bart Preneel and Demosthenes Ikonomou, editors, Privacy Technologies and Policy, pages 55-72, Berlin, Heidelberg, 2014. Springer Berlin Heidelberg.

[103] Tanvi Vyas. Contextual identities on the web. https://blog.mozilla.org/tanvi/2016/06/16/contextual-identities-on-the-web/, 2016.

[104] Mark R. Warner and Deb Fischer. Deceptive experiences to online users reduction (DETOUR) act. https://www.scribd.com/document/405606873/DetourAct-Final, 2019.

[105] Jim Waterson. FaceApp denies storing users' photographs without permission. The Guardian, July 2019.

[106] Fiona Westin and Sonia Chiasson. Opt out of Privacy or "Go Home": Understanding Reluctant Privacy Behaviours through the FoMO-Centric Design Paradigm. In Proceedings of the New Security Paradigms Workshop, NSPW 19, pages 57-67, New York, NY, USA, 2019. Association for Computing Machinery.

[107] Fiona Westin and Sonia Chiasson. [Poster] Giving up on Privacy for Fear of Missing Out. SERENE-RISC Annual Conference, 2019. Posters and Others.

[108] Lance Whitney. How to use screentime in apple ios 12. https://www.pcmag. com/feature/363837/how-to-use-screen-time-in-apple-s-ios-12/6, 2018. Accessed: 2019-26-01.

[109] Primal Wijesekera, Joel Reardon, Irwin Reyes, Lynn Tsai, Jung-Wei Chen, Nathan Good, David Wagner, Konstantin Beznosov, and Serge Egelman. Contextualizing privacy decisions for better prediction (and protection). In Proceedings of the 2018 CHI Conference on Human Factors in Computing Systems, CHI '18, pages 268:1-268:13, New York, NY, USA, 2018. ACM.

[110] Claire A Wolniewicz, Mojisola F Tiamiyu, Justin W Weeks, and Jon D Elhai. Problematic smartphone use and relations with negative affect, fear of missing out, and fear of negative and positive evaluation. Psychiatry research, 262:618$623,2018$.

[111] Nobukazu Yoshioka, Hironori Washizaki, and Katsuhisa Maruyama. A survey on security patterns. Progress in informatics, 5(5):35-47, 2008.

[112] Alyson Leigh Young and Anabel Quan-Haase. Privacy protection strategies on facebook: The internet privacy paradox revisited. Information, Communication \& Society, 16(4):479-500, 2013. 
[113] Shoshana Zuboff. The age of surveillance capitalism: The fight for a human future at the new frontier of power. Profile Books, 2019.

[114] Xenia Zürn, Mendel Broekhuijsen, Doménique van Gennip, Saskia Bakker, Annemarie Zijlema, and Elise van den Hoven. Stimulating photo curation on smartphones. In Proceedings of the 2019 Conference on Human Information Interaction and Retrieval, CHIIR 19, page 255259, New York, NY, USA, 2019. Association for Computing Machinery. 


\section{Appendix A}

\section{Pre-Screener Questionnaire}

\section{A.1 Consent Form}

This pre-screener will require you to complete a short questionnaire, hosted by the online survey platform, Qualtrics. You will be asked to respond to 13 questions to assess your suitability to participate in the larger study. This survey will take approximately 3-5 minutes to complete. We will contact a subset of respondents to participate in an interview study.

The risks associated with your participation in this study are no greater than the risks you take in your daily activities at work or at school. While this risk is expected to be minimal, we will take precautions to protect your identity. Your responses will be confidential but might be disclosed in case of data breach or court order. Qualtrics servers are located in Toronto, Canada.

Participation in this pre-screener is voluntary. You will not be paid for your participation in the pre-screener.

You have the right to end your participation in the study at any time during the session by simply closing the browser. If you withdraw from the study before completion, all information you have provided will be immediately destroyed. You can withdraw within 30 days after submitting your pre-screener answers by contacting fiona.westin@carleton.ca.

When the study is complete, the data will be downloaded and deleted from the Qualtrics server. After recruitment has been completed, your email address will be deleted from the dataset to anonymize the data. The data will be stored on the researchers password-protected computer and may be kept for comparison with future studies. Results of the study will be used for research purposes and may be published.

The ethics protocol for this project was reviewed by the Carleton University Research Ethics Board, which provided Clearance (CUREB-B Clearance \# 111950) to 
carry out the research. If you have any ethical concerns with the study, please contact CUREB-B by phone at 613-520-2600 ext. 4085 or via email at ethics@carleton.ca.

Please indicate whether or not you agree to participate in the study.

1. I agree with the above and wish to participate

2. I do not wish to participate

\section{A.2 Screener Questions}

1. Are you at least 18 years old?
(a) Yes
(b) No

2. Are you comfortable participating in an interview in English?
(a) Yes
(b) No

3. With which of the following are you familiar (including those you dont currently use)?

(a) Social media (e.g., Facebook, Twitter, Instagram)

(b) Instant messaging apps (e.g., WhatsApp, FB Messenger, Telegram)

(c) Message boards (e.g., Reddit, Quora, Stack Overflow)

(d) Online multiplayer video games (e.g., Fortnite, World of Warcraft, League of Legends)

\section{A.3 Fear of Missing Out Scale (FoMOS)}

1

\footnotetext{
${ }^{1}$ This scale is borrowed in its entirety from Przyblylski et al.'s 2013 paper, "Motivational, emotional, and behavioral correlates of fear of missing out" 81.
} 
Below is a collection of statements about your everyday experience. Using the scale provided please indicate how true each statement is of your general experiences. Please answer according to what really reflects your experiences rather than what you think your experiences should be. Please treat each item separately from every other item.

Not at all true of me (1) Slightly true of me (2) Moderately true of me (3) Very true of me (4) Extremely true of me (5)

1. I fear others have more rewarding experiences than me.

2. I fear my friends have more rewarding experiences than me.

3. I get worried when I find out my friends are having fun without me.

4. I get anxious when I dont know what my friends are up to.

5. It is important that I understand my friends in jokes.

6. Sometimes, I wonder if I spend too much time keeping up with what is going on.

7. It bothers me when I miss an opportunity to meet up with friends.

8. When I have a good time it is important for me to share the details online (e.g., updating status).

9. When I miss out on a planned get-together it bothers me.

10. When I go on vacation, I continue to keep tabs on what my friends are doing.

Enter email Please enter your email so we can contact you if you are selected for the study. 


\section{Appendix B}

\section{Pre-Interview Questionnaire}

\section{B.1 Interview Informed Online Consent Form}

Participant ID:

\section{Name and Contact Information of Researchers}

Fiona Westin, Master's student

School of Computer Science, Human-Computer Interaction

Carleton University, Ottawa, Canada

fiona.westin@carleton.ca

Dr. Sonia Chiasson, Supervisor

School of Computer Science

Carleton University, Ottawa, Canada

chiasson@scs.carleton.ca

Project Title Investigating Motivations for Online Behaviours

Project Sponsor and Funder Tri-Council NSERC Discovery File \#106724

Carleton University Project Clearance CUREB-B Clearance \#: 111950

Date of Clearance: November 26, 2019

Invitation You are invited to take part in a research project because you are over the age of 18, are comfortable speaking English, are familiar with social media, messaging boards, and/or online multiplayer video games, and completed our pre-screening questionnaire. The information in this form is intended to help you understand what we are asking of you so that you can decide whether you agree to participate in this study. Your participation in this study is voluntary, and a decision 
not to participate will not be used against you in any way. As you read this form, and decide whether to participate, please ask all the questions you might have, take whatever time you need, and consult with others as you wish.

What is the purpose of the study? The goal of this study is to explore how users choose whether to share their information online and the factors that influence their decisions. The results will benefit future research concerning online behaviours, and will inform design of future online interactive technologies.

What will I be asked to do? If you agree to take part in the study, we will ask you to participate in a one-on-one interview about your online experiences. The session will take place on Carleton campus, in a public venue, or over an online video-chatting platform such as Skype. You may choose to skip questions during the interview if you wish. You will also be asked to complete a pre- and post-interview questionnaire, hosted by the online survey platform, Qualtrics. You will be asked demographic questions (age, occupation, etc.) and about your online habits and attitudes. The interview session will last 30-60 minutes and will be audio-recorded to aid in the note-taking process. If you do not want to be audio-recorded, you will not be able to participate in this study. Only the researchers will have access to the recordings, which will be deleted as soon as transcription is complete.

Risks and Inconveniences The risks associated with your participation in this study are no greater than the risks you take in your daily activities at work or at school. While this risk is expected to be minimal, we will take precautions to protect your identity. Your responses will be confidential but might be disclosed in case of data breach or court order. Qualtrics servers are located in Toronto, Canada. Trint, an online software will be used to transcribe data. If the session is done remotely, it will be using Skype. Trint and Skype have servers in the United States, therefore, data is subject to US laws on data privacy.

Possible Benefits You may not receive any direct benefit from your participation in this study. However, your participation may allow researchers to better understand 
factors leading to users online interaction decisions, and the following research may help inform future design of and discussion surrounding digital technologies.

Compensation/Incentives You will be compensated with \$20.00 CAD (cash or INTERAC e-transfer) or an Amazon gift card of equivalent value for your participation in this study. Cash compensation is possible only for in-person interviews. Participants outside of Canada are restricted to receiving the Amazon gift card. You will still receive full compensation even if you withdraw from the study.

No waiver of your rights By signing this form, you are not waiving any rights or releasing the researchers from any liability.

Withdrawing from the study You may choose to withdraw from the study at any point during the session simply by informing the researcher. If you withdraw, the researcher will ask whether the information collected from you before your withdrawal can still be used or whether it should be removed from the study data. If you wish your data to be removed, it will be immediately destroyed. Because we are not linking your responses to your identity, withdrawal after the session is not possible.

Confidentiality We will remove all identifying information from the study data as soon as possible; if you inadvertently disclose any identifying information, it will be left out of the transcription of interviews. We will treat your personal information as confidential, although absolute privacy cannot be guaranteed. No information that discloses your identity will be released or published. Research records may be accessed by the Carleton University Research Ethics Board in order to ensure continuing ethics compliance. The results of this study may be published or presented at an academic conference or meeting, but the data will be presented so that it will not be possible to identify any participants. You will be assigned a code (e.g., P1, P2) so that your identity will not be associated with the data you have provided.

Data Retention Audio files will be deleted as soon as transcription is complete. Consent forms will be destroyed after one year. After the study is completed, your 
de-identified data will be retained for future research use. All data, including coded information, will be kept in a password-protected file on a secure computer.

Ethics review This project was reviewed and cleared by the Carleton University Research Ethics Board B, CUREB-B Clearance \# 111950). If you have any ethical concerns with the study, please contact Carleton University Research Ethics Board (by phone at 613-520-2600 ext. 4085 or by email at ethics@carleton.ca).

Please indicate whether or not you agree to participate in the study.

*If you do not agree to be audio-recorded, you will not be able to participate in the study. We need the audio recording to ensure that we accurately capture your feedback.

1. I voluntarily agree to participate in this study.

2. I agree to be audio recorded.*

\section{B.2 Pre-Interview Demographics Questionnaire}

1. Please select your gender:

(a) Female

(b) Male

(c) Nonbinary

(d) Other [please specify]

(e) Prefer not to say

2. Please enter your age

3. What is your field of specialization? [Please enter]

4. Current employment status: Employed full-time (1) Employed part-time (2) Full-time student (3) Part-time student (4) Self-employed (5) Not employed (6) Retired (7) Other [please specify] (8) 
5. Highest degree or level of school you have completed: Less than a high school diploma (1) High school degree or equivalent (2) Bachelors degree (3) Masters degree (4) Doctorate (5) Other [please specify] (6)

6. How frequently do you use each of the following online social platforms: Several times per day (1) Daily (2) Weekly (3) Monthly (4) Less than monthly (5) Do not use (6)

(a) Instagram

(b) Snapchat

(c) TikTok

(d) Twitter

(e) Youtube

(f) Facebook

(g) Pinterest

(h) LinkedIn

(i) Instant messaging (e.g., FB Messenger, WhatsApp, Telegram)

(j) Online forums (e.g., Reddit, Quora, Stackexchange)

(k) Online multiplayer games (e.g., Overwatch, Fortnite, World of Warcraft)

7. Which of the following activities do you do on your online social platforms: Post content (1) View content (2) Interact with others' content (3) Do not use (4)
(a) Instagram
(b) Snapchat
(c) TikTok
(d) Twitter
(e) Youtube
(f) Facebook
(g) Pinterest 
(h) LinkedIn

(i) Instant messaging (e.g., FB Messenger, WhatsApp, Telegram)

(j) Online forums (e.g., Reddit, Quora, Stackexchange)

8. Do you use any online social platforms that are not listed above? If yes, please list them, their frequency of use, and activities performed on them: 


\section{Appendix C}

\section{Interview Guide}

\section{Interview Guide}

Today we are conducting research on people's motivations for their online behaviours and their decisions to share information online. There are no right or wrong answers - everything you say is helpful to us in learning more about how real people behave online.

The purpose is to help us understand how to improve technology to better align with people's needs. We encourage you to be open about your experiences and thoughts. If you are uncomfortable answering a question let us know and we can skip that particular question.

Any questions?

Introduction and posting habits

Intent: to understand the context of the participant's online interactions.

- I'd like to hear about the kinds of interactions you have online. What platforms do you use every day (e.g., social media/games/message boards/apps)? What platforms do you use only occasionally? (Why?) How often do you post on [platform]?

○ What makes you post more? / Less?

- Do you find there's a certain rhythm of posting you try to keep?

o Do you tend to post "in the moment", or later?

- How often do you interact with posts on [platform]?

○ What makes you interact more? / Less?

Joining and staying on websites

Intent: to find out reasons why people join and stay on websites, and to find out if they ever feel pressured to sign up for or stay on a website.

- What makes you sign up for a new website or download a new app?

$\circ$ (If they have trouble coming up with an answer): What made you sign up for/download [specific app/website]?

- How much does a platform's popularity influence your decision to adopt it?

- How much do you factor in friends also having an account/the app in your decision to adopt it?

- Do you tend to be the first or last in your social circle to adopt a new platform?

- Have you ever convinced other people to adopt and app or website that you joined first?

- Can you think of a time you ever felt reluctant to sign up for a website or install an app?

○ Why were you reluctant?

- Did you sign up/install anyway? Why or why not?

- Can you think of a time you've ever "jumped on the bandwagon" regarding an online trend, adopting a new platform, or downloading a new app?

- Have you ever regretted posting something online?

- Do you expect your likes/comments/follows to be reciprocated? If so: what if they aren't?

- Have you ever showed support for someone or for a cause by commenting, liking, or sharing?

- Have you ever felt obliged to interact with certain kinds of media online?

○ How so?

- What would make you feel like you didn't have to?

- Do you ever feel compelled to share more information online than you want to?

- What would compel you to share less than you wanted to?

- Do you feel pressured to keep friends up to date on your life? 
- Do you tend to have the same audience on different platforms?

- Do you ever feel pressured to keep certain friends on social media, or to accept friend requests?

- Can you think of any instances where you acted a certain way online because you were afraid of missing an experience?

○ Have you ever bought something, installed something, or shared something for this reason?

- Can you think of any instances where you acted differently than usual online to project a better impression about yourself to other people?

- Can you think of a time a website or app made you feel uncomfortable in its requests for information?

- Did you continue? Why or why not?

- What could have been changed to improve the situation?

- Some people have described the feeling they get when asked to share their information online as "creepy"... have you experienced this?

\section{Leaving websites}

Intent:

What factors make someone decide to leave a website?

What factors make people return to a website, or feel like they can't leave?

- Have you ever deactivated or deleted an account or app?

- Why or why not?

- Did you return to it? Why or why not?

- Have you considered giving up any of the platforms you're currently on?

○ Do you have examples of platforms that you have stopped using?

- What made you/would make you decide to give them up?

- If you didn't have these technologies, how do you envision yourself keeping in touch with your loved ones?

\section{Perceptions of others' online habits and expectations}

Intent:

Do people consciously conform to social norms of online use?

Do people negatively judge those who do not conform to social norms of online use?

- Do you think your friends share the same attitudes as you regarding online behaviour?

- Have you ever experienced pushback from others due to your behaviour online?

- Have you ever changed your behaviour to be more in line with your friends' expectations?

- What do you think of people who have very little or no active online presence?

○ Do you think these people miss out by not being online?

Conclusion:

If you had the ultimate power to change something about the interactive technologies you use most, what would it be?

That brings us to the end of this interview. Do you have any questions for me? 


\section{Appendix D}

\section{Post-Interview Questionnaire}

\section{D.1 OSN Attitudes}

1 Note: OSN = Online Social Network

The following questions are answered on this scale: Strongly Disagree (1) Disagree

(2) Somewhat disagree (3) Neutral (4) Somewhat agree (5) Agree (6) Strongly agree

1. I am often concerned that OSN provider could store my information for the next couple of years

2. Every now and then I feel anxious that OSN provider might know too much about me

3. I am often concerned other parties (e.g. marketing, HR, government agencies) could actually collect my publicly available information on OSN

4. I am often concerned that my current publicly available information could be stored at some other party (e.g. marketing, HR, government agencies) many years from now

5. I am often concerned that other parties (e.g. marketing, HR, government agencies) could share the information they have collected about me on OSN

6. It often worries me that other parties (e.g. marketing, HR, government agencies) could use the information they have collected about me from OSN for commercial purposes

7. I am often concerned that someone might purposefully embarrass me on OSN

\footnotetext{
${ }^{1}$ C.1 AND C.2 are borrowed from Krasnova et al.'s work, "Privacy concerns and identity in online social networks" 55
} 
8. It often worries me that other users might purposefully write something undesired about me on OSN

9. I am often concerned that other users might take advantage of the information they learned about me through OSN

10. I am often concerned that I dont have control over the actions of other users

\section{D.2 OSN Disclosure}

11. I have a comprehensive profile on OSN

12. I find time to keep my profile up-to-date

13. I keep my friends updated about what is going on in my life through OSN

14. When I have something to say, I like to share it on OSN

15. I am always honest in the information I provide on OSN

16. I am always truthful when I write about myself on OSN

17. When I post something on OSN, I am always careful about what exactly I am saying about myself

18. When I express myself on OSN, I always consider who can see the information I publish

19. I think carefully how much I reveal about myself on OSN

\section{D.3 Repeat of FoMOS (See Pre-screener)}

